\title{
Methyl epigenetic mechanisms in the freeze- tolerance response of Rana sylvatica nervous tissue
}

\author{
By
}

Tighe Joseph Bloskie

B.M.Sc. Honours, Western University, 2016

A Thesis Submitted to the Faculty of Graduate Studies and Research in Partial Fulfillment of the Requirements for the Degree of

Master of Science

Department of Biology

Carleton University

Ottawa, Ontario, Canada

(C) Copyright 2021

Tighe J. Bloskie 


\begin{abstract}
Wood frog freeze tolerance is a classic example of metabolic rate depression (MRD), which facilitates reprioritization of minimal anaerobic resources to pro-survival pathways. Global gene expression is consequentially suppressed due, in part, to transcriptional controls, but to date, specific mechanisms have received little attention. Methylation of DNA and histone lysine residues are common epigenetic mechanisms that are tightly associated with control of transcription and thus have been implicated in MRD. However, preliminary findings appeared tissue- and species-specific, and considering research into nervous tissues was lacking, further investigation is required. This thesis tracks the expression and activity of some key methyl epigenetic modifiers like lysine/DNA methyltransferases and DNA demethylases, as well as selected putative targets across the wood frog freeze-thaw cycle and associated sub-stresses. This thesis provides strong evidence in favour of roles for $\mathrm{H} 3 \mathrm{~K} 9$ and DNA hypomethylation during freeze recovery, which are largely correlated with changes in expression of catalyzing enzymes. Some non-histone target roles are also suggested. Alleviation of repressive epigenetic controls likely contribute to the resumption of a permissive transcriptional state and may induce the activity of essential repair pathways during thawing.
\end{abstract}




\section{ACKNOWLEDGEMENTS}

There is not a single person in this lab that does not deserve appreciation. I would like to thank Sam, Liam and Hanane for their guidance, as well as their light, enjoyable conversations as my desk productivity began to dwindle. I wish the pandemic did not minimize these interactions. I would like to thank Anchal, Aakriti and Maire in their attempts to teach me another language, and I apologize for the many struggles. Gurjit and Stuart, thank you for all of your direction/kindness. Sarah and Aline, thanks for the many times you'd help me in 511 when I'd bumble on in.

Most importantly, I would like to thank Ken and Jan for their incredible guidance, and for the positive environment they facilitate in this lab. Jan also for editing the many documents and making them seamlessly better (and Ken of course!). Ken thanks for all that you do, and for the many life lessons and sport discussions throughout the course of my masters. 


\section{TABLE OF CONTENTS}

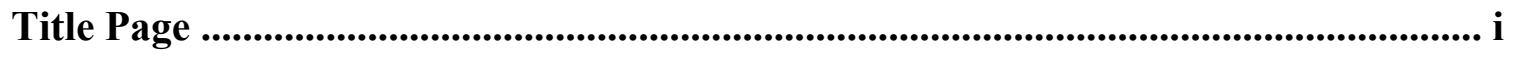

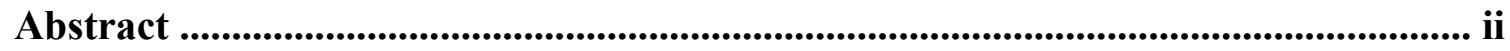

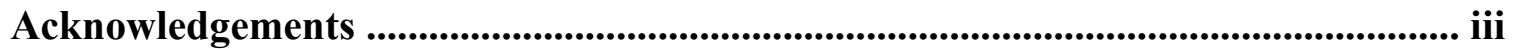

Table of Contents ................................................................................................ iv

List of Abbreviations ............................................................................................................. $\mathrm{V}$

List of Figures ............................................................................................................. vii

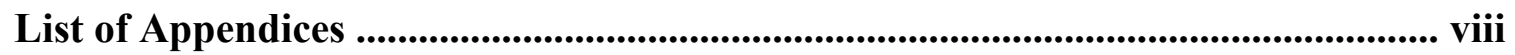

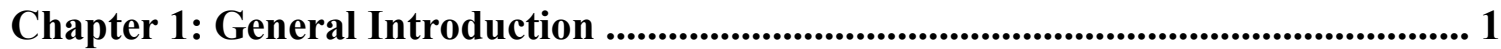

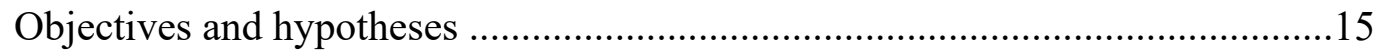

Chapter 2: General Materials and Methods ..............................................................18

Chapter 3: Repressive H3K9 methylation reduced in Rana sylvatica cryo-recovering

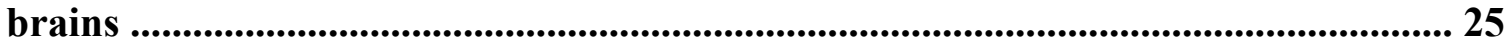

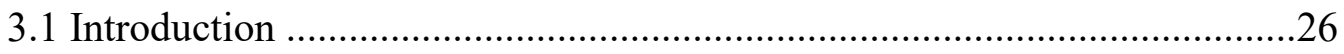

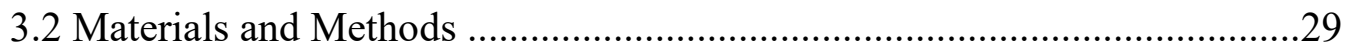

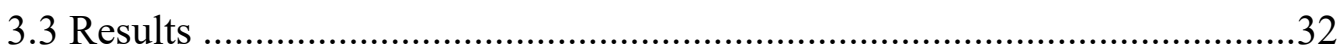

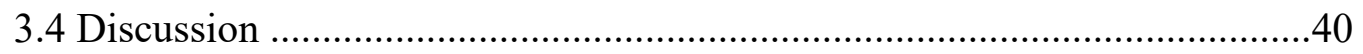

Chapter 4: DNA hypomethylation in Rana sylvatica cryo-recovering brains............48

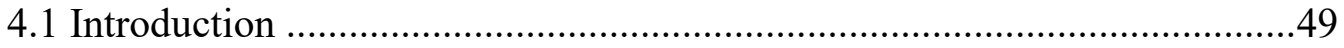

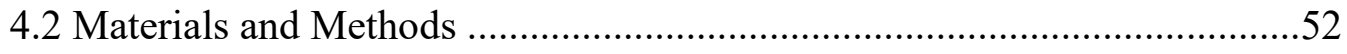

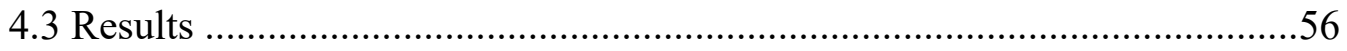

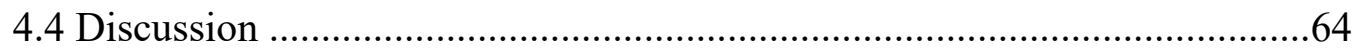

Chapter 5: General Discussion .....................................................................................................71

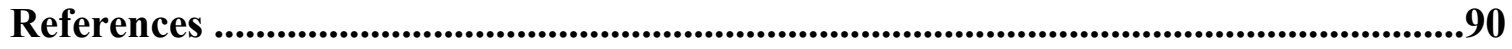

Appendices...............................................................................................................................106 


\section{LIST OF ABBREVIATIONS}

5-mC 5-methylcytosine

5-hmC 5-hydroxymethylcytosine

ANOVA Analysis of variance

APS Ammonium persulfate

ASH2L ASH2 like histone lysine methyltransferase complex subunit

ATP Adenosine triphosphate

ChIP-seq Chromatin immunoprecipitation sequencing

DNA Deoxyribonucleic acid

DNMT DNA methyltransferase

EDTA Ethylenediaminetetraacetic acid

EHMT2 Euchromatic histone-lysine N-methyltransferase 2

ESET ERG-associated protein with SET domain

EZH2 Enhancer Of Zeste 2 Polycomb Repressive Complex 2 Subunit

gDNA Genomic DNA

GLUT Glucose transporter

DNMT DNA (cytosine-5)-methyltransferase

DTT 1,4-dithiothreitol

H3K4me1 Monomethylated histone H3 lysine 4

H3K9me3 Trimethylated histone H3 lysine 9

H3K27me1 Monomethylated histone H3 lysine 27

H3K36me2 Dimethylated histone H3 lysine 36

H4K20me1 Monomethylated histone H4 lysine 20

HDAC Histone deacetylase

HEPES 4-(2-hydroxyethyl)-1-piperazineethanesulfonic acid

HIF-1 $\alpha$ Hypoxia inducible factor $1 \alpha$

HP1 Heterochromatin protein 1

HRP Horse radish peroxidase

INP Ice nucleating protein

kDa Kilodalton 


$\begin{array}{ll}\text { KDM } & \text { Lysine demethylase } \\ \text { KMT } & \text { Lysine methyltransferase } \\ \text { MBD } & \text { Methyl-CpG-binding domain } \\ \text { MeCP2 } & \text { Methyl-CpG binding protein 2 } \\ \text { MLL } & \text { Mixed-lineage leukemia } \\ \text { MRD } & \text { Metabolic rate depression } \\ \text { mRNA } & \text { Messenger RNA } \\ \text { miRNA } & \text { MicroRNA } \\ \text { OD } & \text { Optical density } \\ \text { PRC } & \text { Polycomb repressive complex } \\ \text { PTM } & \text { Post-translational modification } \\ \text { PVDF } & \text { Polyvinylidene difluoride } \\ \text { Rb } & \text { Retinoblastoma tumor suppressor protein } \\ \text { RBBP5 } & \text { Retinoblastoma binding protein } \\ \text { ROS } & \text { Reactive oxygen species } \\ \text { RNA } & \text { Ribonucleic acid } \\ \text { SAM } & \text { S-adenosyl methionine } \\ \text { SDS } & \text { Sodium dodecyl sulfate } \\ \text { SEM } & \text { Standard error of the mean } \\ \text { SET } & \text { Su(var)3-9, Enhancer of zeste, and Trithorax } \\ \text { SMYD2 } & \text { SET and MYND domain containing 2 } \\ \text { SUV39H1 } & \text { Suppressor of variegation 3-9 homolog 1 } \\ \text { TBST } & \text { Tris-buffered saline with Tween-20 } \\ \text { TDG } & \text { Thymine DNA glycosylase } \\ \text { TEMED } & \text { N,N,N',N'-Tetramethylethane-1,2-diamine } \\ \text { TET } & \text { Ten-eleven translocation } \\ \text { TF } & \text { Transcription factor } \\ & \end{array}$




\section{LIST OF FIGURES}

Figure 1.1: Overview of Rana sylvatica freeze tolerance.

Figure 1.2: Overview of histone lysine methylation and DNA methylation.

Figure 3.1: Relative expression of lysine methyltransferases (A) SUV39H1, ESET, SETD7 and SETD8 and (B) SMYD2, SET1A, ASH2L and RBBP5 in brain tissue of Rana sylvatica across freeze-thaw plus anoxic and dehydrated sub-stresses as determined by Western immunoblotting.

Figure 3.2: Relative expression of standardized methylated histone lysine residues H3K4me1, H3K9me3, H3K27me1, H3K36me2 and H4K20me1 in brain tissue of Rana sylvatica across freeze-thaw plus anoxic and dehydrated sub-stresses as determined by Western immunoblotting.

Figure 3.3: Relative HMT activity on H3K9 of control, 24h frozen, 8h thawed, 24h anoxic and $40 \%$ dehydrated nuclear extracts of Rana sylvatica brain tissue.

Figure 3.4: Relative HMT activity on H3K27 of control, 24h frozen, 8h thawed, 24h anoxic and $40 \%$ dehydrated nuclear extracts of Rana sylvatica brain tissue

Figure 3.5: Relative expression of HP $1 \gamma$ in brain tissue of Rana sylvatica across freezethaw plus anoxic sub-stress as determined by Western immunoblotting.

Figure 4.1: Relative expression of DNA methyltransferases DNMT1, DNMT3A, DNMT3B, DNMT3L in brain tissue of Rana sylvatica across freeze-thaw plus anoxic and dehydrated sub-stresses as determined by Western immunoblotting.

Figure 4.2: Relative DNMT total enzymatic activity of control, 24h frozen, $8 \mathrm{~h}$ thawed, $24 \mathrm{~h}$ anoxic and $40 \%$ dehydrated nuclear extracts of Rana sylvatica brain tissue.

Figure 4.3: Relative expression of methyl-binding domain proteins in brain tissue of Rana sylvatica across the freeze-thaw cycle as determined by Western immunoblotting.

Figure 4.4: Relative expression of DNA demethylase enzymes (TET2/3) and TDG in brain tissue of Rana sylvatica across the freeze-thaw cycle as determined by Western immunoblotting.

Figure 4.5: Relative genomic 5-hmC content of control, $24 \mathrm{~h}$ frozen and $8 \mathrm{~h}$ thawed Rana sylvatica brain tissue.

Figure 5.1: Proposed mechanisms of methyl epigenetics during freezing and freeze recovery of wood frog brain tissue. 


\section{LIST OF APPENDICES}

Appendix A: Immunoblotting conditions

Appendix B: Antibody information

Appendix C: Loading control for immunoblotting

Appendix D: Total protein extract validation

Appendix E: Nuclear enrichment validation

Appendix F: Genomic DNA validation

Appendix G: Anoxia/Dehydrated immunoblot bands 


\section{CHAPTER 1}

\section{General Introduction}




\section{Freeze tolerance vs avoidance}

Prolonged exposure to freezing temperatures to the point where body temperature $\left(\mathrm{T}_{\mathrm{b}}\right)$ drops below $0^{\circ} \mathrm{C}$ has lethal consequences for most animals. When temperatures drop below the freezing point of body fluids (generally -1 to $-2^{\circ} \mathrm{C}$ depending on body fluid osmolality), ice begins to form, first in extracellular spaces but then inside cells (Mazur, 1984). With ice formation comes a variety of devastating stresses: the cessation of heartbeat and blood flow (ischemia), a halt to respiration and oxygen transport (anoxia), substantial losses of liquid water volume that interrupts cell functions (dehydration), and a strong elevation of ions and metabolites in all remaining liquid compartments (osmotic stress) (Storey and Storey, 1988). Physiologically, growing ice crystals can perforate vulnerable cell and subcellular membranes (Steponkus and Lynch, 1989), while other cells undergo cytoskeletal collapse from extensive water loss. Tissues suffer similar mechanical damage leading to multi-organ failure (Costanzo et al., 1992). For unadapted animals, whole-body freezing is uncontrolled, irreversible and leads to certain death (Mazur, 1984). Animals that live at high latitudes or altitudes are faced with these suboptimal environments on an annual basis; however, many have evolved effective overwintering strategies.

Survival strategies for dealing with sub-zero temperatures are classed mainly into two major categories: (1) freeze avoidance, and (2) freeze tolerance. As the name suggests, in freeze avoidance, animals prevent freezing of body fluids, which can be achieved through geographical, ecological, physiological, or biochemical methods (Duman, 2001; Lee and Costanzo, 1998). For some bird and mammal species (including select humans) who have capacities to travel great distances, seasonal migration is an 
effective avoidance strategy. For others without this ability, sheltering in thermally buffered environments provides the necessary protection, for example, retreating underwater into ponds, lakes or rivers (a strategy of various frog and turtle species) or deep underground below the frost line (a strategy of some snake and lizard species). Underground hibernation is particularly common in invertebrates that have wax-coated cuticles and can burrow deep into the earth or harbor into insulated plants (Zachariassen, 1985). The third most common freeze avoidance strategy is via the ability to supercool body fluids below environmental temperatures to prevent freezing. This is accomplished through vast production of antifreeze proteins/agents and cryoprotectants (e.g., glycerol) that effectively lower the freezing point of body fluids to a value substantially below the sub-zero temperature range of the environment (Lowe et al., 1971). In many cases, avoidance is successful through a combination of the above means.

Although largely outnumbered by freeze-avoiding species, a variety of other animals have evolved biochemical mechanisms to tolerate the controlled acceptance of ice in extracellular spaces of their bodies. Freeze tolerance has evolved independently within many classes of ectotherms from invertebrates to amphibians to select reptiles, all of which display common adaptive mechanisms although not always using the same types of cryoprotectants (Murphy, 1983; Schmid, 1982; Storey, 1990). Crucial to freeze tolerance for most species is a strategy that allows controlled ice nucleation, generally initiated at temperatures just below the freezing point of body fluids (i.e., limited supercooling capacity). This can begin in a few ways: (1) direct contact with environmental ice, usually across the skin, (2) the action of ice-nucleating agents such as by bacteria on the skin surface or in the gut, or (3) the production of specific ice- 
nucleating proteins (Storey and Storey, 2013; Zachariassen and Kristiansen, 2000). By triggering and regulating ice formation at temperatures just below $0^{\circ} \mathrm{C}$, freeze-tolerant organisms promptly manage and limit ice crystal growth to minimize membrane damage and gain sufficient time to trigger other cryoprotective measures and protect crucial intracellular processes (Mazur, 1984). To counteract the rising extracellular osmolality from pure water lost to ice crystals, water moves out of cells via aquaporin channels, causing cells to shrink. However, excess water loss from cells would trigger cytoskeletal collapse, so to counteract this, animals produce vast concentrations of cryoprotectants (e.g., glucose and urea in R. sylvatica) that they either synthesize intracellularly (e.g., liver makes and exports most of the glucose needed) or take up from the blood (most other tissues). In wood frogs, glucose provides both a fuel source and osmotic action to resist cell volume reduction (Storey, 1990; Storey and Storey, 1988). Urea is a known waste product of protein catabolism but is also retained by tissues as an osmolyte to help sustain a minimum cell volume during freezing (Costanzo and Lee, 2005). Increasing intracellular solute concentrations via cryoprotectants also functions to lower the freezing point of intracellular fluids, encouraging INP-mediated ice formation to occur only in extracellular spaces.

\section{Metabolic rate depression}

Even for the well-adapted, freeze tolerance is an extremely rigorous survival mechanism. As mentioned above, accepting ice is consequential; animals must contend with the physiological challenges of anoxia, ischemia, dehydration, and hyperglycemia to name a few, and therefore must implement robust adaptations to survive prolonged 
freezing. Collectively, animals enter some form of metabolic rate depression (MRD), which is highly multi-faceted in its functions (Storey and Storey, 2004a). Metabolic suppression exists, to varying degrees, among many species, not just cold hardy animals, but mammalian hibernators (Heldmaier et al., 2004), anoxia-tolerant turtles (Hochachka and Lutz, 2001), estivating amphibians (Storey and Storey, 1990) as well as supporting dormancies of many invertebrates (Denlinger, 2002).

Freeze tolerance also requires a strong suppression of metabolic rate, partly achieved due to sub-zero temperatures and partly due to other triggers of metabolic rate depression including anoxia and ischemia. Without oxygen as its final electron acceptor, mitochondrial oxidative phosphorylation is halted and cells must switch to anaerobic glycolysis using glucose or glycogen as substrates for energy production. This yields only roughly $5 \%$ of the ATP that would otherwise be gained from full oxidation of carbohydrates to $\mathrm{CO}_{2}$ and water and also leads to the accumulation of lactate within cells (Churchill and Storey, 1992; Packard and Packard, 2004). Second, without an influx of nutrients from the blood stream, cells must rely on internal fuel reserves only, sugars and some amino acids being the only macromolecules that can be metabolized in the absence of oxygen. Freeze-tolerant animals have vast liver glycogen stores that they break down into cryoprotectants in preparation for prolonged freezing (Storey and Storey, 2017). Energy consumption must balance this greatly reduced output to not deplete limited supply, leading to the reprioritization of energetic resources to essential pro-survival pathways.

During hypometabolism, many non-essential cellular processes must be turned off or strongly suppressed: e.g. from DNA replication to cell cycle progression, ion active 
transport, and gene expression (Biggar and Storey, 2012; Fraser et al., 2001; Perez-

Pinzon et al., 1992; Wu and Storey, 2012). Transcription and translation are highly costly cellular processes (Rolfe and Brown, 1997), thus making them key targets for downregulation during MRD. Not surprisingly, increasing evidence points to transcriptional and translational suppression during hypometabolism (Biggar and Storey, 2014; Fraser et al., 2001; Frerichs et al., 1998; Morin and Storey, 2006a), however these mechanisms have been found to be animal- and tissue-specific, likely due to the functional roles of specific tissues during extreme stress responses. Gene regulation is controlled at a variety of levels: from epigenetic modifications and transcription factors (TFs) at the transcriptional level, to m6a methylation and small non-coding regulatory RNAs at the post-transcriptional level, to translation factors, protein modification and turnover at the translational levels. TFs are critical regulators of MRD, as their control can limit the synthesis of new transcripts for those essential pro-survival genes, including chaperone proteins and anti-apoptotic proteins/peptides (Gerber et al., 2016; Storey and Storey, 2019; Sullivan et al., 2015; Sullivan and Storey, 2012; Wu et al., 2018).

Considerable research on post-transcriptional control of MRD has focused on the role of microRNA (reviewed in Biggar \& Storey, 2015, 2018) that, depending on the complementarity of base-pairing with mRNA targets, can either repress mRNA translation, target mRNAs for degradation by nucleases, or store them in stress granules until favourable conditions return. The phosphorylation of ribosomal elongation factor 2 alpha (eIF2 $\alpha$ ) has emerged as a dominant repressor of global protein translation during hypometabolism (Frerichs et al., 1998). For proteins already made, post-translational modifications provide a fast, cheap, and dynamic mechanism for controlling the activity 
or abundance of enzymes during MRD (reviewed in Storey \& Storey, 2017). Prominent modifications include phosphorylation, methylation, acetylation (which often control enzymatic activity) and ubiquitination (which targets proteins to the proteosome for degradation). Of interest to this thesis is epigenetic regulation (e.g., DNA methylation, histone methylation/acetylation), a central mediator of transcriptional control. The coordinated action of gene regulation at all of the above levels is essential to hypometabolism, and more importantly, to survival of extreme environmental stresses.

\section{Rana sylvatica}

The wood frog, Rana sylvatica, is a well-characterized model organism of vertebrate freeze tolerance. The species has a wide range across North America, with physiologically distinct Alaskan and Ohioan subpopulations, and is the only frog species to reside north of the Arctic Circle. In the Arctic, with air temperatures reaching as low as $-30^{\circ} \mathrm{C}$, the anuran burrows under leaf cover in the autumn that is then covered by an insulating layer of snow such that temperatures at the hibernation site remain relatively mild (around $-5^{\circ} \mathrm{C}$ ) and survives there over the winter months. Wood frogs in the Ottawa area use similar survival strategies. Wood frogs can tolerate the freezing of up to $\sim 65 \%$ of total body water for prolonged periods of time (Costanzo et al., 1993), with recent research showing that Alaskan wood frogs can stay in frozen suspended animation for an average of 193 days (Larson et al., 2014). Frogs in the fall, winter, and spring never eat even when presented with food. At these times of the year, frogs required clean, empty guts to prevent ice nucleation from digestive matter and survive freeze tolerance. Related, frogs cannot digest food at temperatures below $15^{\circ} \mathrm{C}$ (Storey and Storey, 2017). Wood 
frog freezing is slow and controlled to allow adequate time for the initiation of freeze survival mechanisms. Ice nucleation begins with inoculation from environmental ice forming on the skin surface, and subsequently blood ice-nucleating proteins (INPs) and non-specific bacterial nucleators can mediate gradual ice formation in extra-organ and extracellular spaces (Storey and Storey, 2017). These spaces are predominantly between skin and skeletal muscle layers, within the abdominal cavity, in vascular system lumen, and in other fluids that surround tissues.

Ice nucleation triggers the initiation of freeze tolerance strategies including generating $\beta$-adrenergic signals to hepatocytes that initiate glycogenolysis (Hemmings and Storey, 1994; Storey and Storey, 1985) and drive a rapid synthesis of glucose. Plasma glucose levels begin to rise immediately, increasing from normal values of 1-4 $\mathrm{mM}$ to around $40 \mathrm{mM}$ one hour post nucleation and soaring to $150-300 \mathrm{mM}$ in core organs once frogs are fully frozen (Storey and Storey, 1986). Transient increases in heart rate (Layne et al., 1989) along with increased glucose transporter action, GLUT2 for liver export (Rosendale et al., 2014), and GLUT4 for tissue uptake (Tessier and Storey, 2010), facilitate the distribution of rising glucose. Glycogenolysis capacity is maintained throughout the entire freezing period in liver hepatocytes, until thawing drives the replenishment of glycogen stores (do Amaral et al., 2016). Glycogen synthase kinase 3 (GSK3), known to inhibit glycogen synthase (GS) via phosphorylation appears to be involved in preventing glycogen synthesis in the frozen state (Dieni et al., 2012). Ice nucleation also induces anti-apoptotic responses, through the overexpression of antiapoptotic Bcl-xL and c-IAP in liver (Gerber et al., 2016) to promote cell survival. Antioxidant defenses, through the tissue-specific upregulation of glutathione peroxidase 
(GPx) (Joanisse and Storey, 1996), catalase, cytosolic superoxide dismutase 1 (SOD1) and mitochondrial superoxide dismutase 2 (SOD2) (Dawson and Storey, 2016; Wu et al., 2018) minimize ROS levels while frozen. Tissue-specific activation of chaperones including, HSP70 and HSP110, aid maintenance of proper protein folding under anoxia, dehydration, or cold conditions (Storey and Storey, 2019). Activation of AMP-activated protein kinase (AMPK), an "energy sensor" that negatively regulates an array of costly biosynthetic pathways, is heavily implicated in hypometabolism and ATP conservation during wood frog freeze tolerance (Rider et al., 2006). Given the energy-expensive nature of transcription and the protein biosynthesis that follows, outside of miRNA interference, a growing body of research points to epigenetic regulation, particularly methyl epigenetics, as another critical modulator of hypometabolism (See Figure 1.1).

\section{Epigenetics and histone lysine methylation}

Epigenetics refers to functional changes to gene expression without alteration to the underlying DNA sequences. Epigenetic regulation is a core component of transcriptional control, with multiple implications on the cellular transcriptome. This is particularly true for stable heritable imprints or changes during embryonic development (reviewed in $\mathrm{Li}, 2002$ ), however increasing evidence points to roles in environmental stress responses, from diet, to exercise, to trauma (McGee and Hargreaves, 2019; Tiffon, 2018; Yehuda and Lehrner, 2018). Key branches of epigenetic mechanisms include histone modifications, DNA methylation and RNA methylation. Histones are small positively charged proteins that make up the functional unit of chromatin, the nucleosome. The nucleosome consists of $\sim 200$ bp of DNA wrapped around a histone 


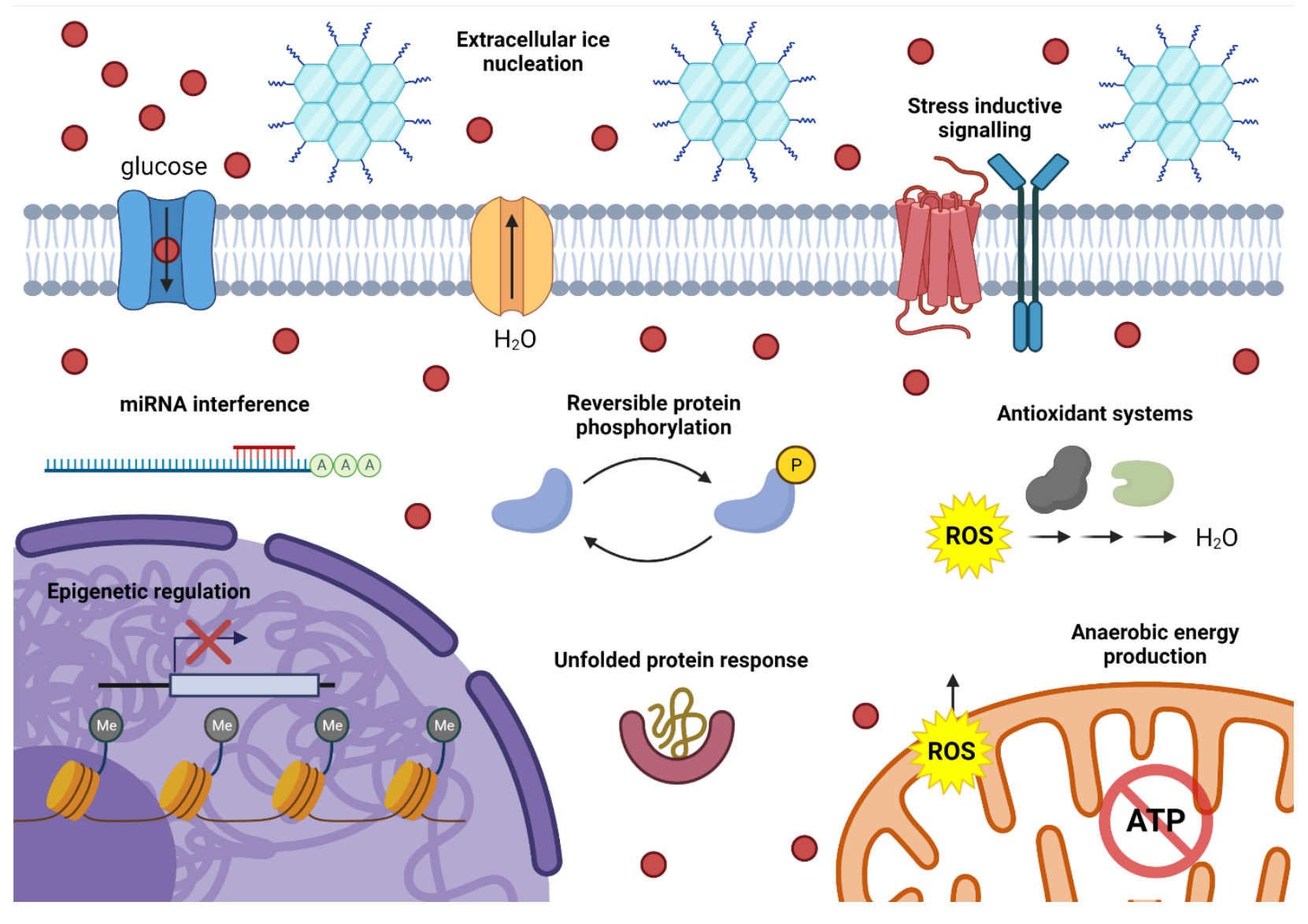

Figure 1.1. Overview of Rana sylvatica freeze tolerance. Following extracellular ice nucleation with the aid of extracellular ice nucleators (INPs), water travels through aquaporin channels across plasma membranes to balance rising external solute concentrations as more and more water is converted to ice. Cells import large amounts of glucose molecules as osmolytes to help minimize water loss, and to provide fuel for anaerobic energy production with the arrest of mitochondrial oxidative phosphorylation. Freezing activates stress-induced signalling cascades that drive a hypometabolic state. DNA methylation, histone modifications, and miRNA interference prioritize transcription and translation of pro-survival genes, like chaperones (HSPs) that stabilize protein structure and antioxidant enzymes (SODs, catalase) that degrade reactive oxygen species (ROS). Post-translational protein modification provides a fast, dynamic mechanism to regulate the activity and expression of a vast number of enzymes. Created with Biorender.com. 
octamer, pairs of $\mathrm{H} 2 \mathrm{~A}, \mathrm{H} 2 \mathrm{~B}, \mathrm{H} 3$ and $\mathrm{H} 4$, which enable intense condensation of genetic material within each cell. Like every other protein, histones are subject to posttranslational modification, particularly the methylation/acetylation of lysine and arginine residues of $\mathrm{N}$-terminal tails, that have functional consequences on nearby gene transcription. Chromatin remodelling is a characteristic effect of histone modification, involving the dynamic interconversion between transcriptionally permissive euchromatin and repressive heterochromatin. Histone lysine acetylation is tightly linked to gene activation through (1) locally relaxing the tight electrostatic interactions of (+)-charged histone proteins with (-)-charged DNA, and (2) providing binding sites for bromodomain "reader" proteins to recruit transcriptional machinery. However, histone lysine methylation has much more variable outcomes dependent on recruited methyl-lysine binding effector proteins.

Histone lysine methylation involves the addition of one, two or three methyl groups onto the side chains of lysine residues. This epigenetic mechanism is reversible; marks are added by "writer" lysine methyltransferases (KMTs), removed by "eraser" lysine demethylases (KDMs), and interpreted by "reader" Chromo, Tudor, PWWP, PHD, WD or MBT domain proteins (reviewed in Hyun et al., 2017). Through chromatin immunoprecipitation sequencing (ChIP-seq) analysis, most methyl-lysine marks are strongly associated with actively or lowly transcribed genes (Barski et al., 2007; Mikkelsen et al., 2007). Methylation of H3K4 is linked to gene activation (H3K4me1 to primed enhancers, $\mathrm{H} 3 \mathrm{~K} 4 \mathrm{me} 3$ to active promoters), whereas di- and tri-methylation of H3K9 and H3K27 are associated with repression, which provide recruitment sites for heterochromatin protein 1 homologs (HP1) (Bannister et al., 2001) and polycomb 
repressive complexes (PRCs) (Cao et al., 2002), respectively. Hypermethylation of H4K20 is also generally associated with silenced chromatin states (Black et al., 2012).

Most KMTs contain the consensus Su(var) 3-9, Enhancer of zeste, and Trithorax (SET) domain as their key catalytic site, using methyl groups from donor substrate Sadenosyl methionine (SAM) to methylate the side chain amino group of lysine residues. Specific KMTs methylate a limited number of lysine residues (reviewed in Hyun et al., 2017); SET1A, SMYD2 and SETD7 can methylate H3K4, SUV39H1 and ESET trimethylate H3K9, SMYD2 can methylate H3K36, and SETD8 mono-methylates H4K20 (See Figure 1.2). Chosen KMTs in this thesis were representative members of the original KMT1-7 classes, which were broadly divided based on distinct histone substrates. Preliminary investigation into histone lysine methylation during the hypometabolic states of wood frogs (Hawkins and Storey, 2018), red-eared sliders (Wijenayake et al., 2018) and hibernating 13-lined ground squirrels (Watts and Storey, 2019) suggested distinct roles, however none have studied the nervous system, where epigenetic regulation is markedly characterized.

\section{DNA methylation}

Like histone lysine residues, DNA is frequently methylated, and this is perhaps the most well studied mechanism of epigenetic regulation. DNA methylation occurs at the 5 '-carbon of cytosine residues $(5-\mathrm{mC})$, typically adjacent to a guanine nucleotide, termed CpG. $\mathrm{CpG}$ residues often exist in $\mathrm{CpG}$ islands, the functional unit of DNA methylation, which are high density $\mathrm{CpG}$ sequences typically found upstream of 
promoter elements. Hypermethylation of $\mathrm{CpG}$ islands is tightly linked to silencing of nearby downstream genes, by sterically hindering TF binding and/or by recruiting repressive methyl-CpG-binding domain proteins (MBDs) (Moore et al., 2013). The highly conserved MBD family has five main members, methyl-CpG binding protein 2 (MeCP2) and MBD1-4. These proteins bind specifically to methylated $\mathrm{CpG}$, recruiting repressive chromatin modifiers like histone deacetylases (HDACs) (Nan et al., 1998) to compact chromatin and reduce access to transcriptional activators.

DNA methylation is reversible. DNA methyltransferase (DNMT) enzymes use SAM to donate methyl groups whereas ten-eleven translocation (TET) demethylase enzymes use $\mathrm{O}_{2}$ and $\alpha$-ketoglutarate to oxidize 5 -mC in multiple steps back to an unmodified cytosine residue (Wu and Zhang, 2017) (See Figure 1.2). Interestingly, DNA can also be demethylated passively by absent maintenance during DNA replication. Active DNA demethylation involves subsequent oxidations, with several transient intermediates, but the stable primary intermediate, 5 -hydroxymethylcytosine $(5-\mathrm{hmC})$ is used as a scientific measure for active demethylation. DNMTs can be classed into (1) maintenance methyltransferases (DNMT1), that conserve methylation patterns in daughter cells during DNA replication by acting on hemi-methylated DNA and (2) de novo methyltransferases (DNMT3A and DNMT3B) that establish new patterns, typically at $\mathrm{CpG}$ islands, during embryonic development or in response to stimuli (reviewed in Lyko, 2018). However, this may be too simple as roles for DNMT3A and DNMT3B in maintenance (Dodge et al., 2005; Feng et al., 2010) and de novo DNMT1 activity at certain loci (Jair et al., 2006) are emerging. DNMT3L is a third member of the DNMT3 group that lacks a catalytic domain, but rather forms complexes with DNMT3A and 


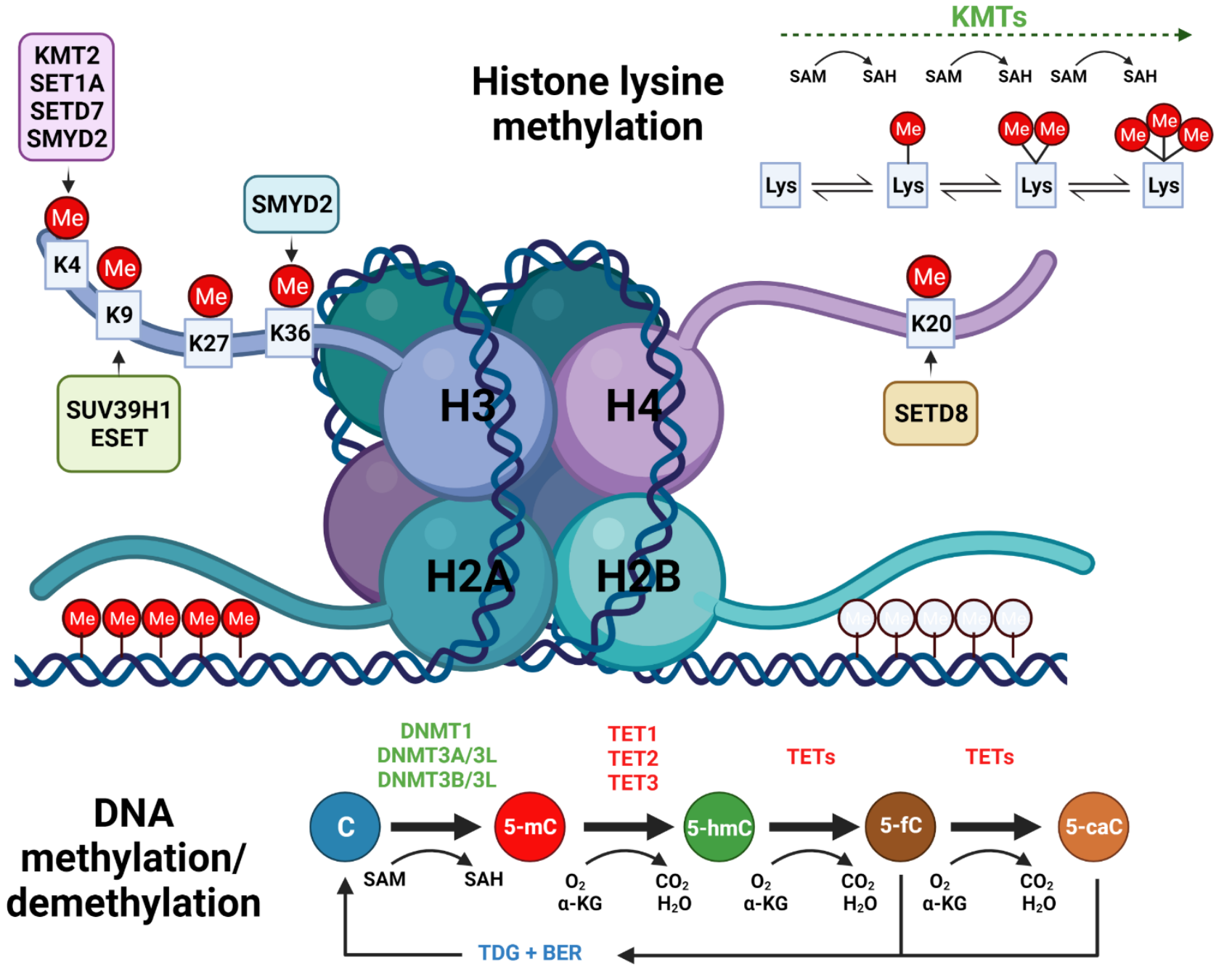

Figure 1.2. Overview of histone lysine methylation and DNA methylation/demethylation with relevant enzymes and biochemistry. The nucleosome contains DNA wrapped around a histone octamer. N-terminal tail lysine residues on histone H3 (e.g., H3K4, H3K9, H3K27, H3K36) and histone H4 (including H4K20) can be mono-, di-, or tri-methylated by lysine methyltransferases (KMTs), that require S-adenosyl methionine (SAM) as the methyl donor. Relevant KMTs and their target residues are shown. $\mathrm{CpG}$ islands exist ubiquitously throughout the genome, often upstream of gene promoter elements. Cytosine residues in these $\mathrm{CpG}$ islands are often methylated by DNMT3A/3L and DNMT3B/3L complexes, whereas DNMT1 functions mainly to maintain 5-mC of hemi-methylated DNA during replication. Like KMTs, DNMTs also require SAM. DNA demethylation requires the coordinated action of TET enzymes with TDG and the base excision repair pathway, generating 5-hydroxymethylcytosine, (5-hmC), 5-fluorocytosine (5-fC) and 5carboxylcytosine $(5-\mathrm{caC})$ intermediates during the process. TETs require oxygen and $\alpha-$ ketoglutarate $(\alpha \mathrm{KG})$ as reaction substrates. Created with Biorender.com 
DNMT3B to regulate their activity (Chédin et al., 2002; Suetake et al., 2004). Active DNA demethylation requires the TET family (TET1-TET3) of enzymes, named for their translocation in many cancers (Rasmussen and Helin, 2016), and base excision repair (BER) by thymine DNA glycosylase (TDG). As a required reaction substrate, the oxygen-sensitive nature of TET enzymes makes them possible candidates for a role in freeze tolerance due to the hypoxic/anoxic state that develops during freezing. Indeed, reduced TET activity has been observed in tumour hypoxia leading to DNA hypermethylation (Thienpont et al., 2016).

Recently, DNA methylation has been implicated in wood frog freeze tolerance (Zhang et al., 2020a), red-eared slider anoxia tolerance (Wijenayake and Storey, 2016) and sea cucumber estivation (Zhao et al., 2015). However, this research lacks investigation of demethylation, and is limited to metabolic and structural tissues. All in all, methyl epigenetic research on the nervous system in animal models of extreme environmental stress response is lacking.

\section{Objectives and hypotheses}

Objective 1: Investigate the role of histone lysine methylation and its transcriptional impact in R. sylvatica brain across the freeze-thaw cycle and associated sub-stresses.

Hypometabolism is characteristic of $R$. sylvatica freeze tolerance. In attempts to balance energy expenditure with vastly reduced ATP production, adaptation requires the suppression of costly, non-essential metabolic pathways. Therefore, it is not surprising that metabolic rate depression drives reductions in both transcription and translation 
(Fraser et al., 2001; Frerichs et al., 1998). Specific factors driving these basal rates are largely unknown but given that histone lysine methylation is tightly linked to transcriptional regulation, its contribution to hypometabolic states supporting freezing survival is likely. Preliminary findings from studies of liver and skeletal muscle implicate H3K4 demethylation across the freeze-thaw cycle, seemingly due to reduced expression of SMYD2 and KMT2-complex factors (Hawkins and Storey, 2018).

Hypothesis 1: Histone lysine methylation markers associated with gene silencing will be either (1) upregulated in freezing or (2) downregulated in freeze recovery of wood frog brains. The inverse is true of permissive transcriptional markers.

Chapter 3 tests the above hypothesis by measuring the expression of transcriptionally relevant histone methyl-lysine residues and underlying KMT enzymes, as well as global methyltransferase activities on certain histone lysine residues across freeze-thaw and associated sub-stresses (anoxia, dehydration) in the wood frog brain. The goal of this chapter is to link KMT expression/activity with the expression of histone lysine targets. This objective is addressed by measuring protein levels of eight KMTs (SET1A, ASH2L, RBBP5, SMYD2, SUV39H1, ESET, SETD7 and SETD8), HMT activity on key repressive $\mathrm{H} 3 \mathrm{~K} 9$ and $\mathrm{H} 3 \mathrm{~K} 27$ residues, and the levels of methylated histone residues (H3K4me1, H3K9me3, H3K27me1, H3K36me2 and H4K20me1). This chapter also measures the relative expression of HP1 $\gamma$, a key methyl-H3K9 "reader" protein. This research will help elucidate coordinated roles for histone lysine methylation in wood frog freeze tolerance. 
Objective 2: Investigate the role of DNA methylation and its transcriptional impact in $R$. sylvatica brain across the freeze-thaw cycle and associated sub-stresses.

Unlike histone lysine methylation, where transcriptional outcomes are highly dependent on recruited "readers", DNA methylation is almost universally repressive on transcription. However, the biological significance of DNA methylation is likely the same in wood frog freeze tolerance: halting transcription to conserve limited resources in hypometabolic states. The mechanism is highly dynamic and reversible. Therefore, DNA methylation will be investigated from both ends - through the combined analysis of activities of DNMT “writers", MBD “readers" and TET “erasers".

Hypothesis 2: Markers of DNA methylation will be either (1) upregulated in freezing or (2) downregulated in freeze recovery of wood frog brains. The inverse is true of DNA demethylation.

Chapter 4 tests the above hypothesis by measuring the expression and combined activity of DNMT enzymes (DNMT1, DNMT3A, DNMT3B and DNMT3L), as well as the abundance of repressive MBD effectors (MBD1, MBD2 and MeCP2) across freezethaw and associated sub-stresses. It will also investigate the expression of TET2-3 (as TET1 does not appear to be present in anurans) as well as TDG. Expression will be linked to activity by measuring the abundance of $5-\mathrm{hmC}$ in isolated gDNA samples. This research will help elucidate the role of DNA methylation dynamics in MRD-mediated transcriptional repression and recovery activation. 


\section{CHAPTER 2}

\section{General Materials and Methods}




\subsection{Animal Experiments}

Adult male wood frogs (Rana sylvatica) were captured from breeding ponds in the Ottawa, Ontario region during early spring. Collected frogs were transported, on ice, to our Carleton University animal care facility. Upon arrival, frogs were bathed in tetracycline and then held in plastic containers containing sphagnum moss for two weeks at $5^{\circ} \mathrm{C}$. Control frogs were sampled at this time.

A subset of remaining frogs was moved into plastic boxes with a layer of damp paper towel on the bottom and transferred to an incubator set to $-4.0^{\circ} \mathrm{C}$ for $45 \mathrm{~min}$ to allow for ice formation on the paper towel that then triggers nucleation of frog body fluids across the skin. Incubation temperature was then raised to $-2.5^{\circ} \mathrm{C}$ and held for 24 hours. A random group of these frogs were sampled at this time, deemed "24h Frozen". Remaining frogs were placed back into a $5^{\circ} \mathrm{C}$ incubator for 8 hours to allow for thawing prior to sampling, deemed " $8 \mathrm{~h}$ Thaw".

In a separate preparation, distilled water was bubbled with $100 \%$ nitrogen gas for roughly $30 \mathrm{~min}$ and used to dampen paper towels, that lined the bottom of incubation chambers. Chambers had nitrogen gas entry and exit ports. In preparation, chambers were flushed with $100 \%$ nitrogen, and then $5^{\circ} \mathrm{C}$ acclimated frogs were introduced to the anoxic environment and lids were sealed and covered with parafilm. Frogs were left in this environment for 24 hours in the $5^{\circ} \mathrm{C}$ incubators. These frogs deemed "24h Anoxia" were sampled at this time.

Dehydration stress was consistent with previous experiments on amphibian dehydration (Malik and Storey, 2009). Animals were weighed and then placed into dry 
buckets (without lids) at $5{ }^{\circ} \mathrm{C}$. Over time, frogs lost body water via evaporation across the skin and, at intervals, frogs were weighed and the change in body mass was used to calculate the percentage body water lost. Initially frogs were weighed twice per day and subsequently at shorter intervals as frogs approached the target desired percent body water lost. The percent body water lost was calculated by the formula:

$$
\% \text { Dehydration }=\frac{M i-M d}{M i-B W C i} \times 100 \%
$$

where $M_{i}$ is initial frog body mass, $M_{d}$ is dehydrated frog mass, and $B W C_{i}$ is initial body water content $\left(0.808 \pm 0.012 \mathrm{~g} \mathrm{H}_{2} \mathrm{O}\right.$ per $\mathrm{g}$ body mass $)$. Animals were sampled when percent dehydration reached $\sim 40 \%$, deemed " $40 \%$ Dehydration".

Frogs from all treatment groups (control, 24h frozen, $8 \mathrm{~h}$ thawed, 24h anoxic and $40 \%$ dehydrated frogs) were euthanized by pithing, at which point brain tissue was dissected out and flash-frozen in liquid nitrogen $\left(\mathrm{T}=-196^{\circ} \mathrm{C}\right)$. Brain tissue was pooled from $n=3-4$ frogs for better yield, and biological replicates $(n=5$ separate pooled samples) were collected. All tissue was stored at $-80^{\circ} \mathrm{C}$ until use. All protocols were conducted with permission of the Carleton University Animal Care Committee (protocol \#106935) and following Canadian Council on Animal Care guidelines.

\subsection{Total Soluble Protein Isolation}

Total soluble protein was isolated from samples of control, $24 \mathrm{~h}$ frozen, $8 \mathrm{~h}$ thawed, $24 \mathrm{~h}$ anoxic and $40 \%$ dehydrated frogs. Frozen tissue samples $(\mathrm{n}=5$ independent replicates, each composed brain from 3-4 frogs) of near equal weight ( $\sim 80 \mathrm{mg}$ ) were 
crushed using a mortar and pestle in liquid nitrogen and homogenized in $1 \times$ lysis buffer (EMD Millipore, \#43-045) (1:5 w:v) using a Polytron PT10. Prior to use, lysis buffer was pre-chilled and combined with $1 \mathrm{mM} \mathrm{Na} \mathrm{VO}_{4}, 10 \mathrm{mM} \mathrm{NaF}, 10 \mathrm{mM} \beta$ glycerophosphate, and $10 \mu \mathrm{L} / \mathrm{mL}$ of protease inhibitor cocktail containing $104 \mathrm{mM}$ AEBSF, $80 \mu \mathrm{M}$ aprotinin, $4 \mathrm{mM}$ bestatin, $1.4 \mathrm{mM} \mathrm{E}-64,2 \mathrm{mM}$ leupeptin, $1.5 \mathrm{mM}$ pepstatin A (Bioshop, PIC001.1). Protein homogenates were left on ice for 30 min with occasional vortexing and then centrifuged at $14,000 \mathrm{x}$ g for $20 \mathrm{~min}$ at $4{ }^{\circ} \mathrm{C}$.

Sample protein was quantified using the BioRad protein assay (Catalogue \# 5000002; BioRad Laboratories, Hercules, CA, USA) at $595 \mathrm{~nm}$ on an MR5000 microplate reader (Dynatech Laboratories, Chantilly, VA, USA). Slightly variable sample concentrations were standardized to $10 \mu \mathrm{g} / \mu \mathrm{L}$ with $1 \times$ lysis buffer. Partial volumes of natured protein were aliquoted for future use and stored at $-70^{\circ} \mathrm{C}$. Remaining volumes were used for immunoblotting. Samples were mixed 1:1 v/v with 2X SDS buffer (100 $\mathrm{mM}$ Tris-base, $4 \% \mathrm{w} / \mathrm{v}$ SDS, $20 \% \mathrm{v} / \mathrm{v}$ glycerol, $0.2 \% \mathrm{w} / \mathrm{v}$ bromophenol blue, $10 \% \mathrm{v} / \mathrm{v} 2$ mercaptoethanol), to generate final $5 \mu \mathrm{g} / \mu \mathrm{L}$ concentrations. Samples were denatured in a boiling water bath for $10 \mathrm{~min}$ and placed on ice immediately thereafter. The integrity of total protein extracts was verified using 10\% SDS-PAGE, stained with Coomassie staining $(0.25 \% \mathrm{w} / \mathrm{v}$ Coomassie Brilliant Blue, $7.5 \% \mathrm{v} / \mathrm{v}$ acetic acid and $50 \%$ methanol) and visualized using a Chemi-Genius Bioimager (Syngene, MD, United States) (See Appendix D: Total protein extract validation). Samples were stored at $-40^{\circ} \mathrm{C}$ until use. 


\subsection{Nuclear Protein Extraction}

Samples of frozen $R$. sylvatica pooled brain tissue $(\mathrm{n}=5$ independent replicates per experimental condition) were weighed then crushed in liquid $\mathrm{N}_{2}$, followed by homogenizing with a Dounce homogenizer 1:4 w/v in chilled cytosolic fraction buffer (10 mM HEPES, 10 mM KCl, 10 mM EDTA, 20 mM $\beta$-glycerophosphate, 1 mM DTT, $0.1 \%$ Triton $\mathrm{X}-100$, and $10 \mu \mathrm{L} / \mathrm{mL}$ of protease inhibitor cocktail (Bioshop, PIC001.1), $\mathrm{pH}$ 7.9), then vortexed briefly and incubated on ice for $60 \mathrm{~min}$. Homogenates were then spun at $10,000 \mathrm{xg}$ for $15 \mathrm{~min}$ at $4{ }^{\circ} \mathrm{C}$ and the cytoplasmic supernatant was collected. Pellets were washed once with cytosolic buffer and resuspended in nuclear fraction buffer (20 mM HEPES, $400 \mathrm{mM} \mathrm{NaCl}, 1 \mathrm{mM}$ EDTA, 10\% v:v glycerol, $20 \mathrm{mM} \beta$ glycerophosphate, $\mathrm{pH} 7.9$ ), sonicated and then incubated on ice for $15 \mathrm{~min}$ followed by centrifuging at $10,000 \mathrm{xg}$ for $15 \mathrm{~min}$ at $4^{\circ} \mathrm{C}$. Nuclear supernatants were transferred to fresh tubes. Nuclear and cytoplasmic fractions were standardized to equivalent concentrations $(5 \mu \mathrm{g} / \mu \mathrm{L})$. Samples were then stored at $-70^{\circ} \mathrm{C}$ until use in enzymatic kit assays or mixed 1:1 v/v with SDS buffer (100 mM Tris-base, 4\% w/v SDS, 20\% v/v glycerol, $0.2 \% \mathrm{w} / \mathrm{v}$ bromophenol blue, $10 \% \mathrm{v} / \mathrm{v} 2$-mercaptoethanol) and denatured in a boiling water bath for immunoblotting. Selected samples were then tested via immunoblotting with cytoplasmic ( $\alpha$-tubulin) and nuclear (histone H3) markers to validate the effective fractionation of nuclear versus cytoplasmic fractions (See Appendix

\section{E: Nuclear enrichment validation).}




\subsection{Immunoblotting}

Samples of equal protein content (10-50 $\mu \mathrm{g}$; previously optimized depending on the target) were then loaded onto discontinuous SDS-PAGE gels (8-15\%; optimized for target molecular weight) along with 4-7 $\mu \mathrm{L}$ of either PiNK Plus pre-stained protein ladder (10.5-175 kDa; Cat\# PM005-0500K; FroggaBio), or BLUeye pre-stained protein ladder (10 to $245 \mathrm{kDa}$; Cat\# PM007-0500; FroggaBio) reference standards (See Appendix A: Immunoblotting conditions optimized for particular targets). Stacking gels were 5\% acrylamide (v/v) in $1 \mathrm{M}$ Tris buffer ( $\mathrm{pH} 6.8$ ) with $0.1 \%$ SDS, $0.1 \%$ APS and $0.1 \%$ TEMED. Separating gels contained $8-15 \%$ acrylamide $(\mathrm{v} / \mathrm{v})$ in $1.5 \mathrm{M}$ Tris buffer $(\mathrm{pH}$ 8.8), with $0.1 \%$ SDS, $0.1 \%$ APS, and $0.1 \%$ TEMED. Loaded gels were separated using the BioRad Mini Protean III system (BioRad Laboratories, Hercules, CA, USA) in Trisglycine running buffer (25 mM Tris-base, $190 \mathrm{mM}$ glycine, $0.1 \% \mathrm{w} / \mathrm{v}$ SDS, $\mathrm{pH} 8.5$ ) at $180 \mathrm{~V}$ for $45-150 \mathrm{~min}$, depending on protein target. Resolved gels were then transferred onto $0.45 \mu \mathrm{m}$ PVDF membranes by electro-blotting at $160 \mathrm{~mA}$ for $45-150 \mathrm{~min}$, depending on protein target, in Tris-glycine transfer buffer (25 mM Tris-base, $190 \mathrm{mM}$ glycine, 10\% v/v methanol, $\mathrm{pH} 8.5)$.

Membranes were blocked with 1-5\% skim milk in $1 \times$ TBST $(20 \mathrm{mM}$ Tris-base, $140 \mathrm{mM} \mathrm{NaCl}, 0.05 \%$ Tween-20) for $30 \mathrm{~min}$ at room temperature to minimize nonspecific interactions. Excess milk was washed away for 3 x 5 min in $1 \times$ TBST. Membranes were then probed with primary antibodies (diluted 1:1000 to 1:5000 v:v as needed) in $1 \times$ TBST, $0.02 \%$ sodium azide at $4^{\circ} \mathrm{C}$ for $\sim 18$ hours (See Appendix B: Antibody information for the complete antibody list). Excess primary antibody was then washed off with $3 \times 5$ min rinses in $1 \times$ TBST and membranes were then probed with 
HRP-linked goat anti-rabbit secondary antibodies (1:5000-8000 v:v in TBST; Catalogue \# APA002P, BioShop Canada Inc., Burlington, ON, Canada) at room temperature for 30 $\min$. Membranes were then given a final wash for 3 x 5 min in $1 \times$ TBST and finally visualized by HRP chemiluminescence (plus $\mathrm{H}_{2} \mathrm{O}_{2}$ and Luminol) using the ChemiGenius Bio Imaging System (Syngene, Frederick, MD, USA). Band intensities were standardized against total protein content after staining with Coomassie blue $(0.25 \% \mathrm{w} / \mathrm{v}$ Coomassie brilliant blue, $7.5 \% \mathrm{v} / \mathrm{v}$ acetic acid, $50 \%$ methanol) to control for any variation in sample loading (See Appendix C: Loading control for immunoblotting for more information).

\subsection{Quantification and Statistics}

Chemiluminescent bands were quantified by densitometry using ChemiGenius Bio Imaging System GeneTools Software (Syngene, Frederick, MD, USA). Band intensities were standardized against the combined absorption of a group of Coomassiestained bands that were unchanged across all samples and well-separated from the bands of interest. Data are expressed as mean \pm SEM with $n=4-5$ samples from pooled samples of different animals. Statistical analysis was performed by one-way ANOVA and a Tukey's post-hoc test $(p<0.05)$ using SigmaPlot 12.0 statistical software (Systat

Software Inc., San Jose, CA, USA). 


\section{CHAPTER 3}

\section{Repressive H3K9 methylation reduced in Rana sylvatica cryo-recovering brains}




\subsection{INTRODUCTION}

The changing of seasons brings drastically different environmental conditions to animal inhabitants in certain parts of the world. In particular, winter presents major challenges for survival of many species. Some animals have the luxury of migrating to more comfortable locations, others insulate themselves deep underground or underwater for warmth, whereas some others have evolved adaptations to endure otherwise lethal cellular stresses brought on by freezing temperature. The wood frog (Rana sylvatica) is a prime example of this latter group. They are freeze-tolerant; a term coined because of their ability to accept ice formation in extracellular and extra-organ spaces (Mazur, 1984; reviewed in Storey and Storey, 2017). The size and location of these ice crystals is controlled by ice-nucleating proteins, and the passive movement of water out of cells across cell membranes to equilibrate the external rising osmolality of unfrozen extracellular fluid causes cells to shrink. Ice nucleation, typically on the skin, triggers the rapid breakdown of liver glycogen and the intracellular accumulation of glucose in cells (Hemmings and Storey, 1994; Storey and Storey, 1986). Glucose acts in a colligative manner with other osmolytes, to lower the freezing point of intracellular fluids and prevent intracellular ice formation. Glucose also conveniently acts to limit cell volume loss above a critical minimum where the cytoskeleton collapses and the lipid bilayers are forced into an amorphous gel state by compression stress (Wolfe and Bryant, 1999). Still, cells dehydrate by upwards of $65 \%$ in tissues of frozen animals (reviewed in Churchill and Storey, 1993).

Ice formation unfortunately brings additional stressors: blood thickening, heartbeat cessation and halted respiration - all of which drive the wood frog into an 
anoxic state. Oxidative phosphorylation collapses without its final electron acceptor, and cells becomes reliant on anaerobic glycolysis as their primary source of energy. This is evidenced by increasing accumulation of lactate across several species over the course of freezing (Churchill and Storey, 1992; Costanzo et al., 2013; Packard and Packard, 2004). L-alanine, another glycolytic end product, is also produced in a tissue-specific fashion, likely to lessen lactate acidosis during prolonged freezing (Storey and Storey, 1986). This anaerobic metabolic conversion yields a reduction of $\sim 95 \%$ in energy output which must be balanced by dropping energy expenditure, a phenomenon termed metabolic rate depression (MRD), while still inducing essential freeze survival pathways (Storey, 1990; Storey and Storey, 1988). Outside of large total energy savings from suppression of digestion, nutrient absorption and peristalsis, a variety of quick, dynamic, and inexpensive mechanisms exist in re-prioritizing energy usage. These include reversible or irreversible modifications at the post-translational level, post-transcriptional RNA interference, and epigenetic transcriptional control. Given the energetically expensive nature of gene expression (Rolfe and Brown, 1997) and that many biochemical pathways have strict regulation on initial steps, it is of no surprise that evidence for large-scale transcriptional suppression is shown during hypometabolic states (Biggar and Storey, 2014; Bocharova et al., 1992; Morin and Storey, 2006b; Van Breukelen and Martin, 2002). Also, considering that MRD is not the complete abolishment of energy expenditure, and that the expression of vital freeze survival genes like fibrinogen (Cai and Storey, 1997a), freeze-responsive Fr10 and Li16 (Cai and Storey, 1997b; McNally et al., 2002), anti-apoptotic Bcl-xL and c-IAP (Gerber et al., 2016) must be induced, transcriptional regulation is heavily implicated in MRD. 
Within chromatin there exists regions of heterochromatin and euchromatin. Heterochromatin contains high nucleosome density with typically low accessibility for polymerase machinery whereas euchromatin has DNA in a relaxed, more transcriptionally active state. Chromatin remodeling allows the dynamic interconversion between states, and in turn the regulation of area genes. Histone lysine methylation on the $\mathrm{N}$-terminal tails of histone $\mathrm{H} 3$ and $\mathrm{H} 4$ of the nucleosome octamer is one emerging contributor in the remodeling process, often through the recruitment of methyl-lysine binding proteins (reviewed in Hyun et al., 2017). The transcriptional consequences of methylated lysine residues of histone tails are variable; some generally act as repressors and others as activators. Through comprehensive ChIP-seq analyses, most methylated histone residues are linked to transcription (Barski et al., 2007). For example, methylation of $\mathrm{H} 3 \mathrm{~K} 4$ and mono-methylation of $\mathrm{H} 4 \mathrm{~K} 20 \mathrm{mel}$ is linked to gene activation, whereas trimethylation of $\mathrm{H} 3 \mathrm{~K} 9$ and $\mathrm{H} 3 \mathrm{~K} 27$ are typically associated with gene silencing (Boyer et al., 2006; Kalakonda et al., 2008; Mikkelsen et al., 2007).

Histone lysine methylation is mediated by the combined activity of "writer" lysine methyltransferases (KMTs) and “eraser” lysine demethylases (KDMs). Most methyltransferases contain the conserved SET domain for catalysis, using S-adenosyl methionine (SAM) to mono-, di- and tri-methylate the side chain amino group of lysine residues. Most KMTs are site-specific; H3K4 is methylated by SET1A and SETD7, SUV39H1 and ESET tri-methylate H3K9, SMYD2 methylates H3K4 and weakly H3K36, and SETD8 mono-methylates H4K20 (reviewed in Martin and Zhang, 2005). ASH2L and RBPP5 are key binding proteins in H3K4-methylating KMT2 complexes, and $\mathrm{HP} 1 \gamma$ is a prominent $\mathrm{H} 3 \mathrm{~K} 9 \mathrm{me} 2 / 3$ "reader" that typically facilitates gene repression 
(reviewed in Lomberk et al., 2006). Preliminary evidence links histone lysine methylation to hypometabolic states. Initial research into wood frog liver and muscle metabolism suggests hypomethylation of permissive H3K4me1 via reduced expression of SMYD2 and ASH2L may contribute to transcriptional repression during freezing (Hawkins and Storey, 2018). Hypermethylation of repressive H3K9me3 by increased expression of methylase EHMT2 was reported to potentially contribute to gene silencing in red-eared slider liver anoxia tolerance (Wijenayake et al., 2018). Tissue-specific roles for methylation have also been implied during thirteen-lined ground squirrel hibernation (Watts and Storey, 2019). Research into epigenetic regulation of the extreme stress response of the nervous system is largely understudied, which is surprising considering the strong links of epigenetic regulation to the CNS in other areas.

In the present chapter, the expression of 8 KMT complex enzymes (SET1A, ASH2L, RBBP5, SMYD2, SUV39H1, ESET, SETD7, SETD8), 5 histone methyl-lysine modifications (H3K4me1, H3K9me3, H3K27me1, H3K36me2, H4K20me1), and 1 methylated H3K9 "reader" (HP1 $\gamma)$ were measured across freeze-thaw and associated substresses in wood frog brain tissue. Enzymatic methyltransferase activities on H3K9 and H3K27 were also quantified. Our findings suggest that coordinated knockdown of repressive H3K9me3, via decreased expression of ESET and SUV39H1 may contribute to large-scale transcriptional activation during thawing recovery after freezing.

\subsection{METHODS}

\section{Animal Experiments}

Animal experiments were performed as described in Chapter 2.1. 


\section{Total Soluble Protein Isolation}

Total protein isolations were performed as described in Chapter 2.2.

\section{Nuclear Protein Extraction}

Nuclear protein extractions were performed as described in Chapter 2.3.

\section{Immunoblotting}

Immunoblotting was performed as described in Chapter 2.4. The expression of eight key KMTs (SET1A, ASH2L, RBBP5, SMYD2, SUV39H1, ESET, SETD7 and SETD8), some histone lysine residues that they methylate (H3K4me1, H3K9me3, $\mathrm{H} 3 \mathrm{~K} 27 \mathrm{me} 1, \mathrm{H} 3 \mathrm{~K} 36 \mathrm{me} 2$ and $\mathrm{H} 4 \mathrm{~K} 20 \mathrm{me} 1)$ and $\mathrm{HP} 1 \gamma$ were assessed across freeze-thaw as well as under anoxia and dehydration sub-stresses. See Appendix A: Immunoblotting conditions for a detailed list of optimized target-specific western blotting conditions, and Appendix B: Antibody information for the full list of antibodies used. G9a, a hypoxiainducible lysine methyltransferase of H3K9 and H3K27 (Chen et al., 2006; Tachibana et al., 2001), was tested in this study, but didn't cross-react with tissues.

\section{Quantification and statistics}

Quantification and statistics were performed as described in Chapter 2.5.

\section{Histone Methyltransferase Activity Assays}

Relative levels of total histone methyltransferase activity on individual histone H3 lysine residues were measured using EpiQuik Histone Methyltransferase Activity/Inhibition Assay Kits (Epigentek, H3K9, Cat\# P-3003; H3K27, Cat\# P-3005) following manufacturer guidelines. All necessary reagents were supplied with these 
ELISA kits. A dilution series of pooled nuclear extracts was used to determine ideal absorbance readings for ELISA kits. For H3K9 and H3K27 kits, $15-40 \mu \mathrm{g}$ of $\mathrm{n}=5$ control, $24 \mathrm{~h}$ frozen, $8 \mathrm{~h}$ thawed, $24 \mathrm{~h}$ anoxic and $40 \%$ dehydrated nuclear extracts were added to wells with supplied AdoMet (Epigentek) and biotinylated substrate (Epigentek) in the provided 96 -well microplate for $60 \mathrm{~min}$ at $37^{\circ} \mathrm{C}$. Blank and control enzyme (300 $\mu \mathrm{g} / \mathrm{ml}$; Epigentek) wells were also run. After incubation, each well was washed 3 times with $150 \mu \mathrm{L}$ of $1 \times$ wash buffer. A $50 \mu \mathrm{L}$ aliquot of diluted (1:100) capture antibody (100 $\mu \mathrm{g} / \mathrm{ml}$; Epigentek) in $1 \times$ wash buffer was added to each well and incubated for $60 \mathrm{~min}$ at room temperature on an orbital shaker (50-100 rpm). The wells were washed 4 times with $150 \mu \mathrm{L}$ of $1 \times$ wash buffer before adding $50 \mu \mathrm{L}$ of diluted (1:1000) detection antibody $(100 \mu \mathrm{g} / \mathrm{ml}$; Epigentek) in 1× wash buffer, which was incubated for $30 \mathrm{~min}$ at room temperature. After a final 5 washes with $150 \mu \mathrm{L}$ of $1 \times$ wash buffer, $100 \mu \mathrm{L}$ of developing solution was added to each well and incubated for $10 \mathrm{~min}$ at room temperature until control enzyme wells turned deep blue (indicating sufficient methyl-lysine). At this stage, $50 \mu \mathrm{L}$ of stop solution was added to each well, and the sample wells were read using a microplate reader (Multiscan Spectrum, Thermo Labsystems) at $450 \mathrm{~nm}$.

A standard curve was generated using different concentrations of HMT standard $(0.1-5.0 \mathrm{ng} / \mu \mathrm{L})$ as per the manufacturer guidelines. All samples were within the range of the standards, and curve slope was used to calculate HMT activity using the following equation:

$$
\text { Activity }\left(\frac{\frac{n g}{h}}{m g}\right)=\frac{O D(\text { sample }- \text { blank })}{[\text { Protein amount }(u g) * \text { incubation time }(h) * \text { slope }]} \times 1000
$$




\subsection{RESULTS}

Freezing, freeze recovery and dehydration stress all contribute to changes in lysine methyltransferase expression

The relative protein levels of six lysine methyltransferases (SET1A, SMYD2, SUV39H1, ESET, SETD7, SETD8) and two KMT2-associated complex subunits (ASH2L, RBBP5) were tracked by immunoblotting across three stress conditions: freezethaw $\left(24 \mathrm{~h}\right.$ freezing at $-2.5^{\circ} \mathrm{C}$ and $8 \mathrm{~h}$ thaw at $\left.5^{\circ} \mathrm{C}\right)$ and freezing-relevant sub-stresses $(24$ $\mathrm{h}$ anoxia, $40 \%$ dehydration, both at $5^{\circ} \mathrm{C}$ ) compared with $5^{\circ} \mathrm{C}$ acclimated control frogs in R. sylvatica brain samples to elucidate adaptive roles for histone lysine methylation in stress tolerance (Fig 3.1). During freezing, SUV39H1 levels rose $1.48 \pm 0.12$-fold in relation to control values, significantly different $(p<0.05)$ from all other conditions except for dehydration. After thawing, SUV39H1 levels fell again to a level that was not significantly different from the control. However, thawing also significantly reduced the levels of ESET, SETD7 and SETD8 to values that were just $50.2 \pm 7 \%, 40.1 \pm 4 \%$ and $46.6 \pm 2 \%$ of control values, respectively (Fig 3.1A). Freeze-recovered ESET levels were significantly less than all but frozen samples, and SETD8 levels were lower than all but anoxic, while thawed. Protein expression of lysine methyltransferases SMYD2 and SET1A, as well as KMT2-associating protein ASH2L were unaffected across the experimental conditions used (Fig 3.1B). Surprisingly, KMT2-associated RBBP5 showed an isolated increase $(1.25 \pm 0.06$-fold vs. controls $)$ during $40 \%$ dehydration, levels that are significant $(p<0.05)$ from all conditions except 24-hour anoxic samples. 


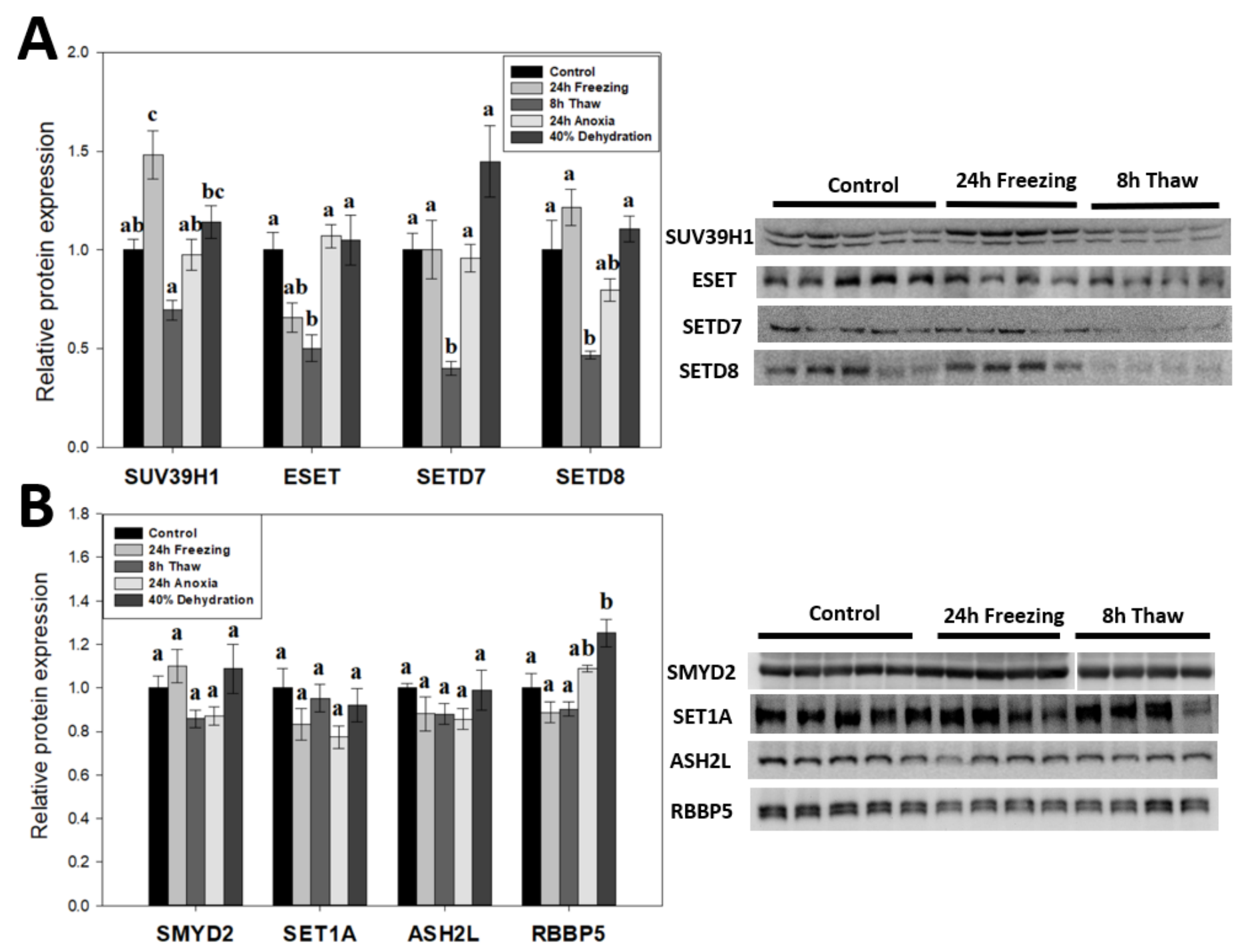

Figure 3.1. Effects of 24h Freezing, $8 \mathrm{~h}$ Thaw, 24h Anoxia and 40\% Dehydration on total protein levels of lysine methyltransferases (A) SUV39H1, ESET, SETD7 and SETD8 and (B) SMYD2, SET1A, ASH2L and RBBP5 in brain tissue of Rana sylvatica as determined by Western immunoblotting. Representative immunoblot bands are also shown. Data are mean \pm SEM, on $n=4-5$ independent trials on tissue samples of different animals. Values labelled by different letters are significantly different from one another $(p<0.05)$. SETD7 (A) and SMYD2 (B) have $n=5$ for frozen samples, while others listed are $n=4$. Immunoblot bands for anoxia/dehydration are found in Appendix G: Anoxia/Dehydrated immunoblot bands. 


\section{Freeze recovery drives decreases in both transcriptionally permissive $H 3 K 27$ me1 and repressive $\mathrm{H} 3 \mathrm{~K} 9 \mathrm{me} 3$}

To link KMT expression with their nucleosomal targets, the relative levels of methylated histone lysine residues (H3K4me1, H3K9me3, H3K27me1, H3K36me2 and H4K20me1) were measured in total soluble protein extracts of control, 24-hour frozen, 8hour thawed, 24-hour anoxic and 40\% dehydrated wood frog brain tissue via immunoblotting (Fig 3.2). Interestingly, total histone $\mathrm{H} 3$ levels were found to be significantly reduced in samples from 24-hour frozen frogs relative to controls $(p<0.05)$, whereas histone $\mathrm{H} 4$ levels were conversely elevated $(p<0.05)$. To account for these discrepancies, $\mathrm{H} 3$ and $\mathrm{H} 4 \mathrm{~K}$ marks were standardized to the expression of total histone protein in the same samples. The data shown in Fig. 3.2 indicate that histone methylation levels did not change significantly during $24 \mathrm{~h}$ freeze exposure but did decrease significantly $(p<0.05)$ after $8 \mathrm{~h}$ thawed; values for $\mathrm{H} 3 \mathrm{~K} 9 \mathrm{me} 3$ and H3K27me1 were reduced to $53.0 \pm 5 \%$ and $50.6 \pm 6 \%$ in brain of thawed frogs relative to controls. Thawed H3K9me3 levels were also significantly reduced as compared with 24-hour anoxic samples, whereas thawing also decreased H3K27me1 expression significantly as compared with 24-hour frozen levels $(p<0.05)$. No observable differences were found for the expression of $\mathrm{H} 3 \mathrm{~K} 4 \mathrm{me} 1, \mathrm{H} 3 \mathrm{~K} 36 \mathrm{me} 2$ and H4K20me1 levels across any experimental conditions. 


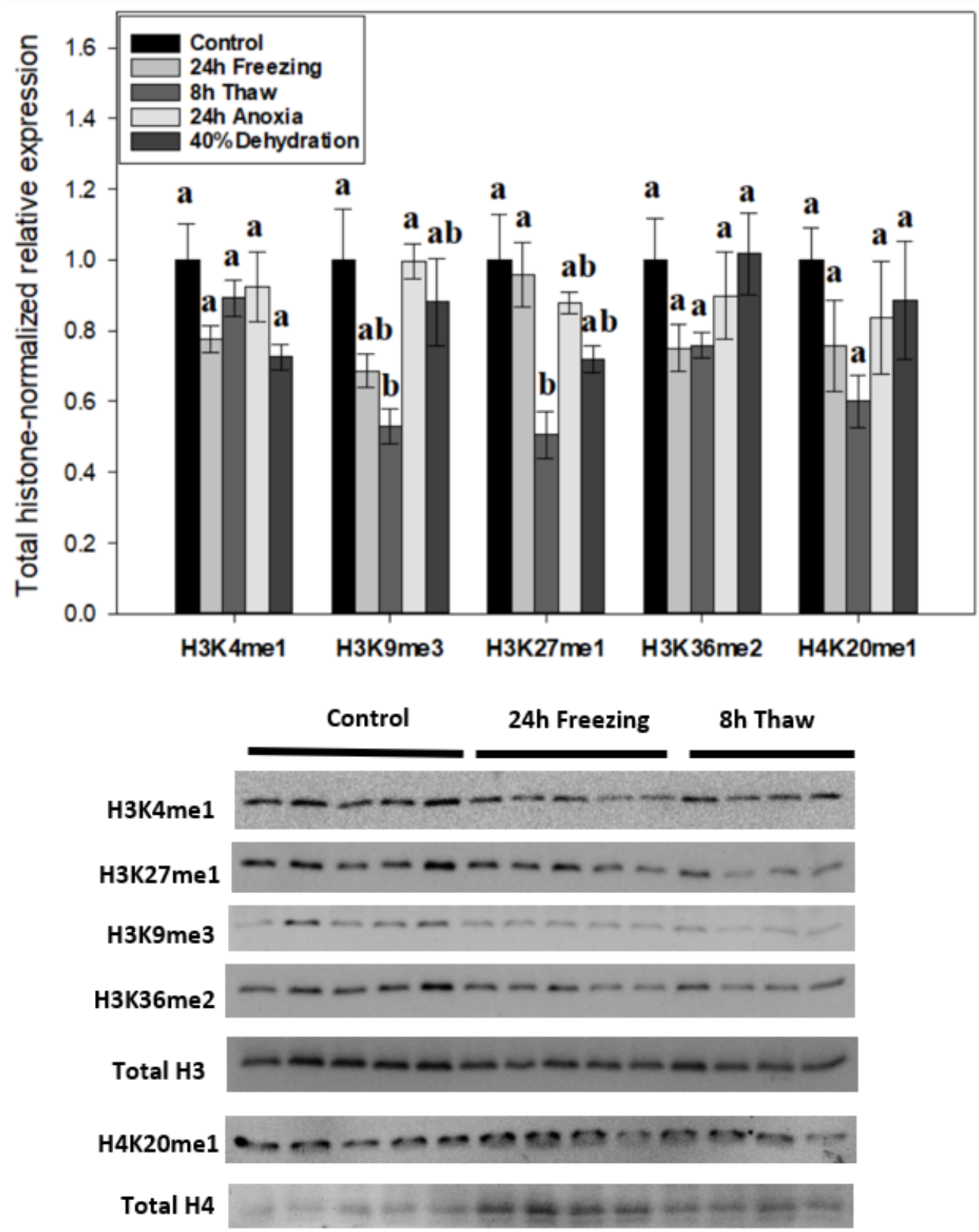

Figure 3.2. Effects of $24 \mathrm{~h}$ Freezing, $8 \mathrm{~h}$ Thaw, $24 \mathrm{~h}$ Anoxia and $40 \%$ Dehydration on relative protein levels of methylated histone lysine residues in brain tissue of Rana sylvatica as determined by Western immunoblotting. Representative immunoblot bands are also shown. Modified histone residues were standardized to total histone band intensities as total proteins was shown to change across stresses. Data are mean $\pm \mathrm{SEM}$, and $n=4-5$ independent trials on tissues of different animals. Values labelled by different letters are significantly different from one another $(p<0.05)$. Immunoblot bands for anoxia/dehydration are found in Appendix G: Anoxia/Dehydrated immunoblot bands. 


\section{Freeze recovery affects coordinated $\mathrm{HMT}$ activity of $\mathrm{H} 3 \mathrm{~K}$, but not $\mathrm{H} 3 \mathrm{~K} 27$}

To determine whether KMT protein expression was linked to enzymatic activity, global histone methyltransferase activities on histone lysine residues H3K9 (Fig. 3.3) and H3K27 (Fig 3.4) were measured in nuclear extracts of brain from control, frozen, thawed, anoxic and dehydrated wood frogs using EpiQuik Histone Methyltransferase Activity/Inhibition Assay Kits as in described in Chapter 3.2. In agreement with ESET and H3K9me3 expression, a sharp decline $(p<0.05)$ in H3K9 HMT activity to $29 \pm 8 \%$ was noted in extracts of freeze-recovered ( $8 \mathrm{~h}$ thawed) brain relative to control values. H3K9 HMT activity was stable across all other conditions. Conversely, no change in H3K27 HMT activity was found in nuclear extracts across any of the experimental treatments.

\section{Like other H3K9me3-relevant factors, key "reader" HP1y levels also reduced during 8- hour thaw}

In a preliminary search to find functional consequences of $\mathrm{H} 3 \mathrm{~K} 9$ hypomethylation during immediate freeze thawing, the relative expression of key genome-wide $\mathrm{H} 3 \mathrm{~K} 9 \mathrm{me} 3$ "reader", HP1 $\gamma$, was compared in control, 24-hour frozen, 8-hour thawed and 24-hour anoxic brain tissue of wood frogs by immunoblotting (Fig 3.5). HP1 $\gamma$, a typical gene silencer, was found to be downregulated in thawing brains (to only $42.8 \pm 6 \%$ of control frogs), consistent with observed trends for other H3K9me3-related data. Stress condition (frozen, anoxic) protein levels were unchanged from control values. 


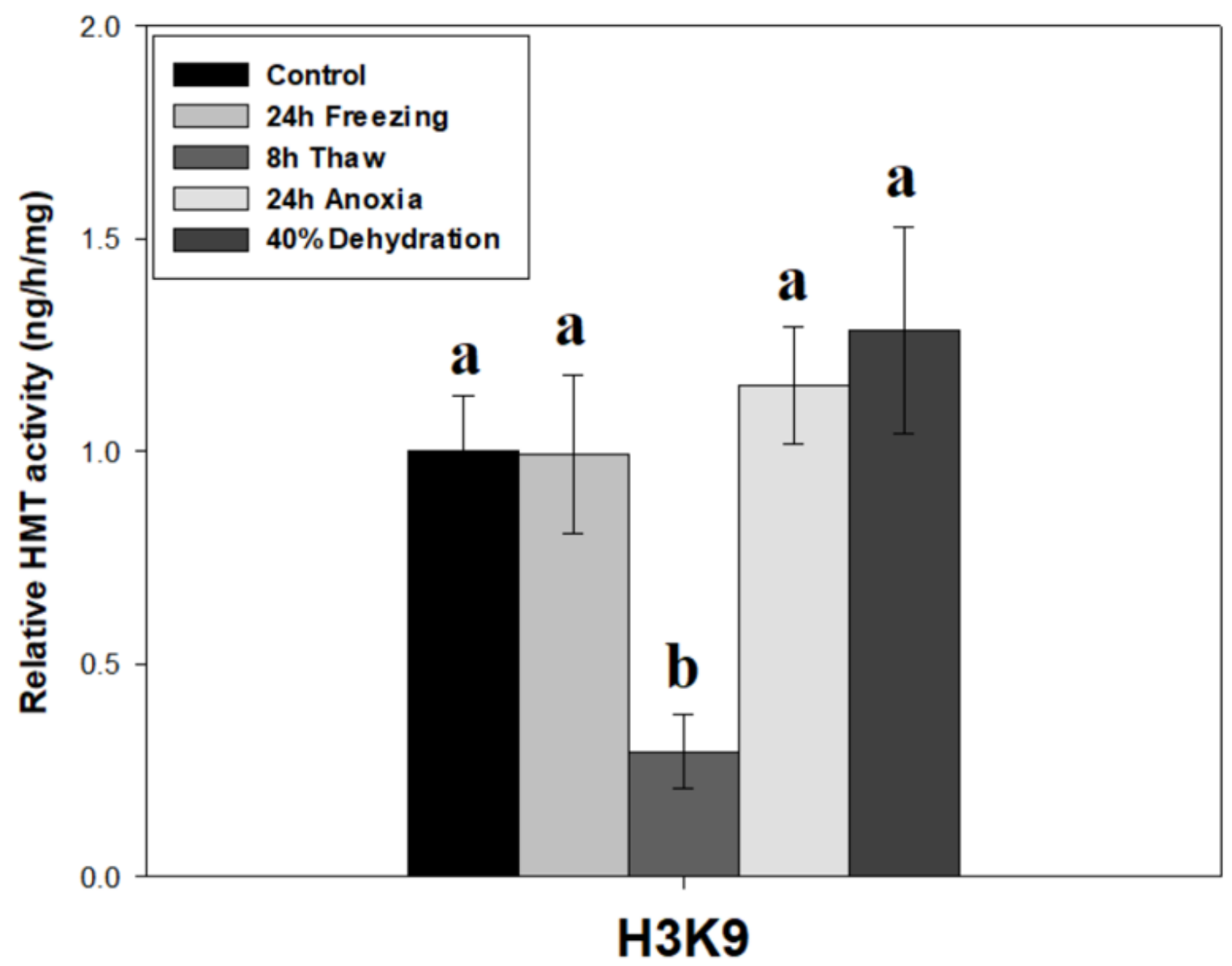

Figure 3.3. Relative HMT activity on $\mathrm{H} 3 \mathrm{~K} 9$ of control, 24h frozen, $8 \mathrm{~h}$ thawed, $24 \mathrm{~h}$ anoxic and $40 \%$ dehydrated nuclear extracts of Rana sylvatica brain tissue. Enzyme activities are expressed in relative enzymatic activity levels. Data are mean $\pm \mathrm{SEM}, n=5$ independent trials on samples from different animals. Actual control activity was $3.73 \pm$ $0.48 \mathrm{ng} / \mathrm{h} / \mathrm{mg}$. Values labelled by different letters are significantly different from one another $(p<0.05)$. 


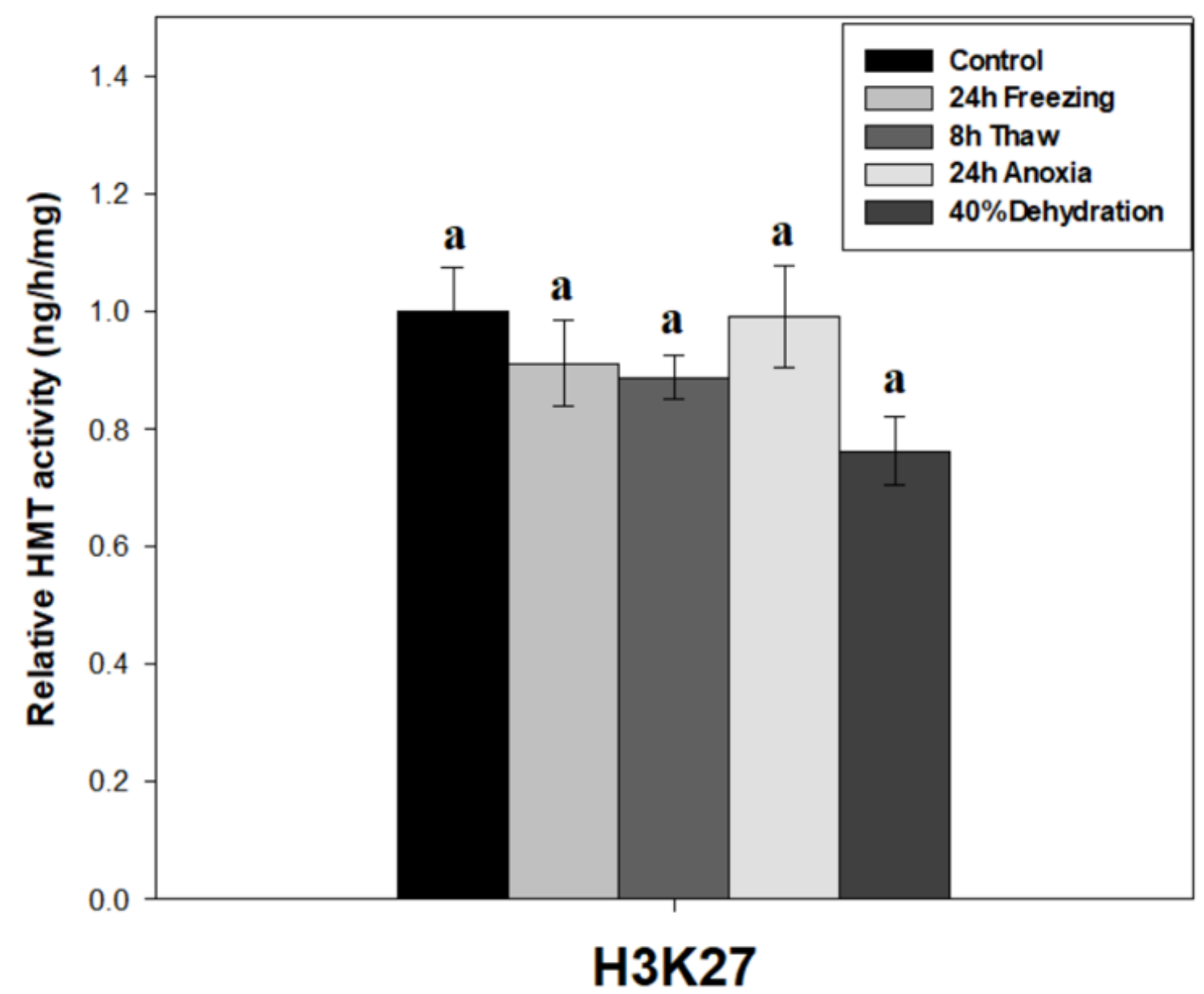

Figure 3.4. Relative HMT activity on H3K27 of control, 24h frozen, $8 \mathrm{~h}$ thawed, $24 \mathrm{~h}$ anoxic and $40 \%$ dehydrated nuclear extracts of Rana sylvatica brain tissue. Enzyme activities are expressed in relative enzymatic activity levels. Data are mean $\pm \mathrm{SEM}, n=5$ independent trials on samples from different animals. Actual control activity was $2.86 \pm$ $0.21 \mathrm{ng} / \mathrm{h} / \mathrm{mg}$. Values labelled by different letters are significantly different from one another $(p<0.05)$. 

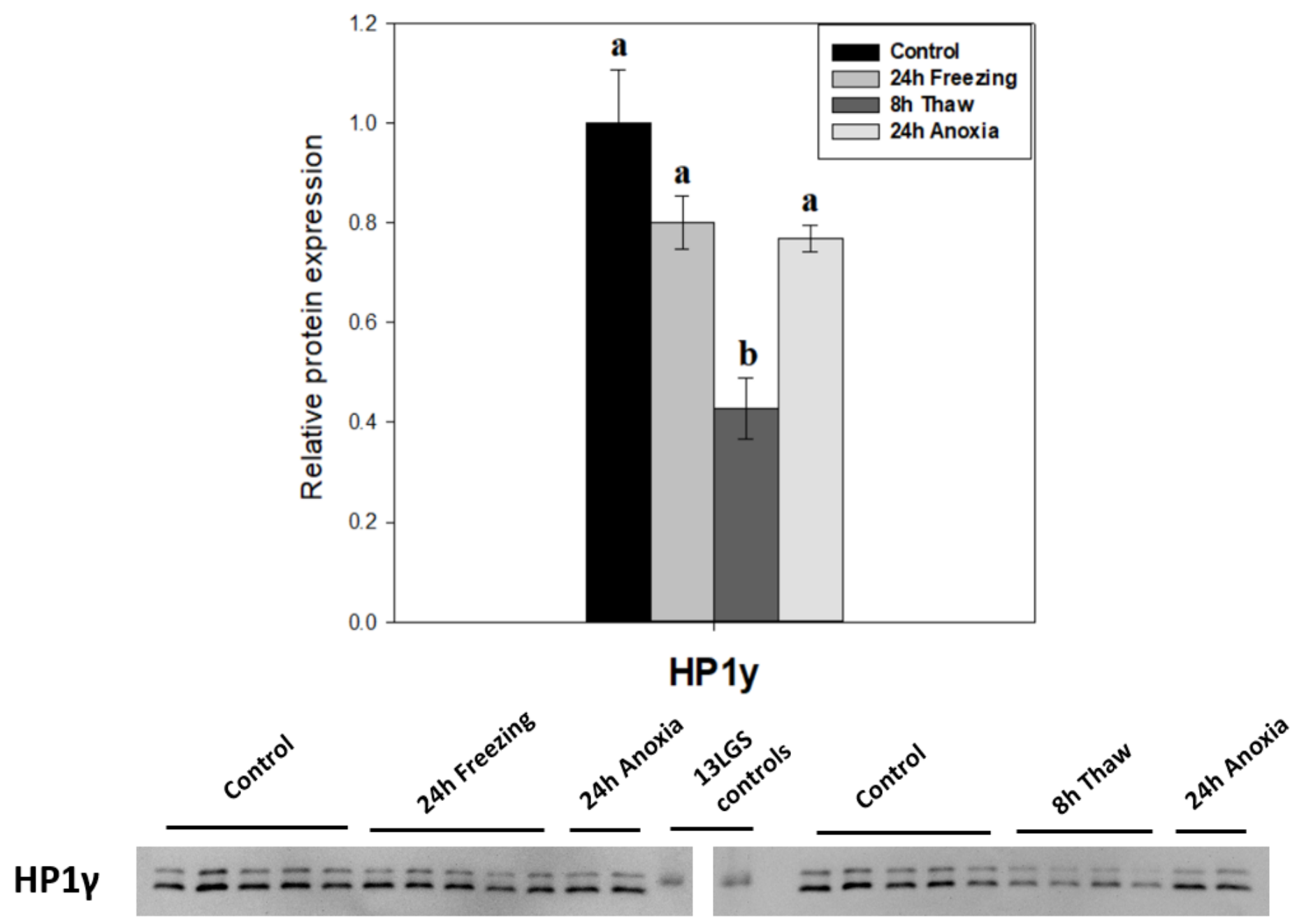

Figure 3.5. Relative expression of heterochromatin protein $1 \gamma$ during the freeze-thaw cycle and anoxia in brain tissue of Rana sylvatica as determined by Western immunoblotting. Representative immunoblot bands are also shown (both bands were used in quantification steps). Data are mean \pm SEM, on $n=4-5$ independent trials on tissue samples of different animals. Values labelled by different letters are significantly different from one another $(p<0.05)$. 


\subsection{DISCUSSION}

To stabilize energy production and not deplete minimal resources during prolonged freezing, the wood frog, Rana sylvatica, can employ a wide variety of regulatory mechanisms to reprioritize energy demands to freeze-survival responses (reviewed in Storey and Storey, 2004). Suppression of transcription (Biggar and Storey, 2014; Bocharova et al., 1992; Morin and Storey, 2006b; Van Breukelen and Martin, 2002) and translation (Fraser et al., 2001; Frerichs et al., 1998) are characteristic of hypometabolic states, and for that reason epigenetic and post-transcriptional controls have emerged as crucial players (reviewed in Hawkins and Storey, 2020). Among them is histone lysine methylation, a dynamic epigenetic mechanism with versatile effects on gene transcription. The degree and site of methylated histone residues act in permissive or repressive manners, depending on recruited methyl-lysine binding proteins (reviewed in Hyun et al., 2017). Indeed, a recent investigation highlighted hypomethylation of H3K4 and reduced expression of permissive H3K4me1, SMYD2 and ASH2L in liver and skeletal muscle of wood frogs as likely contributors to transcriptional repression during freeze tolerance (Hawkins and Storey, 2018). Conversely, hypermethylation of H3K9, combined with induced expression of $\mathrm{H} 3 \mathrm{~K} 9 \mathrm{me} 3$ and EHMT2 appear to facilitate gene silencing in liver of red-eared sliders (Trachemys scripta elegans) when oxygen is withdrawn from these anoxia tolerant turtles (Wijenayake et al., 2018). Intricate tissuespecific roles for histone lysine methylation are also suggested over the torpor-arousal cycle of thirteen-lined ground squirrels during hibernation (Watts and Storey, 2019).

Growing research outlines the complexity of these responses; they are not entirely consistent across species or between bodily organs, likely due to separate cellular 
physiology and functional requirements during stress and recovery responses, which warrants further study. Epigenetic research into the nervous system under extreme environmental stress conditions and the adaptive responses displayed is still a largely understudied area, which is perplexing as compared with the wealth of brain epigenomic interest in other areas (reviewed in Bale, 2015; Stankiewicz et al., 2013). The data in this chapter is the first to document methyl-lysine-mediated epigenetic regulation of nervous tissue in support of vertebrate freeze tolerance.

\section{SUV39H1, ESET and $\mathrm{H} 3 \mathrm{~K} 9 \mathrm{me} 3$ are critical regulators of freezing and recovery transcriptional states}

Given that histone lysine methylation is carried out by KMTs, which are highly limited in their histone lysine targets, the current study began with a measure of the relative expression of notable KMTs and associated factors across the wood frog freezethaw cycle. Also, in an attempt to determine the driving force behind KMT expression changes in the multi-faceted freezing stress, the independent effects of both dehydration and anoxia stresses were also studied (Fig 3.1). During 24-hour freezing, relative levels of SUV39H1 increased significantly, before returning to control levels during 8-hour thawed recovery. This is expected since SUV39H1 acts to tri-methylate $\mathrm{H} 3 \mathrm{~K} 9$, a highly repressive mark via recruitment of heterochromatin protein 1 (HP1) homologs (Bannister et al., 2001). SUV39H1 largely deposits H3K9me3 marks on constitutive heterochromatic, pericentromeric, and telomeric regions (Peters et al., 2001). This suggests that elevated SUV39H1 likely contributes to blocking aberrant transcriptional activity in non-coding regions (such as by viral/transposable elements) and may also promote heterochromatin formation in coding regions of non-essential genes to suppress 
their transcription. ESET, another H3K9me3 methylase like SUV39H1, also showed depressed expression during 8-hour thawing recovery - suggesting that repressive H3K9me3 may be alleviated to facilitate the global reactivation of gene expression in freeze recovery. ESET (also known as SETDB1) is a major regulator of embryonic stem cell identity, particularly in developing nervous tissue, where it has been implicated in an array of neuropsychiatric disorders (reviewed in Zhu et al., 2020). ESET depresses transcription through two major mechanisms: (1) KAP1/KRAB-Zfp that recruits the histone deacetylase complex NuRD (Schultz et al., 2001) and (2) DNA methylation machinery MBD1/DNMT3 (Ichimura et al., 2005; Lundberg et al., 2013), outlining the intricacies of epigenetic crosstalk.

Further results strengthen our suggestion that global reactivation of gene expression during freeze recovery may be coordinated through eased $\mathrm{H} 3 \mathrm{~K} 9$ me3-mediated repressive mechanisms: (1) H3K9me3 levels were reduced during thawed recovery of wood frogs relative to controls (Fig 3.2), (2) global H3K9 methyltransferase activity was only reduced in 8-hour thawed frogs (Fig 3.3), and (3) the expression of methylated H3K9 “reader" HP1 $\gamma$ was suppressed in freeze recovery (Fig 3.5). HP1 proteins $(\alpha, \beta$ and $\gamma$ ) typically bind $\mathrm{H} 3 \mathrm{~K} 9 \mathrm{me} 2 / 3$ to facilitate heterochromatin formation and gene silencing (reviewed in Lomberk et al., 2006). HP1 $\gamma$ is a crucial player in genome-wide regulation, enriched in both euchromatic and heterochromatic regions, whereas $\alpha$ - and $\beta$-isoforms are primary to heterochromatin (Minc et al., 2000). Despite some euchromatic roles for HP1 $\gamma$ in transcriptional elongation and RNA processing (Saint-André et al., 2011; Vakoc et al., 2005), HP1 $\gamma$ is essential to repression of various gene promoters (Chéné et al., 2007; Choi et al., 2012; Duong and Weitz, 2014). Taken together, it can be suggested that 
decreased H3K9me3 (Fig 3.2), a result of depressed H3K9 methyltransferase activity (Fig 3.3) via reduced SUV39H1 and ESET expression (Fig 3.1), further supported by less HP1 $\gamma$ (Fig 3.5) aid in heightened transcriptional activity during recovery from hypometabolic conditions such as freezing. Our results agree with other research highlighting the importance of repressive $\mathrm{H} 3 \mathrm{~K} 9$ methylation in hypometabolic adaptive responses (Wijenayake et al., 2018).

\section{SETD7 and SETD8 downregulation do not facilitate changes in H3K4me1 and H4K20me1 during freeze recovery}

Two lysine methyltransferases, SETD7 and SETD8, which act on histone proteins to promote transcription via $\mathrm{H} 3 \mathrm{~K} 4 \mathrm{me} 1$ and $\mathrm{H} 4 \mathrm{~K} 20 \mathrm{me} 1$, respectively, were not affected by freezing but both show reduced expression during the 8-hour thaw period (Fig 3.1). In both cases, the reduced protein levels of these enzymes did not correlate with suppressed levels of their histone targets (Fig 3.2). In the case of SETD7, this is not particularly surprising when total protein levels of all other tested proteins involved in H3K4 methylation (SET1A, ASH2L, RBBP5 and SMYD2) were unchanged in response to freezing or other stress exposures (anoxia, dehydration) in wood frog brain. This research does not appreciate the gene-specificity of these epigenetic marks and their writers, but the repression of SETD7 may point toward roles for methylation of non-histone targets

during freeze recovery. SETD7 is a regulatory hub, methylating a plethora of non-histone targets (>30) with diverse effects which include hypoxia-inducible factor $1 \alpha$ (HIF-1 $1 \alpha), \beta$ catenin, yes-associated protein 1 (YAP1) and retinoblastoma protein (Rb) (Batista and Helguero, 2018). 
HIF-1 $\alpha$ is the master transcriptional regulator of cell adaptation to low oxygen availability, activating genes to alter metabolism and maintain tissue integrity (reviewed in Semenza, 2001). Indeed, HIF-1 $\alpha$ upregulation has been well implicated in hypometabolic states (Maistrovski et al., 2012; Morin and Storey, 2005; Morin et al., 2005). Methylation of K32 by SETD7 stimulates HIF- $1 \alpha$ by preventing ubiquitination and subsequent degradation (Kim et al., 2016). SETD7 has also been shown to monomethylate $\mathrm{H} 3 \mathrm{~K} 4$ at promoters of HIF-1 $\alpha$ target genes, suggesting its role in hypoxic responses (Liu et al., 2015). Repressed SETD7 expression during freeze recovery may act to destabilize HIF-1 $\alpha$, allowing the transition from anaerobic freezing back to aerobic cellular metabolism. $\beta$-catenin is a transcriptional activator of many genes involved in cell proliferation, migration, and invasion (reviewed in Valenta et al., 2012). Phosphorylation of $\beta$-catenin by glycogen synthase kinase-3 beta (GSK3 $\beta$ ) triggers its degradation, preventing cell division. SETD7 methylates $\beta$-catenin at K180, strengthening its destabilizing interaction with GSK3 $\beta$ (Shen et al., 2015). Reduced SETD7 levels may indirectly promote resumed cell proliferation and migration during thawing by alleviating repressive effects on $\beta$-catenin. Similarly, YAP1 interacts with other factors to enhance transcription of anti-apoptotic and cell proliferation genes (reviewed in Pan, 2010). Hippo signaling triggers methylation of YAP1 K494 by SETD7, preventing its nuclear translocation and transcriptional activity (Oudhoff et al., 2013). As above, SETD7 depression might also contribute to proliferation and anti-apoptotic responses during recovery through YAP1 nuclear activation. Finally, SETD7 methylation of $\mathrm{Rb}$ at $\mathrm{K} 873$ is required for its activity in $\mathrm{G}_{1} / \mathrm{S}$ cell cycle arrest (Munro et al., 2010). Also, mono-methylation of $\mathrm{Rb}$ at $\mathrm{K} 810$ by SETD7 prevents cyclin-dependent kinase 
phosphorylation of Rb, stabilizing its connection with E2F1 and stops E2F1

transcriptional activity (Carr et al., 2011). SETD7 depletion during recovery may release E2F1 from Rb, allowing cell cycle progression to resume through the $\mathrm{G}_{1} / \mathrm{S}$ checkpoint. Indeed, evidence for Rb-E2F1 mediated cell cycle arrest during red-eared slider anoxia tolerance has been recently provided (Biggar and Storey, 2018b).

Non-histone roles for SETD8 repression could also occur during freeze recovery, particularly via p53 and NUMB de-methylation. The p53 transcription factor is a major tumor suppressor, frequently inactivated in cancer phenotypes. During stress, p53 activates the transcription of hundreds of genes involved in numerous processes, including DNA damage repair and apoptosis (reviewed in Hafner et al., 2019). NUMB promotes p53-mediated apoptosis by preventing ubiquitination of p53 by the E3 ligase MDM2 in the tripartite NUMB-p53-MDM2 complex. SETD8 both (1) mono-methylates p53 at K382, suppressing its transcriptional activity (Shi et al., 2007), and (2) methylates K158 and K163 on NUMB, releasing it from the complex and driving p53 degradation via MDM2 (Dhami et al., 2013). Hence, increased ROS production during reoxygenation/reperfusion after thawing, in conjunction with repressed SETD8 expression, may stimulate p53 directly and/or indirectly through NUMB, to facilitate DNA damage repair and apoptosis in cells damaged during freezing or counteract oxidative stress associated with recovery. 


\section{Permissive H3K27me1 down during freeze recovery, despite no change in $\mathrm{H} 3 \mathrm{~K} 27$ methyltransferase activity}

The relative expression of $\mathrm{H} 3 \mathrm{~K} 27 \mathrm{me} 1$ was depressed significantly in brain during freeze recovery relative to control and freezing conditions (Fig 3.2). This was not correlated with a decrease in methyltransferase activity of H3K27 (Fig 3.4), however, the activity assays used cannot discriminate between specific mono-, di- or tri- H3K27me states. Regardless, given the dynamic nature of methylation, lysine demethylase research is warranted. $\mathrm{H} 3 \mathrm{~K} 27 \mathrm{mel}$ is a relatively rare epigenetic mark (deposited at roughly $4 \%$ of K27me sites) that is enriched in intragenic regions of actively transcribed genes (Ferrari et al., 2014; Vakoc et al., 2006). As a transcriptionally permissive mark, H3K27me1 reduction in freeze recovery is surprising, however it has been reported previously in wood frog liver and muscle tissues (Hawkins and Storey, 2018). Further investigation into how reduction of $\mathrm{H} 3 \mathrm{~K} 27 \mathrm{me} 1$ contributes to freeze recovery is required.

\section{Conclusions}

In summary, this chapter provides strong evidence for roles of histone lysine methylation in stress-adaptive strategies of the wood frog brain. SUV39H1 up-regulation during freezing likely plays a key role in creating a suppressed transcriptional state whereas de-repression of H3K9me3, SUV39H1, ESET and H3K9 methyltransferase activities likely contribute to transcriptional activation during thawing. Non-histone roles for SETD7 and SETD8 are likely and H3K27me1 may also contribute to freeze recovery. Why RBBP5 expression might increase during dehydration stress, while its binding partner ASH2L did not is perplexing, although it does suggest that there are as of yet 
unexplored intricacies in the regulation of homologous KMT2 complexes involved in H3K4 methylation. 


\section{CHAPTER 4}

\section{Repressive DNA methylation reduced in Rana sylvatica cryo-recovering brains}




\subsection{INTRODUCTION}

In recent years, critical roles for epigenetic regulation within hypometabolic states have begun to be established, particularly via DNA methylation and histone modification mechanisms. Evidence for epigenetic control in MRD has been found in freeze-tolerant anurans (Hawkins and Storey, 2018; Zhang et al., 2020a), anoxia-tolerant turtles (Wijenayake et al., 2018; Wijenayake and Storey, 2016), hibernating ground squirrels (Biggar and Storey, 2014; Morin and Storey, 2006b; Watts and Storey, 2019), and invertebrates (Zhao et al., 2015). Given that epigenetics is a major transcriptional control, and that gene transcription alone utilizes $1-10 \%$ of the cell's total energy budget (Rolfe and Brown, 1997), it is expected that the suppressed production of new transcripts during entrance/maintenance of hypometabolism (Bocharova et al., 1992; Van Breukelen and Martin, 2002) is mediated by tight epigenetic regulation.

DNA methylation is a post-replicative covalent modification of the fifth carbon on genomic cytosine residues that is stable and yet can be modified by the actions of enzymes that add or remove methyl marks. Methylation occurs most often on $\mathrm{CpG}$ dinucleotides, where cytosine is 5' adjacent to a guanine residue and creates 5methylcytosine (5-mC). Regions of high $\mathrm{CpG}$ density are called $\mathrm{CpG}$ islands and these are upstream of the promoters of most genes. Hypermethylation of $\mathrm{CpG}$ islands correlates with transcriptional silencing of downstream genes by (1) direct interference of transcription factor binding to promoter/enhancer elements, and/or (2) through the recruitment of repressive methyl-CpG-binding proteins like MBD1, MBD2 and MeCP2 (reviewed in Bogdanović and Veenstra, 2009; Moore et al., 2013). These "reader" proteins bind methylated $\mathrm{CpG}$ regions, and recruit chromatin remodeling complexes (like 
histone deacetylases) to block the access of transcriptional machinery to promoter elements (Nan et al., 1998).

Placement of methyl marks onto cytosine is carried out by DNA methyltransferases (DNMTs) that transfer methyl groups donated from S-adenosyl methionine (SAM) onto cytosine residues. Two major classes of DNMTs exist: (1) maintenance methyltransferases, like DNMT1, that bind hemi-methylated DNA to ensure that methylation patterns are passed to daughter cells during DNA replication, and (2) de novo methyltransferases like DNMT3A and DNMT3B, that target unmethylated CpG islands during embryonic development or in response to stimuli (reviewed in Lyko, 2018). However, evidence for DNMT3A and DNMT3B action in maintenance methylation (Dodge et al., 2005; Feng et al., 2010) and de novo DNMT1 activity at certain loci (Jair et al., 2006) suggest that these definitions are incomplete. A catalytically inactive third member of the DNMT3 family, called DNMT3L, forms complexes with DNMT3A and DNMT3B to help regulate their activity (Chédin et al., 2002; Suetake et al., 2004).

DNA methylation was long considered to be a very stable epigenetic mark with established roles in gene expression, development, disease states and stress responses (Bestor et al., 2015; Jaenisch and Bird, 2003; Suzuki and Bird, 2008). Until recently, 5$\mathrm{mC}$ demethylation was thought to occur passively, and often being lost during subsequent replications of genomic material. However, this poorly explained the dynamic reprogramming during embryonic development or in responses to stress (Wu and Zhang, 2011). Twelve years ago, 5-hydroxylmethylcytosine (5-hmC) was discovered as an enzymatic derivative of 5-mC in mammalian DNA, formed by the action of ten-eleven- 
translocation 1 (TET1) proteins in the presence of Fe(II) and 2-ketoglutarate (Tahiliani et al., 2009). Shortly after, two other enzymes, TET2 and TET3 were also shown to catalyze the same reaction (Ito et al., 2011). This showed the presence of an active demethylation process that was then shown to be completed by the base excision repair (BER) pathway, where thymine DNA glycosylase (TDG) excises the intermediates 5-fluorocytosine (5fC) or 5-carboxylcytosine (5-caC), resulting in an unmodified cytosine residue (Shen et al., 2013). Indeed, active DNA demethylation provides a site-specific mechanism to regulate transcription in response to environmental stressors like freezing, anoxia and dehydration, among others. Given the oxygen-sensitive nature of this DNA modification, in that TET enzymes require $\mathrm{O}_{2}$ substrates, it could be a likely regulator involved in Rana sylvatica freeze tolerance.

Wood frog freeze tolerance involves complex responses to several environmental stresses: extracellular ice formation drives the passive movement of water out of cells through aquaporin channels to balance internal/external osmolality but leaves cells severely dehydrated, the influx of high concentrations of cryoprotectant glucose brings hyperglycemic stress, and halted oxygen transport puts cells into a deep anoxic state (reviewed in Storey and Storey, 2017). Cells turn to less efficient anaerobic glycolysis of intracellular glucose for ATP production and enter a hypometabolic state by lowering energetic demands to prevent the depletion of limited resources over the course of prolonged freezing. Growing research has outlined numerous mechanisms that contribute to the maintenance of MRD (largely focused on liver or skeletal muscle tissues), ranging from reversible post-translational protein modification (Dawson and Storey, 2016; Dieni and Storey, 2011, 2010, 2009) to post-transcriptional miRNA control (reviewed in Biggar 
and Storey, 2018, 2015) and increasingly to transcriptional control via epigenetic mechanisms like DNA methylation (Zhang et al., 2020a). However, research on the brain (the crucial organ needed to orchestrate thawed recovery of frogs) and into the role of DNA demethylation is currently lacking. This warrants further study and is the focus of this chapter.

The present chapter investigates the expression and global activity of DNMT enzymes (DNMT1, DNMT3A, DNMT3B and DNMT3L), as well as the abundance of repressive MBD effectors (MBD1, MBD2 and MeCP2) across freeze-thaw and associated sub-stresses in wood frog nervous tissue. To appreciate the dynamic nature of epigenetic marks, the study also investigates the expression of active demethylation enzymes, TET2, TET3 and TDG across freeze-thaw (note that TET1 does not appear to be present in anurans). The abundance of genomic $5-\mathrm{hmC}$ is also compared across freezethaw to determine whether enzyme expression translates into functional changes on a genome-wide scale. The results give strong indications of robust gene activation during recovery from freezing, with coordinated roles of depressed DNA methylation and induced demethylation.

\subsection{METHODS}

\section{Animal Experiments}

Animal experiments were performed as described in Chapter 2.1.

\section{Total Soluble Protein Isolation}

Total protein isolations were performed as described in Chapter 2.2. 


\section{Nuclear Protein Extraction}

Nuclear protein extractions were performed as described in Chapter 2.3.

\section{Immunoblotting}

Immunoblotting was performed as described in Chapter 2.4. The expression of key DNA methyltransferases (DNMT1, DNMT3A, DNMT3B and DNMT3L) was measured across freeze-thaw plus anoxic and dehydrated sub-stresses. See Appendix $\boldsymbol{A}$ : Immunoblotting conditions for a detailed list of optimized target-specific western blotting conditions and Appendix B: Antibody information for the full list of antibodies used,

\section{Quantification and statistics}

Quantification and statistics were performed as described in Chapter 2.5.

\section{DNMT Activity ELISA}

DNMT activity was quantified using the EpiQuik DNMT Activity/Inhibition Assay Ultra Kit (Epigentek, Cat\#: P-3009), following manufacturer guidelines. All necessary reagents were supplied with the ELISA kits. A dilution series of pooled nuclear extracts (10-40 $\mu \mathrm{g})$ was used to optimize ideal absorbance readings for the kits. Blank and control enzyme (300 $\mu \mathrm{g} / \mathrm{ml}$; Epigentek) wells were also run. For samples, $30 \mu \mathrm{g}$ each of nuclear extracts from $\mathrm{n}=5$ control, $24 \mathrm{~h}$ frozen, $8 \mathrm{~h}$ thawed, $24 \mathrm{~h}$ anoxic and $40 \%$ dehydrated conditions were added to wells supplied with DNMT substrates and incubated for $2 \mathrm{~h}$ at $37^{\circ} \mathrm{C}$. Wells were then washed three times in $1 \times$ wash buffer, before $5-\mathrm{mC}$ 
capture antibody was added to each well and incubated for $1 \mathrm{~h}$ at room temperature. The wells were again washed three times and incubated in detection antibody for $30 \mathrm{~min}$ at room temperature. Following four washes in $1 \times$ wash buffer, the enhancer solution was incubated in target wells for $30 \mathrm{~min}$ at room temperature. After a final five washes, the supplied developer solution was incubated in each well until the positive control wells turned deep blue at which point the supplied Stop Solution was added to each well and absorbance was read at $450 \mathrm{~nm}$.

Total DNMT activity was calculated using the formula:

DNMT Activity $(\mathrm{OD} / \mathrm{h} / \mathrm{mg})=\frac{(\text { Sample OD-Blank OD })}{[\text { Protein Amount }(\mu g) \text { x Incubation Time }(h)]} \times 1000$

\section{Genomic DNA Extraction}

Genomic DNA was extracted from $25 \mathrm{mg}$ samples of frozen tissue ( $\mathrm{n}=5$ per experimental condition) using the Quick-DNA Miniprep Plus Kit (Zymo Research Cat\#: D4068) according to the manufacturer directions for tissue samples. Briefly, tissues were digested with proteinase $\mathrm{K}$ overnight at $55^{\circ} \mathrm{C}$, then centrifuged at $12,000 \mathrm{xg}$ for $1 \mathrm{~min}$, and the aqueous supernatant containing DNA was transferred and bound to the supplied spin column. Spin columns were washed multiple times with the provided wash buffer, then eluted in heated DNA elution buffer (10 mM Tris-HCl, $0.1 \mathrm{mM}$ EDTA, $\mathrm{pH} 8.5)$. Genomic DNA samples were measured using a Take3 Micro-Volume plate (BioTek, Vermont, USA). All samples had a 260/280 ratio > 1.8, concentrations ranging from 20$70 \mathrm{ng} / \mu \mathrm{L}$ and DNA integrity was validated on a $0.5 \%$ agarose gel (See Appendix $\boldsymbol{F}$ :

\section{Genomic DNA validation).}




\section{5-Hydroxymethylcytosine ELISA}

Genomic 5-hmC content was quantified using the Global 5-hmC DNA ELISA kit (Active Motif, Cat\#: 55025), as per manufacturer guidelines. All necessary reagents were included with ELISA kits. Briefly, genomic DNA ( $\mathrm{n}=4$ per experimental condition) was fragmented via $\mathrm{MseI}$ digestion at $37^{\circ} \mathrm{C}$ for 3 hours. To coat the wells, supplied DNA binding agent was added to wells and incubated for 1 hour at room temperature. A $15 \mathrm{ng}$ aliquot of denatured genomic DNA was loaded per well, this amount being previously shown to be within the linear range of a pooled sample dilution series. A standard curve was also run via serial dilutions of a 5-hmC standard. Wells containing gDNA, as well as blank and standard curve wells, were incubated at $37^{\circ} \mathrm{C}$ for 2 hours to enable gDNA binding. With three washes between each subsequent step, wells were incubated with 5hmC primary antibody (1:2000 v/v) and anti-rabbit HRP-conjugated secondary antibody $(1: 4000 \mathrm{v} / \mathrm{v})$ for 1 hour at room temperature with mild agitation. Finally, wells were incubated with developing solution until a range of darkening blue could be seen within the standard curve wells, at which point the stop solution was added. OD450 and the reference wavelength OD655 were measured. The $\% 5-\mathrm{hmC}$ was calculated by the following equations:

$$
\begin{gathered}
\text { ng 5-hmC }=\frac{(\text { Norm. Sample OD-Y-intercept) }}{(\text { Slope } \times 9.5)} \\
\quad \% 5-h m C=\frac{(\text { ng } 5-\text { hmC })}{(\text { ng DNA input })} \times 100
\end{gathered}
$$

Note: 9.5 is a standardization factor to account for the standard only containing $9.5 \% 5$ $\mathrm{hmC}$. 


\subsection{RESULTS}

DNMT expression agrees with the transcriptional state of cells across wood frog freezethaw

To determine if DNA methylation played a role in the response of wood frog nervous tissue exposed to whole body freezing, the relative expression of canonical DNA methyltransferase family members (DNMT1, DNMT3A, DNMT3B, DNMT3L) was examined across freeze-thaw and associated sub-stresses in $R$. sylvatica brain total protein homogenates using immunoblotting (Fig 4.1). The de novo methyltransferase partners DNMT3A/3L showed similar reductions in expression during post-freeze thawing (to $69 \pm 4 \%$ and $70 \pm 5 \%$, respectively; $p<0.05$ ) as compared to controls. However, 8-hour thawed DNMT3A levels were not significantly different from levels in wood frog brains exposed to anoxia. Conversely, in relation to controls, DNMT3B had a strong induction of expression during 24-hour freezing $(1.51 \pm 0.09$-fold; $p<0.05)$ that was maintained through freeze recovery $(1.71 \pm 0.18$-fold $)$ whereas DNMT3B levels in brain of anoxia-exposed frogs were not different than control levels. Interestingly, DNMT1 levels in brains of frogs dehydrated of $40 \%$ of total body water were greatly elevated in comparison to all other experimental conditions (up 1.95 \pm 0.18-fold compared with controls; $p<0.05)$ and DNMT1 was the only one of the four DNMTs that responded to dehydration stress. 


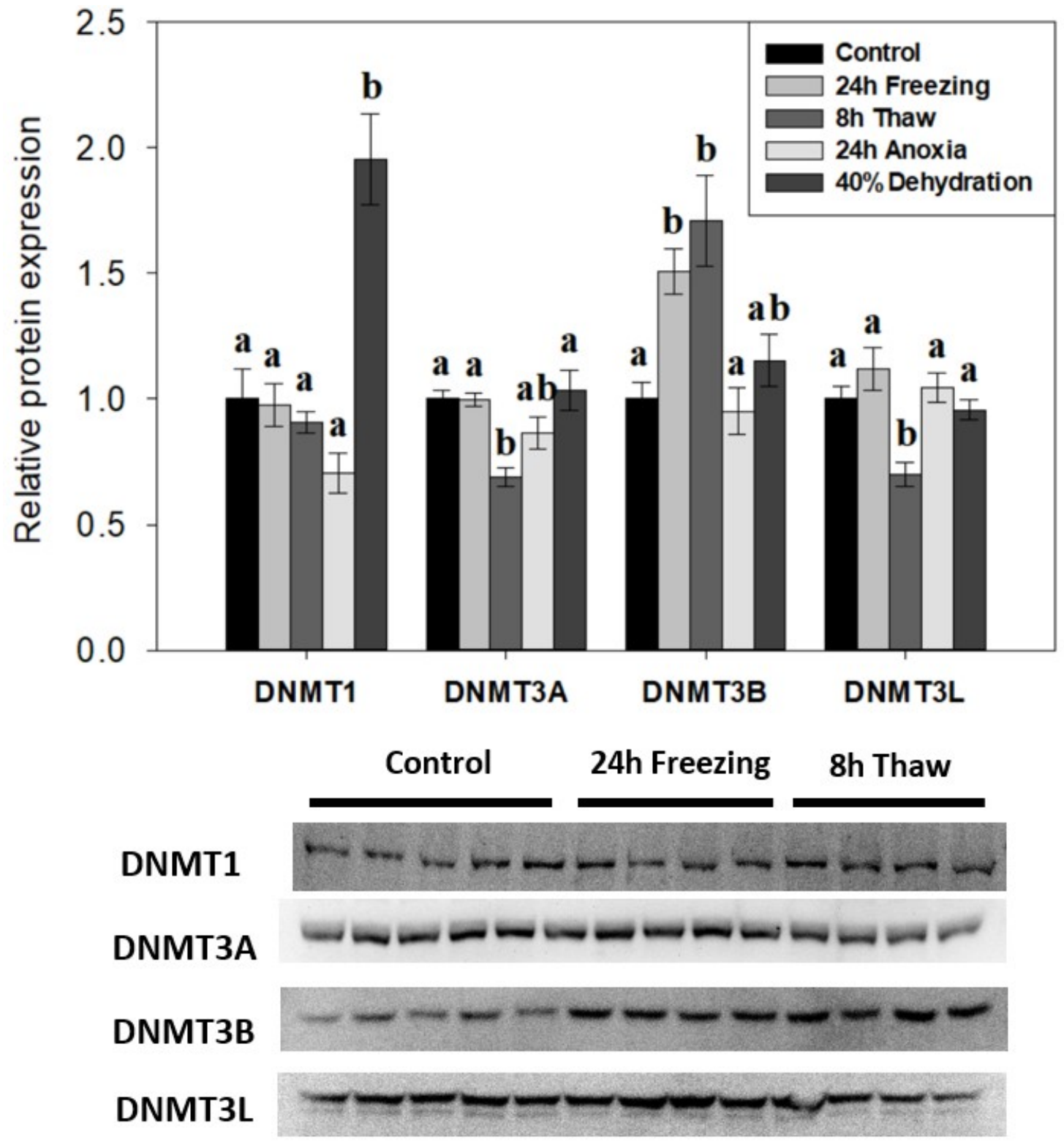

Figure 4.1. Effects of 24h Freezing, 8h Thaw, 24h Anoxia and 40\% Dehydration on total protein levels of DNA methyltransferases DNMT1, DNMT3A, DNMT3B and DNMT3L in brain tissue of Rana sylvatica as determined by Western immunoblotting. Representative immunoblot bands are also shown. Data are mean \pm SEM, on $n=4-5$ independent trials on tissue samples of different animals. Values labelled by different letters are significantly different from one another $(p<0.05)$. DNMT3A has $n=5$ for frozen samples, while others listed are $n=4$. Immunoblot bands for anoxia/dehydration are found in Appendix G: Anoxia/Dehydrated immunoblot bands. 


\section{Noticeable depression in DNA methyltransferase activity during freezing, freeze recovery and anoxia}

To test whether DNMT activity correlated with protein expression, total DNMT activity was measured on wood frog brain nuclear extracts across freeze-thaw and associated sub-stresses (Fig 4.2). Our results indicate a decreasing trend of activity across the freeze-thaw cycle, with relative DNA methylation levels down to $64 \pm 7 \%$ in 24 -hour freezing $(p<0.05)$, and a further reduction to $31 \pm 5 \%$ during freeze recovery $(p<0.05)$, relative to control extracts. The 24-hour anoxia nuclear samples also showed very low DNMT activities that were not significantly different from the $24 \mathrm{~h}$ frozen or $8 \mathrm{~h}$ thawed conditions, whereas DNMT activities in samples from brain of dehydrated frogs were unchanged as compared with controls.

\section{Methyl-CpG binding protein expression unchanged across the freeze-thaw cycle}

The expression of methyl-CpG-binding proteins MBD1, MBD2 and MeCP2 was tested across the freeze-thaw cycle in wood frog nervous tissue by immunoblotting to link DNA methylation activity with "reader" proteins (Fig 4.3). The levels of all three effector proteins were unchanged during freezing and thawed recovery. 


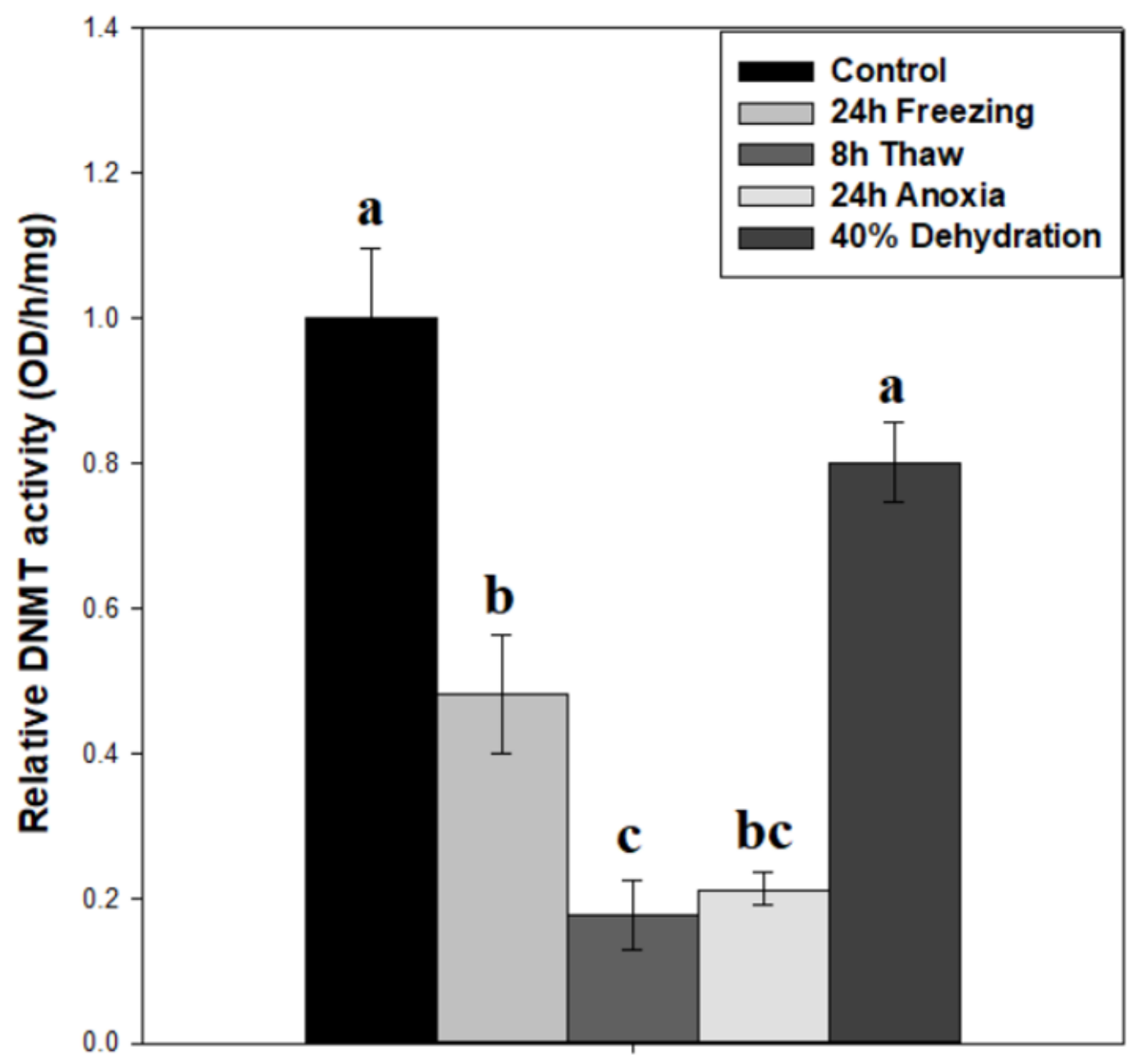

Figure 4.2. Relative DNMT total enzymatic activity in nuclear extracts of brain tissue from control, 24h frozen, $8 \mathrm{~h}$ thawed, $24 \mathrm{~h}$ anoxic and $40 \%$ dehydrated Rana sylvatica. Enzyme activities are expressed in relative enzymatic activity levels. Data are mean \pm SEM, $n=5$ independent trials on samples from different animals. Actual quantified control activity was $5.19 \pm 0.47 \mathrm{OD}$ units $/ \mathrm{h} / \mathrm{mg}$. Values labelled by different letters are significantly different from one another $(p<0.05)$. 

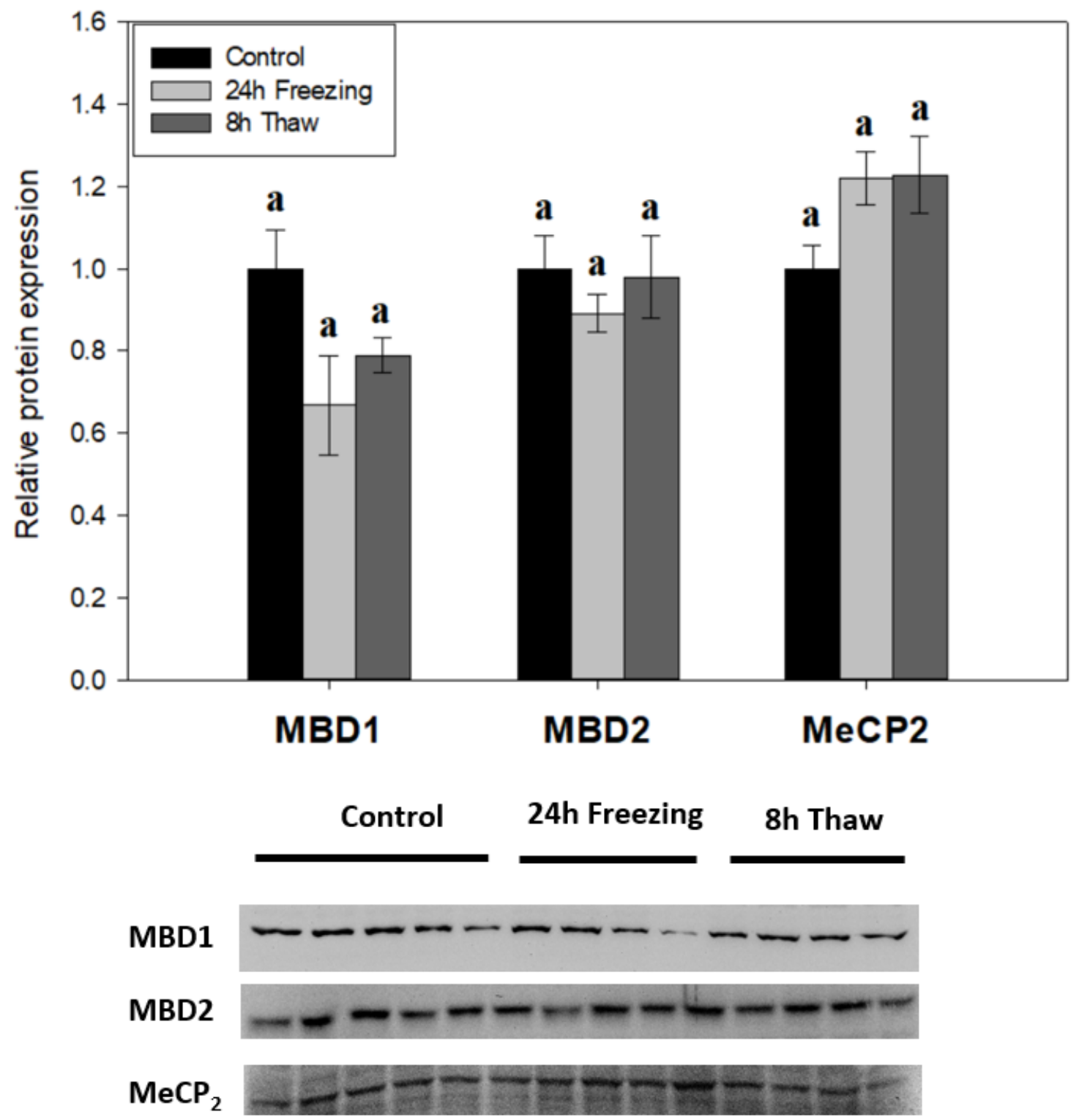

Figure 4.3. Relative expression of methyl-CpG-binding proteins MBD1, MBD2 and $\mathrm{MeCP} 2$ across the freeze-thaw cycle in brain tissue of Rana sylvatica as determined by Western immunoblotting. Representative immunoblot bands are also shown. Data are mean \pm SEM, for $n=4-5$ independent trials on tissue samples of different animals.

Values labelled by different letters are significantly different from one another $(p<0.05)$. 


\section{Multi-faceted support for increased DNA demethylation during freeze recovery}

Demethylation factors were also assessed across the brain freeze-thaw cycle given the dynamic nature of DNA methylation. The relative protein levels of TET2, TET3 and TDG demethylases were measured during freeze-thaw using immunoblotting (Fig 4.4). The results indicate dual up-regulation of TET2 and TET3 expression during thawed recovery $(p<0.05)$; values increased by 1.47 -fold and 1.75 -fold over comparable frozen levels, respectively. However, TDG levels were not affected by either freezing or thawing. To test whether the changes in TET expression were linked to DNA demethylation, the relative 5-hmC content of genomic DNA was measured across the freeze-thaw cycle of wood frog brain tissue (Fig 4.5). In agreement with the results for TETs, the relative 5-hmC content rose significantly for gDNA from thawed versus frozen frogs $(p<0.05)$, providing good evidence for enhanced DNA demethylation during freeze recovery. 

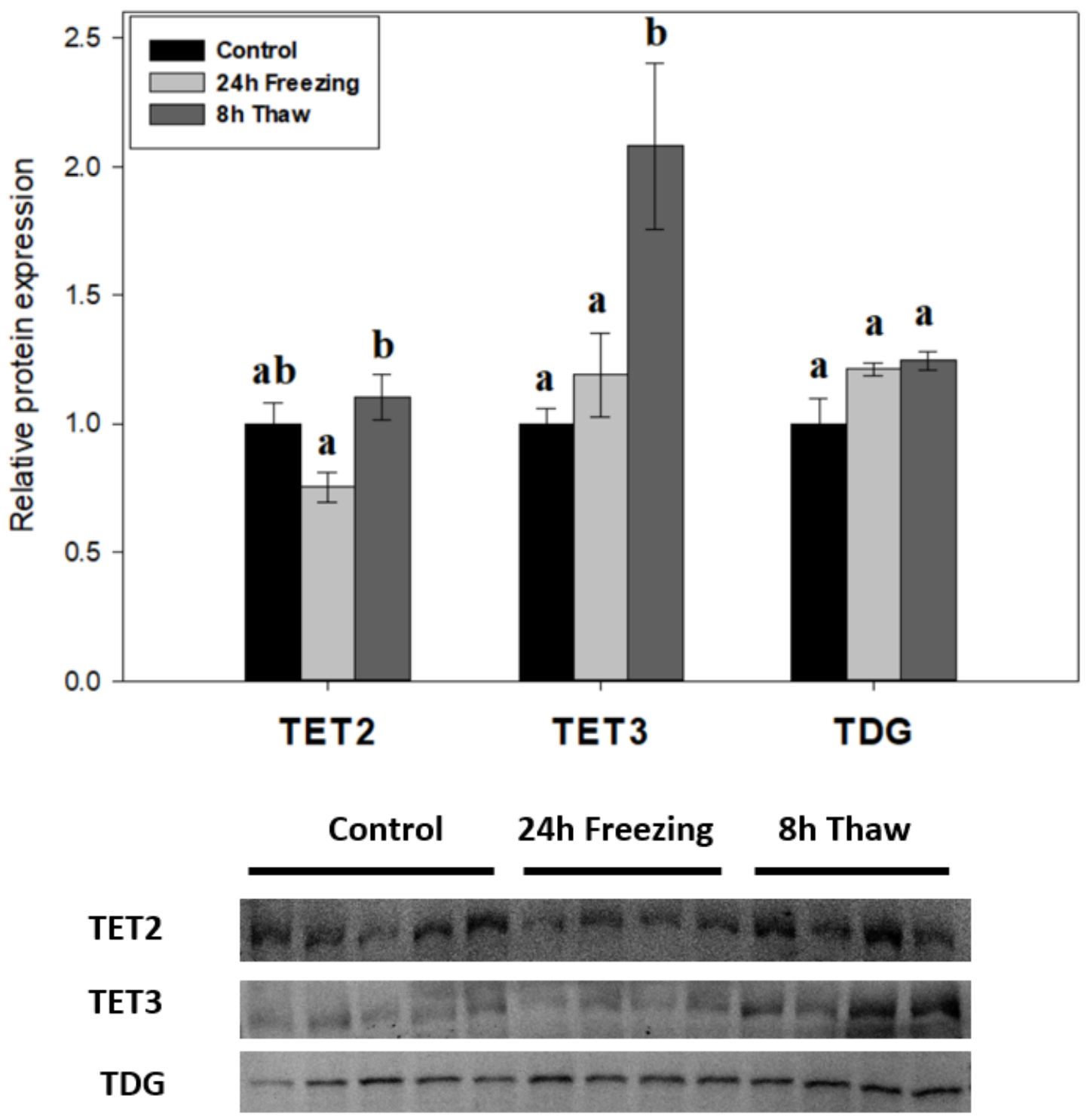

Figure 4.4. Relative expression of DNA demethylase enzymes TET2, TET3 and TDG across the freeze-thaw cycle in brain tissue of Rana sylvatica as determined by Western immunoblotting. Representative immunoblot bands are also shown. Data are mean \pm SEM, on $n=4-5$ independent trials on tissue samples of different animals. Values labelled by different letters are significantly different from one another $(p<0.05)$. *Proteomic analysis indicated that TET1 was not expressed in wood frog brain. 


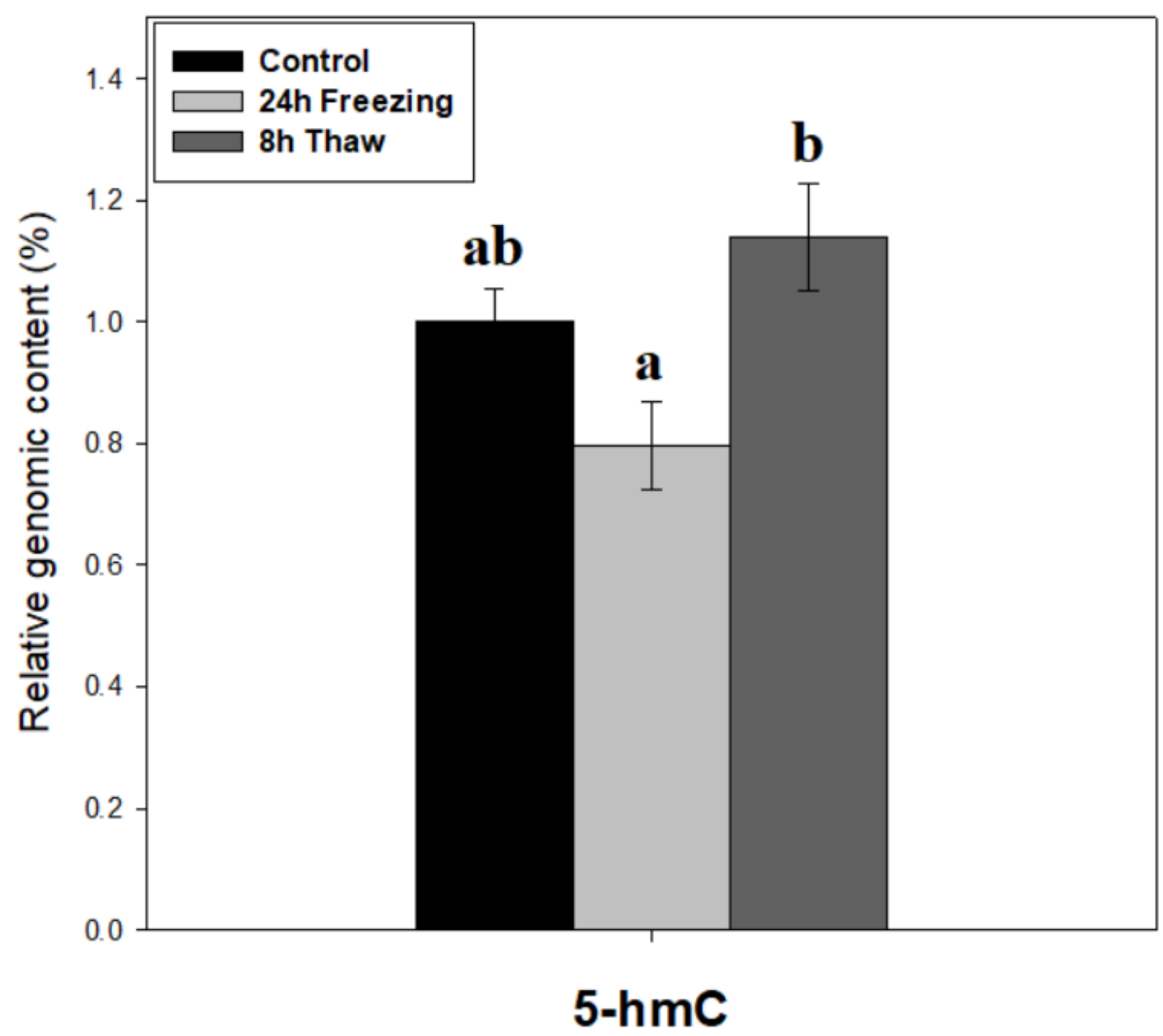

Figure 4.5. Relative genomic 5-hmC content of control, $24 \mathrm{~h}$ frozen and $8 \mathrm{~h}$ thawed Rana sylvatica brain tissue. Data are mean $\pm \mathrm{SEM}, n=4$ independent trials on DNA samples from different animals. Aliquots of $15 \mathrm{ng}$ of gDNA were tested, and genomic 5-hmC content ranged from $\sim 1-1.5 \%$. Values labelled by different letters are significantly different from one another $(p<0.05)$. 


\subsection{DISCUSSION}

Recent studies on freeze-tolerant and anoxia-tolerant animals have identified epigenetic mechanisms as notable regulators of global transcriptional repression (Hawkins and Storey, 2018; Wijenayake et al., 2018; Wijenayake and Storey, 2016; Zhang et al., 2020a), a hallmark of metabolic rate depression (Bocharova et al., 1992; Morin and Storey, 2006a; Van Breukelen and Martin, 2002). Similarly, epigenetic controls have been linked to stress recovery states, with evidence for rebounded transcriptional activation (See Chapter 3). Methylation of histone lysine and arginine residues, of DNA cytosines and of mRNA adenosines highlight the current research, with notable gaps in demethylation pathways. Also, nervous tissue is largely understudied in the field at this time. This chapter addresses both needs, by investigating the role of reversible DNA methylation in the freeze-tolerance of wood frog brain. Specifically, this work measured the expression of DNMT1/3 enzymes along with global methyltransferase activity. DNA methylation mechanisms were further explored through analysis of the relative levels of key methyl-CpG-binding proteins MBD1, MBD2 and MeCP2. The expression of TET2/3 demethylases, TDG that acts in base excision repair, and the consequential 5-hmC genomic content was also examined to inspect the reversible nature of the epigenetic marks. This chapter builds on preliminary DNA methyltransferase research on liver and skeletal muscle of wood frogs during hypometabolism (Zhang et al., 2020a). 


\section{Diverse roles for DNA methyltransferases in brain during wood frog freeze tolerance}

The relative expression of the four canonical DNA methyltransferase enzymes was tracked across the freeze-thaw cycle in wood frog brain tissue, along with related responses to anoxia and dehydration sub-stresses (Fig 4.1). The results show elevated levels of DNMT3B during freeze-thaw compared to controls, while also showing opposite decreases in DNMT3A and DNMT3L expression after $8 \mathrm{~h}$ thawed recovery $(p<$ 0.05). Interestingly, a strong up-regulation of maintenance DNMT1 expression occurred in response to dehydration stress. However, none of the four DNMT proteins responded significantly to anoxia stress in wood frog brain. In linking protein expression with total DNA methyltransferase activity, these parameters were at odds in wood frog brain in frozen, thawed and anoxic states. Enzyme activity was strongly suppressed (Fig 4.2) whereas protein levels were largely unaffected or, for DNMT3B, increased. However, this conflict could be a result of post-translational modification of one or more of the enzymes, leading to reduced activity during freezing, thawing or anoxia conditions. Hence, these results suggest that oxygen limitation, and not dehydration, is the primary driving force for decreased DNMT activity during freezing.

DNMT3B, along with DNMT3A, are primary de novo methyltransferase enzymes, establishing new $\mathrm{CpG}$ methylation patterns in response to stimuli. DNMT3B has emerged as the dominant methylase of centromeric, pericentromeric and subtelomeric repeats in the genome (Gopalakrishnan et al., 2009; Yehezkel et al., 2008) as well as, more recently, in methylating intragenic loci of active genes (Baubec et al., 2015; Jeziorska et al., 2017). The outcome of these results may be explained by the complexity of epigenetic crosstalk, particularly in linking histone lysine with DNA methylation. 
Chapter 3 noted increased SUV39H1 expression during 24-hour freezing (Fig 3.1), which similarly acts in a repressive manner on centromeric, pericentromeric and telomeric regions (Peters et al., 2001). Moreover, SUV39H1 is known to interact with DNMT3A/3B through HP1 in heterochromatin (Fuks et al., 2003) and is suggested to stimulate de novo DNA methylation. Therefore, it can be proposed that increased DNMT3B levels may work with increased SUV39H1 in heterochromatic regions to suppress aberrant transcriptional activity during wood frog freezing. Sustained high DNMT3B levels may also illustrate why permissive H3K27me1 levels were paradoxically repressed during freeze recovery (Fig 3.2). Given that both localize to intragenic loci of active genes, and that DNMT3B has been shown to interact with the polycomb repressive complex subunit EZH2 (Viré et al., 2006) that can convert H3K27me 1 to repressive H3K27me2/3 (Shen et al., 2008), the current data suggest elevated DNMT3B may be involved in reducing H3K27me1 prevalence during stress recovery. This may help to coordinate initial resumed gene expression to critical genes necessary for post-freezing survival. Indeed, similar trends were found in wood frog skeletal muscle (Hawkins and Storey, 2018; Zhang et al., 2020a). Conversely, gene body CpG hypermethylation has also been positively associated with transcription elongation (Lister et al., 2009; Varley et al., 2013), suggesting that elevated DNMT3B may also serve contributing roles in the transcriptionally permissive state of thawing.

During 8-hour thaw, the relative expression of DNMT3A and DNMT3L, which form a catalytic hetero-tetramer complex (Zhang et al., 2010), were both decreased relative to control values (Fig 4.1). It is likely that these reduced DNMT3A/3L levels are a crucial factor in suppressed methyltransferase activity during freeze recovery (Fig 4.2). 
DNMT3L stimulates DNMT3A de novo activity of CpG dinucleotide density, with a characteristic repressive role on transcription (Suetake et al., 2004). Reductions in DNMT3A, DNMT3L and DNMT activity during recovery from freezing is not surprising, and likely facilitates the return to standard transcriptional activity under normal aerobic metabolism. It may also allow the expression of increased defense and repair mechanisms following freezing damage.

DNMT1 expression was found to be sharply increased during dehydration stress (Fig 4.1), a result that was quite unexpected. DNMT1 acts primarily in maintenance methylation during DNA replication, with an increased affinity towards hemi-methylated CpG substrates (Hermann et al., 2004). In the non-proliferative state of wood frog brain under high dehydration, increased DNMT1 expression in a maintenance methyltransferase role is difficult to explain. However, de novo activities for DNMT1 have been shown more recently (Jair et al., 2006; Jeltsch and Jurkowska, 2014), particularly in response to vertebrate oxidative stress (Laget et al., 2014). That reasoning is further complicated by unchanged DNMT1 in 24-hour freezing and anoxia stresses (Fig 4.1), which also pose oxidative stressors. The difference may lie in stress response timelines, freezing and anoxic responses are rapid, where dehydration is a slow, gradual loss of body fluids. The present results suggest that increased DNMT1 expression may partly answer why global DNA methyltransferase activity is not depressed during dehydration but is strongly reduced during freezing and anoxia stresses (Fig 4.2). The difference may be further attributable to hypoxia, which reduces the levels of the universal methyl donor, S-adenosyl methionine (SAM) (Liu et al., 2011). Depleted SAM 
may be limiting for DNA methylase activity in frozen and anoxic frogs, but less so in dehydration.

Considering that protein expression of none of the investigated DNMT enzymes was reduced despite suppressed DNMT activity in both frozen and anoxic brain samples, it can be proposed that post-translational regulation of DNMTs may be the answer. For example, DNMT1 is negatively regulated by protein kinase $\mathrm{C}(\mathrm{PKC})$-mediated phosphorylation of the N-terminal serine residues (Lavoie et al., 2011), and PKC may be hyperactive in wood frog brain during freezing (Holden and Storey, 1996). Similarly, DNMT3A is phosphorylated by casein kinase 2 (CK2) at S386 and S389 to repress its activity (Deplus et al., 2014). CK2 is an under-investigated factor in freeze-tolerance mechanisms at the present time, but its implication in cell cycle control, DNA repair and circadian rhythm regulation (reviewed in Litchfield, 2003) make it particularly noteworthy for future study. Reduced DNA methyltransferase activity was similarly found in the liver during wood frog hypometabolic stresses (Zhang et al., 2020a).

\section{Coordinated evidence for hyperactive DNA demethylation during thawed recovery}

To investigate the role of active DNA demethylation in adaptive strategies, the expression of TET2/3 and TDG (Fig 4.4) as well as the relative 5-hmC genomic content (Fig 4.5) were tracked across the freeze-thaw cycle of wood frog brain tissue. The transition from freezing to thawing drove significant increases in TET2, TET3 and relative 5-hmC levels $(p<0.05)$ as compared with values in the frozen state, which agrees with the transcriptional status under both conditions. These results suggest that 
enhanced DNA demethylation action helps to alleviate repressive CpG methylation and facilitate a return to active transcription during thawed recovery. This correlates with earlier results showing lower DNMT3A and DNMT3L protein levels and reduced DNMT activity during recovery after freezing.

TET enzymes require $\mathrm{O}_{2}$ as a reaction substrate in subsequent oxidations of the 5'-methyl group on cytosine residues. Given their oxygen-sensitive nature, elevation of DNA demethylation during reoxygenation/reperfusion is not surprising. Moreover, HIF$1 \alpha$ knockdown has been shown to induce TET2 expression and demethylase activity (Fischer and Miles, 2017). TET enzymes have also been linked to the DNA damage response; TET1 is a target of ataxia telangiectasia mutated (ATM) kinase, while TET3 a target of ataxia telangiectasia and Rad3-related protein (ATR), both of which stimulate double-strand break repair (Jiang et al., 2017, 2015). Elevated ROS production during reoxygenation likely requires the induction of DNA damage responses, in which increased TET expression may be involved. Additionally, TET3 is implicated in cell cycle control by promoting cyclin D1 expression (Lv et al., 2014). Indeed, cyclin D1 expression was found to be strongly induced during freeze recovery (Zhang and Storey, 2012), which may be under the regulation of TET3. TET2 and TET3 also activate transcription via non-catalytic roles, interacting with $O$-GlcNAc transferase (OGT) to generate permissive H3K4me3 modification and stimulate transcription (Deplus et al., 2013).

Induction of TET $2 / 3$ protein expression during freeze recovery may be due to alleviation of post-transcriptional controls. In particular, TET2 is regulated at the posttranscriptional level by microRNAs miR-22, miR-29, miR-101 and miR-125 (Cheng et 
al., 2013; Song et al., 2013). Further, miRNA-seq analysis of wood frog brains show that relative expression of $\mathrm{miR}-22$ and miR-125 were reduced in thawing after $24 \mathrm{~h}$ freezing (Hadj-Moussa and Storey, 2018). Therefore, it can be hypothesized that TET2 induction

during recovery from freezing may be due, in part, to the mitigation of repressive miR-22 and miR-125 silencing controls.

\section{Conclusions}

In summary, this chapter is the first to highlight DNA methylation regulatory mechanisms in a nervous tissue (brain) of a vertebrate species that endures multiple environmental stress (freezing, anoxia, dehydration) with specific adaptive strategies including metabolic rate depression. The present results provide strong evidence in favour of DNA hypomethylation during recovery after freezing as supported by lower DNMT3A and DNMT3L protein levels, strongly reduced DNMT activities, and increased TET2 and TET3 expression as well as elevated 5-hmC content. Elevated DNMT3B during freeze-thaw and DNMT1 during dehydration are also noteworthy. These mechanisms likely contribute to the rebound state of transcription in cells during recovery after freezing, and may also have roles in DNA damage repair and cell cycle control. 


\section{CHAPTER 5}

General Discussion 


\section{Freeze tolerance and MRD}

The Earth's many environments can be terribly unforgiving for its animal residents. For many ecosystems, the changing of seasons can bring about diverse living conditions, which requires implementation of strict adaptive strategies to promote animal survival. This is particularly true for animals living at high latitudes or altitudes, who must contend with freezing sub-zero temperatures during the winter months. Differing freeze-survival strategies have emerged for specific animals; but most ectotherms either (1) supercool body fluids to prevent ice nucleation (Lowe et al., 1971) or (2) tolerate controlled ice formation in extracellular and extra-organ spaces, known as freeze tolerance (reviewed in Storey and Storey, 2017). A characteristic freeze-tolerant model organism is the wood frog, Rana sylvatica, which can accept freezing of approximately $65 \%$ of total body water.

For wood frogs, freezing is a complicated stress - encompassing a variety of cellular stressors, like dehydration, hyperglycemia, and anoxia. Dehydration emerges as cells passively lose water to balance the increasing extracellular osmolality caused by ice formation in extracellular and extra-organ spaces (Storey and Storey, 2013).

Hyperglycemia occurs from synthesizing massive amounts of glucose as a cryoprotectant to prevent cell volume from decreasing below a critical minimum and to supply an intracellular fuel source throughout the freeze (Storey, 1990; Storey and Storey, 1988). Blood thickening and the physical constraints of ice prevent heart and lung function, blocking the transport of oxygen and driving cells into a hypoxic and then anoxic state. Despite mitigation efforts by upregulation of multiple defensive strategies including the clotting factor fibrinogen (Cai and Storey, 1997a), antioxidant enzymes (Joanisse and 
Storey, 1996; Wu et al., 2018), heat-shock protein chaperones (Storey and Storey, 2019), and anti-apoptotic defenses (Gerber et al., 2016), cells still must contend with anaerobic metabolism, which yields only a fraction of ATP equivalents and produces acidic (lactate) by-products (Costanzo et al., 2013). Frogs must also survive using only existing fuel stores since they enter a state of dormancy at freezing onset. To combat this, wood frogs, as well as many organisms exposed to challenging environmental conditions (like hibernating ground squirrels, freeze-avoiding invertebrates, anoxia-tolerant freshwater turtles, and estivating molluscs/amphibians), use coordinated metabolic rate depression (MRD) to suppress and reprioritize the use of limited internal fuel resources away from anabolic functions and into essential freeze-survival pathways (Storey and Storey, 2004a). MRD and freeze tolerance strategies have enabled wood frogs to spread their geographic range much further north than any other frog species, deep into the Northwest Territories, Yukon and northern Alaska.

\section{Biochemical mechanisms of wood frog MRD}

The underlying mechanisms of wood frog hypometabolism are being elucidated, which are increasing organ-specific. cDNA microarray screens of frozen wood frog heart and liver have identified dozens of genes that are upregulated in response to freezing, some of which include hypoxia-inducible factor-1 (HIF-1), freeze-responsive Fr10 and Li16, ADP/ATP translocase, adenosine A1 and atrial natriuretic peptide (ANP) receptors and fibrinogen $\alpha$ and $\gamma$ subunits (Cai et al., 1997; Cai and Storey, 1997b, 1997a; Storey and Storey, 2004b). Reversible post-translational modifications have also been found to alter the activities of a variety of metabolic enzymes including, pyruvate kinase 
(Smolinski et al., 2017), pyruvate dehydrogenase (Al-attar et al., 2019) and glutamate dehydrogenase (Green and Storey, 2017). Next, miRNA sequencing analysis of wood frog skeletal muscle, heart and brain has highlighted several well-known miRNAs that are responsive during freeze-thaw, indicative of robust post-transcriptional controls (Bansal et al., 2016; Biggar et al., 2009; Hadj-Moussa and Storey, 2018). Pathway analysis of putative mRNA targets suggest miRNA-mediated roles in the actin cytoskeleton, hypertrophic cardiomyopathy, PI3K and MAPK signalling pathways, antiapoptotic responses, and cell cycle control. Finally, considering the costly nature of gene transcription (Rolfe and Brown, 1997), research into transcriptional control measures has outlined involvement of transcription factors, like NFkB, ChREBP and ETS-1 (Al-attar et al., 2020; Al-attar and Storey, 2020; Gupta et al., 2020) as well as epigenetic regulation (Hawkins and Storey, 2018; Zhang et al., 2020b) as key players in wood frog freeze tolerance. For example, epigenetic mechanisms, specifically histone lysine and DNA methylation, could facilitate transcriptional suppression and would provide highly efficient energy savings in support of the hypometabolic state of frozen wood frogs. Conversely, such mechanisms could readily coordinate transcriptional activation during thawing recovery, contributing to the resumption of aerobic energy metabolism.

\section{The role of histone lysine methylation in MRD}

Histone lysine methylation can have both permissive and repressive roles in regulating gene transcription. The functional outcome of methylation is site-specific, degree-specific and mediated by the recruitment of methyl-lysine "reader" proteins. For example, on histone $\mathrm{H} 3$ tails, methylation of lysine-4 is generally associated with 
activation of gene transcription, whereas methylation of lysine- 9 and -27 are linked with repression (Barski et al., 2007; Mikkelsen et al., 2007). Lysine methyltransferases (KMTs), which "write" the histone methyl-lysine code are also site-specific, making KMTs and putative histone methyl-lysine targets strong markers of the transcriptional state of wood frogs in both frozen and thawed states. Indeed, a recent study suggested hypomethylation of $\mathrm{H} 3 \mathrm{~K} 4$, along with reduced expression of $\mathrm{H} 3 \mathrm{~K} 4 \mathrm{me} 1, \mathrm{ASH} 2 \mathrm{~L}$ and SMYD2 may contribute to transcriptional suppression during freezing in wood frog liver and muscle (Hawkins and Storey, 2018). Chapter 3 of this thesis expands on this research, investigating similar mechanisms in another tissue, the brain, an organ where epigenetic regulation is well-characterized in other fields but understudied in species exhibiting extreme stress responses.

The current data on wood frog brain epigenetic controls do not correlate with findings for liver and skeletal muscle (Hawkins and Storey, 2018) but provide a different view of the transcriptional state of cells across freeze-thaw and the regulatory mechanisms involved. During 24-hour freezing, the expression of the H3K9 methyltransferase SUV39H1 rose significantly (Fig 3.1b), before dropping back to control levels upon thawing. However, this did not translate to increased H3K9me3 expression (Fig 3.2) or H3K9 methylase activity (Fig 3.3). Regardless, this might imply repressive roles on transcriptional activity at specific loci as SUV39H1 largely deposits H3K9me3 in constitutive heterochromatin (Peters et al., 2001). In Chapter 4, raised DNMT3B levels were also seen during 24-four freezing (Fig 4.1). DNMT3B can interact with SUV39H1 through HP1 at heterochromatin regions (Fuks et al., 2003) and has been suggested to stimulate de novo DNA methylation. Hence, heightened DNMT3B may 
work with increased SUV39H1 at heterochromatic loci to suppress aberrant transcriptional activity in non-coding regions during the hypometabolic frozen state. SUV39H1/DNMT3B may also stimulate heterochromatin formation in coding regions of non-essential genes to suppress their transcription and facilitate MRD during wood frog freezing. Investigation into HP1 $\alpha / \beta$, the prominent heterochromatin HP1 homologs (Minc et al., 2000), may help solidify this repressive interaction. Indeed, HP1 upregulation has been similarly shown to be a factor in late torpor of hibernating ground squirrels (Biggar and Storey, 2014). Alternatively, SUV39H1 may be connected to increased generation of another heterochromatic mark H3K20me3, through stimulating methylation of SETD8 (Kudithipudi et al., 2017). The role of H3K20me3 in MRD is unstudied and is certainly worth inquiry going forward.

Sustained high DNMT3B expression may also help illustrate why permissive H3K27me1 was paradoxically depleted during freeze recovery (Fig 3.2). Both DNMT3B and H3K27me1 are enriched at intragenic loci of active genes (Baubec et al., 2015; Ferrari et al., 2014), and DNMT3B has been shown to interact with polycomb repressive complex 2 (PRC2) subunit EZH2 (Viré et al., 2006). Knockout of EZH2 depletes H3K27me2/3, while having either no effect or increasing H3K27me1 in different studies (Mcgarvey et al., 2007; Mu et al., 2018), suggesting it can act as a substrate for repressive H3K27 methylations. Hence, during thawing, elevated DNMT3B may work with PRC2 to reduce $\mathrm{H} 3 \mathrm{~K} 27 \mathrm{me} 1$ and help coordinate the expression of critical genes at arousal onset. In agreement, similar trends were found in another wood frog organ, skeletal muscle (Hawkins and Storey, 2018; Zhang et al., 2020a). Investigation of EZH2, H3K27me2 and H3K27me3 may help support this link. Conversely, other research 
suggests that gene body $\mathrm{CpG}$ hypermethylation is positively linked with transcription elongation (Lister et al., 2009; Varley et al., 2013), suggesting the heightened DNMT3B through freeze-thaw may work to stimulate freeze-responsive genes during freezing, or work with other epigenetic enzymes to restore an active transcriptional state during freeze recovery.

Observations in this thesis provide evidence for stricter transcriptional control via histone lysine methylation after thawing, rather than during freezing itself. Specifically, decreased levels of H3K9me3 (Fig 3.2), a result of depressed H3K9 methyltransferase activity (Fig 3.3) via reduced SUV39H1, ESET, or HP1 $\gamma$ expression (Fig 3.1; Fig 3.5), can aid in resumed transcriptional activity during freeze recovery. This compares with the permissive histone lysine methylation/acetylation mechanisms linked to early arousal states of mammalian hibernation (Rouble et al., 2018; Tessier et al., 2017; Watts and Storey, 2019). Acetylated histone lysine residues, and KAT enzymes that catalyze these reactions are generally associated with active transcription. For example, during early arousal from hibernation in I. tridecemlineatus skeletal muscle, global H3K14ac and H3K18ac contents are elevated (Tessier et al., 2017) whereas KAT2A and KAT2B protein levels are lifted in the liver (Rouble et al., 2018). Similarly, in both hepatic and muscular tissues, permissive $\mathrm{H} 3 \mathrm{~K} 4 \mathrm{me} 1$ prevalence is raised during entrance into and arousal from torpor, proposed to be a result of increased KMT2 complex enzyme (ASH2L, RBBP5) expression (Watts and Storey, 2019). Transcriptional activation of nervous tissue during freeze thawing may relate to its critical roles in recovery from freezing. The first recovery step during thawing is a heartbeat, which beats because of Purkinje fibre leakage of $\mathrm{Na}+$ and $\mathrm{K}+$ ions. Heart beating provides blood circulation 
which drives the return of brain activity. Brain activity stimulates gulping and eye blinking, which are the first indicative signs of being alive (Storey and Storey, 2017).

\section{Proposed non-histone roles for reduced SETD7 and SETD8 expression during freeze recovery}

The current data also show thaw-mediated reduced expression of two methyltransferases, SETD7 and SETD8 (Fig 3.1), however these did not affect the relative levels of their histone targets (H3K4me1 and $\mathrm{H} 3 \mathrm{~K} 20 \mathrm{me}$, respectively) on the global scale (Fig 3.2). Given that both are histone marks that are associated with active genes (Barski et al., 2007; Kalakonda et al., 2008), it can be proposed that there are possible non-histone roles for SETD7 and SETD8 alleviation during thawing, that may include control over the hypoxia-inducible transcription factor $1 \alpha(\mathrm{HIF}-1 \alpha)$ as well as other transcriptional regulatory proteins such as $\beta$-catenin, retinoblastoma protein $(\mathrm{Rb})$, yes-associated protein 1 (YAP1), p53 and NUMB (Batista and Helguero, 2018; Hafner et al., 2019). The functional outcomes of these proposed non-histone targets could have impacts on major cellular pathways including aerobic metabolism, cell cycle progression, apoptosis, and DNA damage repair.

HIF-1 $\alpha$ is a master transcriptional regulator responding to oxygen deprivation (reviewed in Semenza, 2001) and is widely upregulated across different forms of hypometabolism (Maistrovski et al., 2012; Morin and Storey, 2005; Morin et al., 2005). SETD7 stabilizes HIF-1 $\alpha$ through methylation of lysine-32, preventing ubiquitination of this site (Kim et al., 2016). Under hypoxia stress, SETD7 also monomethylates H3K4 at HIF-1 $\alpha$ target gene promoters to enhance their transcription (Liu et al., 2015). Freeze 
elevation of HIF-1 $\alpha$ protein levels is reversed back to control values during thawing recovery of another freeze-tolerant species, despite consistent transcript expression (Morin et al., 2005), suggesting post-translational control as described here. Repressed SETD7 expression during freeze recovery likely destabilizes HIF-1 $\alpha$ and may help coordinate the transition back to aerobic metabolism.

$\beta$-catenin is a transcriptional activator of many cell proliferation/migration genes and is frequently overexpressed in cancer phenotypes (reviewed in Valenta et al., 2012). Phosphorylation of $\beta$-catenin by glycogen synthase kinase-3 beta (GSK3 $\beta)$ mediates its decay, thereby arresting the cell cycle at the $\mathrm{G}_{2} / \mathrm{M}$ phase. SETD7 methylates $\beta$-catenin at lysine-180, strengthening the $\beta$-catenin/GSK3 $\beta$ interaction (Shen et al., 2015). In related studies, evidence in favour of a hyperactive GSK $3 \beta$ during wood frog freezing (Dieni et al., 2012) as well as strong upregulation of $\beta$-catenin expression during ground squirrel arousal from hibernation (Brooks et al., 2015) have been shown. Depressed levels of SETD7 may similarly promote cell cycle progression through the $\mathrm{G}_{1} / \mathrm{S}$ checkpoint via releasing $\mathrm{Rb}$ from $\mathrm{E} 2 \mathrm{~F} 1$. Upon phospho-Rb inactivation, $\mathrm{E} 2 \mathrm{~F} 1$ stimulates cyclin $\mathrm{E}$ transcription and passage from $\mathrm{G}_{1}$ to $\mathrm{S}$ phase of the cell cycle (Ohtani et al., 1995). SETD7 enhances Rb via methylations of lysine-873, and lysine-810 (Carr et al., 2011; Munro et al., 2010). The former is required for $\mathrm{Rb} / \mathrm{E} 2 \mathrm{~F} 1$-mediated $\mathrm{G}_{1} / \mathrm{S}$ arrest and the latter stabilizes $\mathrm{Rb} / \mathrm{E} 2 \mathrm{~F} 1$ by blocking cyclin-dependent kinase phosphorylation of $\mathrm{Rb}$ to prevent E2F1-mediated transcriptional activity. SETD7 also methylates E2F1 at lysine185 to promote ubiquitination and proteasomal degradation (Kontaki and Talianidis, 2010). Indeed, $\mathrm{Rb} / \mathrm{E} 2 \mathrm{~F} 1$-mediated cell cycle arrest during anaerobiosis has been recently suggested for the anoxia-tolerant red-eared slider turtle (Biggar and Storey, 2018b). 
Therefore, it can be proposed that reduced SETD7 levels likely contribute to resumption of cell cycle through $\mathrm{G}_{2} / \mathrm{M}$ and $\mathrm{G}_{1} / \mathrm{S}$ during freeze recovery by alleviating repressive effects on $\beta$-catenin and E2F1.

SETD7 and SETD8 may similarly be involved in coordinating apoptotic or DNA damage repair responses in cells damaged by freezing, while resuming proliferative activity of various cell types during thawing. This may be mediated by regulatory actions of SETD7 with YAP1, and SETD8 with p53 and NUMB. YAP1 enters the nucleus and interacts with other factors to upregulate transcription of anti-apoptotic and cell proliferation genes (reviewed in Pan, 2010). Interestingly, YAP1 forms cooperative complexes with both $\beta$-catenin (Rosenbluh et al., 2012) and E2F1 (Kapoor et al., 2014) to enhance their activity (both mentioned above). SETD7 works in the Hippo signaling pathway to negatively methylate YAP1 at lysine-494, preventing nuclear translocation and transcriptional activity (Oudhoff et al., 2013). Taken together, SETD7 downregulation might promote the resumption of cell proliferation during thawing recovery by enabling YAP1 nuclear translocation and may be involved with $\beta$-catenin and E2F1.

For cells damaged during freezing or by elevated ROS during reoxygenation/reperfusion, apoptotic and DNA damage repair mechanisms must be facilitated during thawing. SETD8 may be involved in this via alleviation of its repressive roles on $\mathrm{p} 53$ and the apoptosis-associated factor NUMB. The $\mathrm{p} 53$ protein is among the most well-described tumor suppressor, activating hundreds of genes involved in processes like apoptosis and DNA damage repair during times of stress (reviewed in Hafner et al., 2019). NUMB stabilizes p53 by blocking its ubiquitination by the E3 ligase 
MDM2 and is essential for p53-mediated apoptosis. SETD8 (1) methylates p53 at lysine382 to suppress its transcriptional activity (Shi et al., 2007), and (2) methylates NUMB at lysine-158 and -163 , releasing it from the tripartite NUMB/p53/MDM2 complex and triggering proteasomal degradation of p53 (Dhami et al., 2013). The lower SETD8 expression during thawing may stimulate p53 directly and/or indirectly via NUMB, to facilitate apoptotic/DNA damage repair in freeze-damaged or oxidative-damaged cells during the thawed/recovery phase. In agreement with this, SETD8 was shown to be similarly depressed in another tissue during wood frog freezing recovery (Hawkins and Storey, 2018).

\section{Evidence for DNA hypomethylation during freeze recovery}

DNA cytosine methylation has a characteristic repressive effect on gene transcription. The process is reversible with methyl groups added by DNA methyltransferase enzymes (DNMTs) and removed by Ten-eleven translocation enzymes (TETs) plus TDG-mediated base excision repair, and is read by methyl-CpG-binding domain proteins (MBDs). Roles for DNA methylation in MRD have been suggested in recent years (Wijenayake and Storey, 2016; Zhang et al., 2020b), however investigation of nervous tissue and DNA demethylation pathways are severely lacking. In Chapter 4, dynamic DNA methylation mechanisms, at all three levels, were investigated in wood frog brain over freeze-thaw and associated stresses. The results indicate coordinated evidence for DNA hypomethylation during freeze-recovery; highlighted by reduced DNMT3A/3L expression (Fig 4.1) and DNA methyltransferase activity (Fig 4.2), and reinforced by elevated TET2/3 (Fig 4.4) and genomic 5-hmC content (Fig 4.5). In 
addition, raised levels of DNMT3B during freeze-thaw and DNMT1 during high dehydration were seen (Fig 4.1).

The demethylation of $\mathrm{CpG}$ islands is tightly linked to active gene transcription. One of the hypotheses for this thesis was that thawing, and the resumption of global transcriptional activity, may be facilitated, in part, by demethylation of repressive 5-mC residues. The data presented in this thesis strongly support this claim, with evidence for both methylase and demethylase roles. Firstly, the relative expression of DNMT3A and DNMT3L, two enzymes that predominantly facilitate de novo methylation (Suetake et al., 2004; Zhang et al., 2010), were both decreased during 8-hour thawing as seen by immunoblot analysis (Fig 4.1). DNMT3A suppression may be via transcriptional controls. $\mathrm{Rb} / \mathrm{E} 2 \mathrm{~F}$ and $\mathrm{p} 53$ both suppress transcription at DNMT3A promoters (Tang et al., 2014), and the current results suggest that these two factors may be hyperactive during recovery from freezing. In addition, global DNA methyltransferase activity was suppressed during thawing (Fig 4.2), which may be at least partly attributable to decreased DNMT3A/3L expression. However, considering that suppressed DNMT activity was also found in frozen and anoxia exposed wood frog brain tissue, despite a lack of change in DNMT enzymes, it is probable that some regulation also comes from post-translational controls. For example, protein kinase C (PKC) negatively phosphorylates the N-terminal serine residues on DNMT1 (Lavoie et al., 2011), and there is evidence for hyperactive PKC in wood frog nervous tissue during freezing (Holden and Storey, 1996). Similarly, DNMT3A activity is depressed by phosphorylation at serine386 and serine-389 by casein kinase 2 (CK2) (Deplus et al., 2014). Research into CK2 involvement in freeze tolerance is currently lacking, but its known roles in cell cycle 
control, DNA repair and circadian rhythm regulation (reviewed in Litchfield, 2003) make an investigation of CK2 action in freezing survival of interest going forward. Posttranslational controls of DNA methyltransferases during hypometabolism also need to be investigated in the coming years.

Albeit somewhat surprising, DNA methyltransferase activity was found to be suppressed in wood frog liver in response to hypometabolic stresses (Zhang et al., 2020a). The current study noted reduced DNMT activity in response to both 24-hour freezing and 24-hour anoxia, but enzyme activity did not respond to high dehydration (Fig 4.2). Elevated DNMT1 protein expression during dehydration (Fig 4.1) appears to explain part of this difference, while hypoxia, that reduces the levels of the universal methyl donor, S-adenosyl methionine (SAM) (Liu et al., 2011), may also be involved. In agreement, glutathione, an antioxidant directly generated from SAM conversion, was accumulated in wood frog tissues during freezing (Dawson and Storey, 2017). Substrate depletion of SAM, through conversion to glutathione, may be limiting DNA methylase activity in frozen and anoxic frogs, but less so in dehydrated ones.

Chapter 4 provides a first look into DNA demethylation as a response to extreme stress, and the current research is among the first to study this within the nervous system. Given the oxygen-sensitive nature of TET enzymes, an induction in brain DNA demethylation (as evidenced by elevated 5-hmC content (Fig 4.5)), during thawassociated reoxygenation/reperfusion is not surprising. Demethylation of $\mathrm{CpG}$ islands at promoter elements stimulates active transcription, that is expected during the resumption of an active transcriptional state. Induced expression of TET2/3 (Fig 4.4) appear to be likely drivers of increased demethylase activity and may be due to alleviated post- 
transcriptional or transcriptional controls. TET mRNAs are regulated by various miRNA species including, miR-22, miR-26, miR-29, miR-101 and miR-125 (Cheng et al., 2013; Fu et al., 2013; Song et al., 2013) and an miRNA-seq analysis of wood frog brain tissue showed attenuated expression of miR-22, miR-26 and miR-125 during thawing after $24 \mathrm{~h}$ frozen (Hadj-Moussa and Storey, 2018). Therefore, it appears that increased TET expression may be due, in part, to eased RNA interference by miR-22, miR-26 and miR125. In addition, at the transcriptional level, HIF-1 $\alpha$ knockdown has been shown to induce TET2 expression and demethylase activity (Fischer and Miles, 2017). This highlights another potential link in epigenetic crosstalk - between SETD7 repression and TET2 induction during freeze recovery, since SETD7 methylation stimulates HIF-1 $\alpha$ (Liu et al., 2015).

Outside of facilitating gene activation, TET enzymes are also linked with the DNA damage response and cell cycle control. In particular, TET3 is a target of ataxia telangiectasia and Rad3-related protein (ATR), which promotes double-strand break repair (Jiang et al., 2017). Elevated ROS production during reoxygenation likely necessitates DNA damage responses, in which, as for SETD8 repression, increased TET3 expression may be involved. Additionally, TET3 is implicated in cell cycle control by promoting cyclin D1 expression at $\mathrm{G}_{1} / \mathrm{S}$ (Lv et al., 2014). Indeed, cyclin D1 expression is strongly induced during thawed recovery after freezing (Zhang and Storey, 2012), which may be promoted by upregulated TET3. TET2/3 also stimulate transcription through noncatalytic interactions with $O$-GlcNAc transferase (OGT), which recruits the lysine methyltransferase SET1A to deposit permissive H3K4me3 marks at active promoters (Deplus et al., 2013). Taken together, this indicates that coordinated DNA 
hypomethylation likely works alongside $\mathrm{H} 3 \mathrm{~K} 9$ hypomethylation to stimulate large-scale transcriptional activity during recovery from freezing events.

\section{Summary and Future Directions}

Extreme stress responses require intense adaptation of major metabolic and biochemical pathways and necessitate ubiquitous gene regulation at a variety of levels. Among these are transcriptional controls, particularly methyl epigenetic mechanisms like histone lysine and DNA methylation. One of the first to investigate epigenetic regulation of the adaptive responses by nervous tissue, this thesis provides initial evidence in favour of significant roles for $\mathrm{H} 3 \mathrm{~K} 9$ and DNA hypomethylation during freeze recovery, which is well-correlated with relevant methyltransferase and demethylase enzyme expression. Along with suggested non-histone roles, alleviation of these repressive methylations likely facilitates the resumption of a normoxic transcriptional state as frogs thaw and resume normal metabolic activities. Proposed methyl epigenetic mechanisms during freezing and freeze recovery are summarized in Figure 5.1.

This thesis only touches the surface on the complex roles that histone and DNA methylation must play in the hypometabolic response of wood frogs during freezing. Chapter 3 investigated the relative expression of eight lysine methyltransferases, five histone methyl-lysine marks and one methyl-lysine binding protein, leaving room for many more players in this field to be explored. Particularly notable are H3K4methylating MLL complexes and H3K27-methylating PRC complexes, as well as 

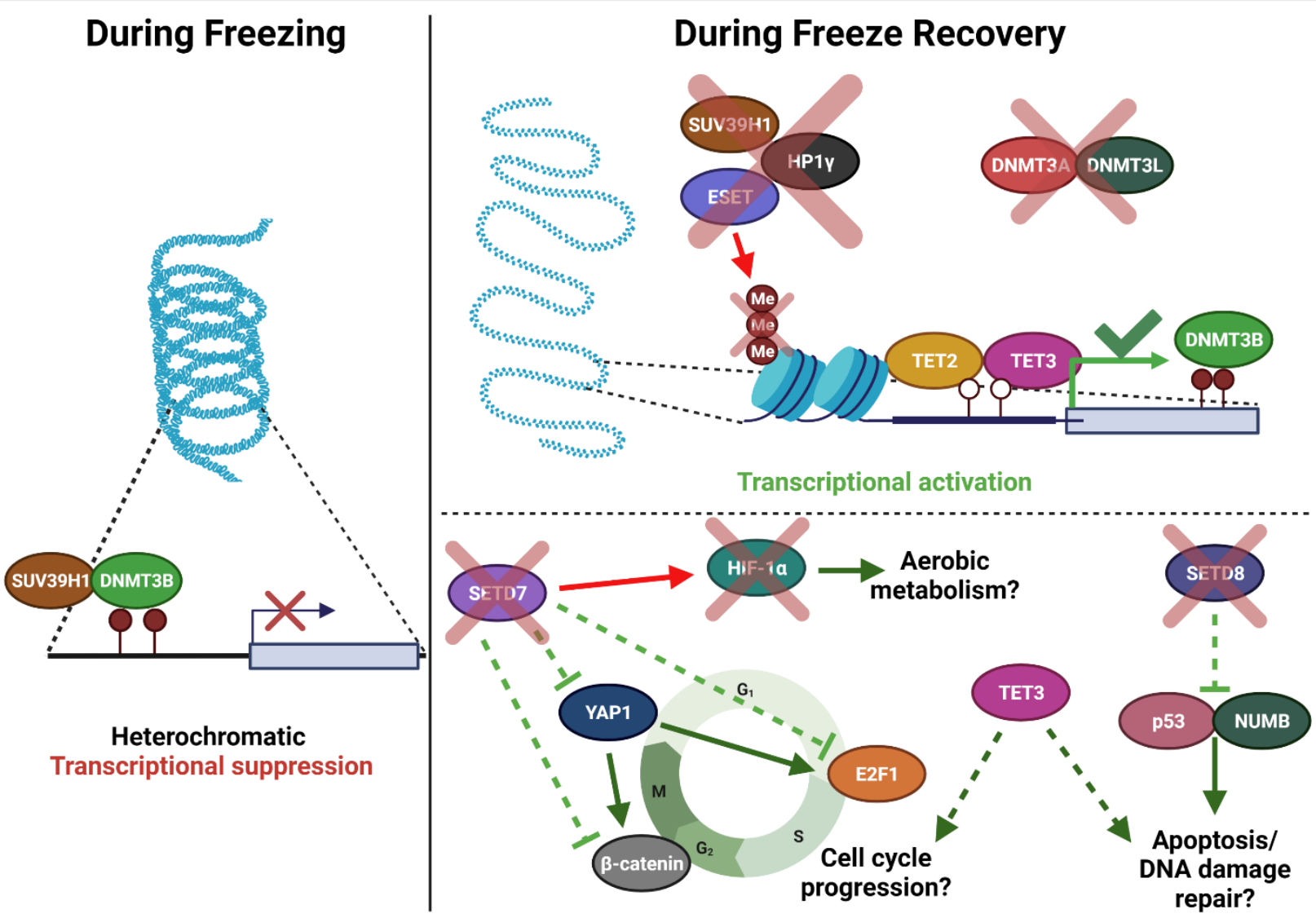

Figure 5.1. Proposed histone and non-histone roles for DNA methylation and histone lysine methylation during wood frog freezing and thawing recovery. The results indicate elevated SUV39H1 and DNMT3B during 24-hour freezing. However, during recovery increases in TET2, TET3 and DNMT3B, balanced by knockdown of ESET, SUV39H1, H3K9me3, HP1 $\gamma$, SETD7 and SETD8 occurred. Raised TET2/3 levels drive an increase in global 5-hmC, implying elevated active DNA demethylation during thawing, whereas reductions in SUV39H1/ESET contribute to decreased H3K9 methylase activity. Created with Biorender.com. 
transcriptionally relevant trimethylations of histones at H3K4, H3K27, H3K36 and H4K20. Purification of histone proteins may allow adequate profiling of methylated lysine residues, whereas purification of specific KMT enzymes, followed by examination of kinetic properties and specific PTMs may give a more complete picture of the mechanisms at play during freeze tolerance and recovery. A logical next step is to investigate the driving factors and functional significance of H3K27me1 knockdown down during freeze recovery. This necessitates not only a study of the "writers" EHMT2 or EZH1, but also site-specific lysine demethylases (KDMs) like KDM6A, 6B and 7A (Pan et al., 2018) as well as diverse methyl-lysine "reader" proteins. Indeed, adequate research into histone lysine methylation controls will require study from all three ends of the "writer/reader/eraser" paradigm. As such, the elucidation of roles for the Jumonji-C family of lysine demethylases during hypometabolism is currently ongoing. Furthermore, lysine methylation of non-histone proteins has emerged as a prominent regulator of enzyme stability/activity and is readily studied in extreme stress responses.

Chapter 4 tracked the expression of four DNMTs, three methyl-binding domain proteins, and three demethylation-involved enzymes. Obvious future directions in which to continue this work include (a) investigations into more "reader" proteins, since the current three examined here is hardly comprehensive, (b) analysis of MBD DNA binding affinities as protein levels were unchanged, and (c) investigation into factors driving down DNA methyltransferase activity during various hypometabolic states. Purification and elucidation of post-translational modifications of DNMT enzymes as well as research into the methionine cycle and glutathione synthesis are warranted. 
A limitation of this thesis is the global level at which our investigations are done, with less appreciation of the specific gene modifications that are taking place. Locating methyl-lysine marks to gene-specific promoter loci, through chromatin immunoprecipitation (ChIP) analyses, and linking with transcript expression levels via qPCR, would give a better understanding of transcriptional controls mediated via histone lysine methylation. Of course, ChIP analysis of wood frog genes would require sequencing and likely also annotation of its genome, which has not yet been done. Bisulphite sequencing, a related tool that could be used to locate 5-mC to specific genomic locations would also rely on wood frog genome sequencing. Investigations on a global level are a great starting point, but more in-depth analysis is warranted to make more specific conclusions.

Methyl epigenetic mechanisms are not limited to histone lysine residues and DNA methylation but encompass a wide array of modifications that also include histone arginine and m6A RNA methylation. Furthermore, transcriptionally relevant histone modifications are not limited to methylation, but rather include acetylation, phosphorylation, ubiquitination and sumoylation. Given the complexity of epigenetic regulation and its crosstalk, all the above mentioned are worth studying in order to obtain the intricate nuances of the mechanisms at play. The roles of (1) protein arginine methyltransferases (PRMTs) with methyl-arginine residues, (2) methyltransferase-like enzymes (METTLs) with methyl-adenosines on mRNA transcripts, and (3) lysine acetyltransferases (KATs) with acetyl-lysine residues are all highlighting current research goals of epigenetic regulation in wood frog freeze tolerance. The findings in this thesis build on previous studies, bringing us one step closer in our understanding of the 
biochemical mechanisms facilitating this incredible adaptive phenomenon, which has strong implications for the development of applied strategies to address human concerns of organ transplant, diabetes and cryopreservation. Diabetics would love to know the secrets of how wood frogs build up $400 \mathrm{mM}$ glucose without molecular damage, while an ability of human organs to be frozen/thawed without damage would improve the viability window. This in turn, would surely increase successful transplantation rates, lower cost, shorten wait times and get the necessary organs to those that need them. 


\section{REFERENCES}


Al-attar, R., Storey, K.B., 2020. RAGE against the stress: Mitochondrial suppression in hypometabolic hearts. Gene 761. https://doi.org/10.1016/j.gene.2020.145039

Al-attar, R., Wijenayake, S., Storey, K.B., 2019. Metabolic reorganization in winter: Regulation of pyruvate dehydrogenase (PDH) during long-term freezing and anoxia. Cryobiology 86 , 10-18. https://doi.org/10.1016/j.cryobiol.2019.01.006

Al-attar, R., Wu, C.W., Biggar, K.K., Storey, K.B., 2020. Carb-loading: Freeze-induced activation of the glucose-responsive chrebp transcriptional network in wood frogs. Physiol. Biochem. Zool. 93, 49-61. https://doi.org/10.1086/706463

Bale, T.L., 2015. Epigenetic and transgenerational reprogramming of brain development. Nat. Rev. Neurosci. 2015166 16, 332-344. https://doi.org/10.1038/nrn3818

Bannister, A.J., Zegerman, P., Partridge, J.F., Miska, E.A., Thomas, J.O., Allshire, R.C., Kouzarides, T., 2001. Selective recognition of methylated lysine 9 on histone H3 by the HP1 chromo domain. Nature 410, 120-124. https://doi.org/10.1038/35065138

Bansal, S., Luu, B.E., Storey, K.B., 2016. MicroRNA regulation in heart and skeletal muscle over the freeze-thaw cycle in the freeze tolerant wood frog. J. Comp. Physiol. B Biochem. Syst. Environ. Physiol. 186, 229-241. https://doi.org/10.1007/s00360-015-0951-3

Barski, A., Cuddapah, S., Cui, K., Roh, T.Y., Schones, D.E., Wang, Z., Wei, G., Chepelev, I., Zhao, K., 2007. High-Resolution Profiling of Histone Methylations in the Human Genome. Cell 129, 823-837. https://doi.org/10.1016/j.cell.2007.05.009

Batista, I. de A.A., Helguero, L.A., 2018. Biological processes and signal transduction pathways regulated by the protein methyltransferase SETD7 and their significance in cancer. Signal Transduct. Target. Ther. https://doi.org/10.1038/s41392-018-0017-6

Baubec, T., Colombo, D.F., Wirbelauer, C., Schmidt, J., Burger, L., Krebs, A.R., Akalin, A., Schübeler, D., 2015. Genomic profiling of DNA methyltransferases reveals a role for DNMT3B in genic methylation. Nature 520, 243-247. https://doi.org/10.1038/nature14176

Bestor, T.H., Edwards, J.R., Boulard, M., 2015. Notes on the role of dynamic DNA methylation in mammalian development. Proc. Natl. Acad. Sci. U. S. A. 112, 6796-6799. https://doi.org/10.1073/pnas.1415301111

Biggar, K.K., Dubuc, A., Storey, K., 2009. MicroRNA regulation below zero: Differential expression of miRNA-21 and miRNA-16 during freezing in wood frogs. Cryobiology 59, 317-321. https://doi.org/10.1016/j.cryobiol.2009.08.009

Biggar, K.K., Storey, K.B., 2018a. Functional impact of microRNA regulation in models of extreme stress adaptation. J. Mol. Cell Biol. 10, 93-101. https://doi.org/10.1093/jmcb/mjx053

Biggar, K.K., Storey, K.B., 2018b. The evaluation of anoxia responsive E2F DNA binding activity in the red eared slider turtle, Trachemys scripta elegans. PeerJ 2018. https://doi.org/10.7717/peerj.4755

Biggar, K.K., Storey, K.B., 2018c. Functional impact of microRNA regulation in models of extreme stress adaptation. J. Mol. Cell Biol. https://doi.org/10.1093/jmcb/mjx053

Biggar, K.K., Storey, K.B., 2015. Insight into post-transcriptional gene regulation: Stress- 
responsive microRNAs and their role in the environmental stress survival of tolerant animals. J. Exp. Biol. https://doi.org/10.1242/jeb.104828

Biggar, K.K., Storey, K.B., 2012. Evidence for cell cycle suppression and microRNA regulation of cyclin D1 during anoxia exposure in turtles. Cell Cycle 11, 1705-1713. https://doi.org/10.4161/cc.19790

Biggar, Y., Storey, K.B., 2014. Global DNA modifications suppress transcription in brown adipose tissue during hibernation. Cryobiology 69, 333-338. https://doi.org/10.1016/j.cryobiol.2014.08.008

Black, J.C., Van Rechem, C., Whetstine, J.R., 2012. Histone Lysine Methylation Dynamics: Establishment, Regulation, and Biological Impact. Mol. Cell. https://doi.org/10.1016/j.molcel.2012.11.006

Bocharova, L.S., Gordon, R.Y., Arkhipov, V.I., 1992. Uridine uptake and RNA synthesis in the brain of torpid and awakened ground squirrels. Comp. Biochem. Physiol. -- Part B Biochem. 101, 189-192. https://doi.org/10.1016/0305-0491(92)90177-S

Bogdanović, O., Veenstra, G.J.C., 2009. DNA methylation and methyl-CpG binding proteins: Developmental requirements and function. Chromosoma. https://doi.org/10.1007/s00412009-0221-9

Boyer, L.A., Plath, K., Zeitlinger, J., Brambrink, T., Medeiros, L.A., Lee, T.I., Levine, S.S., Wernig, M., Tajonar, A., Ray, M.K., Bell, G.W., Otte, A.P., Vidal, M., Gifford, D.K., Young, R.A., Jaenisch, R., 2006. Polycomb complexes repress developmental regulators in murine embryonic stem cells. Nature 441, 349-353. https://doi.org/10.1038/nature04733

Brooks, N.E., Myburgh, K.H., Storey, K.B., 2015. Muscle satellite cells increase during hibernation in ground squirrels. Comp. Biochem. Physiol. Part - B Biochem. Mol. Biol. 189, 55-61. https://doi.org/10.1016/j.cbpb.2015.07.006

Cai, Q., Greenway, S.C., Storey, K.B., 1997. Differential regulation of the mitochondrial ADP/ATP translocase gene in wood frogs under freezing stress. Biochim. Biophys. Acta Gene Struct. Expr. 1353, 69-78. https://doi.org/10.1016/S0167-4781(97)00057-2

Cai, Q., Storey, K.B., 1997a. Freezing-induced genes in wood frog (Rana sylvatica): Fibrinogen upregulation by freezing and dehydration. Am. J. Physiol. - Regul. Integr. Comp. Physiol. 272. https://doi.org/10.1152/ajpregu.1997.272.5.r1480

Cai, Q., Storey, K.B., 1997b. Upregulation of a novel gene by freezing exposure in the freezetolerant wood frog (Rana sylvatica). Gene 198, 305-312. https://doi.org/10.1016/s03781119(97)00332-6

Cao, R., Wang, L., Wang, H., Xia, L., Erdjument-Bromage, H., Tempst, P., Jones, R.S., Zhang, Y., 2002. Role of histone H3 lysine 27 methylation in polycomb-group silencing. Science (80-. ). 298, 1039-1043. https://doi.org/10.1126/science.1076997

Carr, S.M., Munro, S., Kessler, B., Oppermann, U., La Thangue, N.B., 2011. Interplay between lysine methylation and $\mathrm{Cdk}$ phosphorylation in growth control by the retinoblastoma protein. EMBO J. 30, 317-327. https://doi.org/10.1038/emboj.2010.311

Chédin, F., Lieber, M.R., Hsieh, C.L., 2002. The DNA methyltransferase-like protein DNMT3L stimulates de novo methylation by Dnmt3a. Proc. Natl. Acad. Sci. U. S. A. 99, 16916- 
16921. https://doi.org/10.1073/pnas.262443999

Chen, H., Yan, Y., Davidson, T.L., Shinkai, Y., Costa, M., 2006. Hypoxic stress induces dimethylated histone $\mathrm{H} 3$ lysine 9 through histone methyltransferase G9a in mammalian cells. Cancer Res. 66, 9009-9016. https://doi.org/10.1158/0008-5472.CAN-06-0101

Chéné, I. Du, Basyuk, E., Lin, Y.L., Triboulet, R., Knezevich, A., Chable-Bessia, C., Mettling, C., Baillat, V., Reynes, J., Corbeau, P., Bertrand, E., Marcello, A., Emiliani, S., Kiernan, R., Benkirane, M., 2007. Suv39H1 and HP1 $\gamma$ are responsible for chromatin-mediated HIV-1 transcriptional silencing and post-integration latency. EMBO J. 26, 424-435. https://doi.org/10.1038/sj.emboj.7601517

Cheng, J., Guo, S., Chen, S., Mastriano, S.J., Liu, C., D’Alessio, A.C., Hysolli, E., Guo, Y., Yao, H., Megyola, C.M., Li, D., Liu, J., Pan, W., Roden, C.A., Zhou, X.L., Heydari, K., Chen, J., Park, I.H., Ding, Y., Zhang, Y., Lu, J., 2013. An Extensive Network of TET2-Targeting MicroRNAs Regulates Malignant Hematopoiesis. Cell Rep. 5, 471-481. https://doi.org/10.1016/j.celrep.2013.08.050

Choi, J., MA, P., JS, L., 2012. Suppression and recovery of BRCA1-mediated transcription by HP1 $\gamma$ via modulation of promoter occupancy. Nucleic Acids Res. 40, 11321-11338. https://doi.org/10.1093/NAR/GKS947

Churchill, T.A., Storey, K.B., 1993. Dehydration tolerance in wood frogs: A new perspective on development of amphibian freeze tolerance. Am. J. Physiol. - Regul. Integr. Comp. Physiol. 265. https://doi.org/10.1152/ajpregu.1993.265.6.r1324

Churchill, T.A., Storey, K.B., 1992. Natural freezing survival by painted turtles Chrysemys picta marginata and C. picta bellii. Am. J. Physiol. - Regul. Integr. Comp. Physiol. 262. https://doi.org/10.1152/ajpregu.1992.262.3.r530

Collins, M.A., An, J., Peller, D., Bowser, R., 2015. Total protein is an effective loading control for cerebrospinal fluid western blots. J. Neurosci. Methods 251, 72-82. https://doi.org/10.1016/j.jneumeth.2015.05.011

Costanzo, J.P., Do Amaral, M.C.F., Rosendale, A.J., Lee, R.E., 2013. Hibernation physiology, freezing adaptation and extreme freeze tolerance in a northern population of the wood frog. J. Exp. Biol. 216, 3461-3473. https://doi.org/10.1242/jeb.089342

Costanzo, J.P., Lee, R.E., 2005. Cryoprotection by urea in a terrestrially hibernating frog. J. Exp. Biol. 208, 4079-4089. https://doi.org/10.1242/jeb.01859

Costanzo, J.P., Lee, R.E., Lortz, P.H., 1993. Physiological responses of freeze-tolerant and intolerant frogs: Clues to evolution of anuran freeze tolerance. Am. J. Physiol. - Regul. Integr. Comp. Physiol. 265. https://doi.org/10.1152/ajpregu.1993.265.4.r721

Costanzo, J.P., Lee, R.E., Wright, M.F., 1992. Cooling rate influences cryoprotectant distribution and organ dehydration in freezing wood frogs. J. Exp. Zool. 261, 373-378. https://doi.org/10.1002/jez.1402610403

Dawson, N., Storey, K., 2017. Passive regeneration of glutathione: glutathione reductase regulation in the freeze-tolerant North American wood frog, Rana sylvatica. J. Exp. Biol. 220, 3162-3171. https://doi.org/10.1242/JEB.159475

Dawson, N.J., Storey, K.B., 2016. A hydrogen peroxide safety valve: The reversible 
phosphorylation of catalase from the freeze-tolerant North American wood frog, Rana sylvatica. Biochim. Biophys. Acta - Gen. Subj. 1860, 476-485.

https://doi.org/10.1016/j.bbagen.2015.12.007

Denlinger, D.L., 2002. Regulation of Diapause. Annu. Rev. Entomol. 47, 93-122.

Deplus, R., Blanchon, L., Rajavelu, A., Boukaba, A., Defrance, M., Luciani, J., Rothé, F., Dedeurwaerder, S., Denis, H., Brinkman, A.B., Simmer, F., Müller, F., Bertin, B., Berdasco, M., Putmans, P., Calonne, E., Litchfield, D.W., De Launoit, Y., Jurkowski, T.P., Stunnenberg, H.G., Bock, C., Sotiriou, C., Fraga, M.F., Esteller, M., Jeltsch, A., Fuks, F., 2014. Regulation of DNA methylation patterns by CK2-mediated phosphorylation of Dnmt3a. Cell Rep. 8, 743-753. https://doi.org/10.1016/j.celrep.2014.06.048

Deplus, R., Delatte, B., Schwinn, M.K., Defrance, M., Méndez, J., Murphy, N., Dawson, M.A., Volkmar, M., Putmans, P., Calonne, E., Shih, A.H., Levine, R.L., Bernard, O., Mercher, T., Solary, E., Urh, M., Daniels, D.L., Fuks, F., 2013. TET2 and TET3 regulate GlcNAcylation and H3K4 methylation through OGT and SET1/COMPASS. EMBO J. https://doi.org/10.1038/emboj.2012.357

Dhami, G.K., Liu, H., Galka, M., Voss, C., Wei, R., Muranko, K., Kaneko, T., Cregan, S.P., Li, L., Li, S.S.C., 2013. Dynamic Methylation of Numb by Set8 Regulates Its Binding to p53 and Apoptosis. Mol. Cell 50, 565-576. https://doi.org/10.1016/j.molcel.2013.04.028

Dieni, C.A., Bouffard, M.C., Storey, K.B., 2012. Glycogen synthase kinase-3: Cryoprotection and glycogen metabolism in the freezetolerant wood frog. J. Exp. Biol. 215, 543-551. https://doi.org/10.1242/jeb.065961

Dieni, C.A., Storey, K.B., 2011. Regulation of hexokinase by reversible phosphorylation in skeletal muscle of a freeze-tolerant frog. Comp. Biochem. Physiol. - B Biochem. Mol. Biol. 159, 236-243. https://doi.org/10.1016/j.cbpb.2011.05.003

Dieni, C.A., Storey, K.B., 2010. Regulation of glucose-6-phosphate dehydrogenase by reversible phosphorylation in liver of a freeze tolerant frog. J. Comp. Physiol. B Biochem. Syst. Environ. Physiol. 180, 1133-1142. https://doi.org/10.1007/s00360-010-0487-5

Dieni, C.A., Storey, K.B., 2009. Creatine kinase regulation by reversible phosphorylation in frog muscle. Comp. Biochem. Physiol. - B Biochem. Mol. Biol. 152, 405-412. https://doi.org/10.1016/j.cbpb.2009.01.012

Dittmer, A., Dittmer, J., 2006. $\beta$-Actin is not a reliable loading control in Western blot analysis. Electrophoresis 27, 2844-2845. https://doi.org/10.1002/elps.200500785

do Amaral, M.C.F., Lee, R.E., Costanzo, J.P., 2016. Enzymatic regulation of seasonal glycogen cycling in the freeze-tolerant wood frog, Rana sylvatica. J. Comp. Physiol. B Biochem. Syst. Environ. Physiol. 186, 1045-1058. https://doi.org/10.1007/s00360-016-1012-2

Dodge, J.E., Okano, M., Dick, F., Tsujimoto, N., Chen, T., Wang, S., Ueda, Y., Dyson, N., Li, E., 2005. Inactivation of Dnmt3b in mouse embryonic fibroblasts results in DNA hypomethylation, chromosomal instability, and spontaneous immortalization. J. Biol. Chem. 280, 17986-17991. https://doi.org/10.1074/jbc.M413246200

Duman, J.G., 2001. Antifreeze and ice nucleator proteins in terrestrial arthropods. Annu. Rev. Physiol. https://doi.org/10.1146/annurev.physiol.63.1.327 
Duong, H.A., Weitz, C.J., 2014. Temporal orchestration of repressive chromatin modifiers by mammalian circadian clock PERIOD complexes. Nat. Struct. Mol. Biol. 21, 126. https://doi.org/10.1038/NSMB.2746

Feng, J., Zhou, Y., Campbell, S.L., Le, T., Li, E., Sweatt, J.D., Silva, A.J., Fan, G., 2010. Dnmt1 and Dnmt3a maintain DNA methylation and regulate synaptic function in adult forebrain neurons. Nat. Neurosci. 13, 423-430. https://doi.org/10.1038/nn.2514

Ferrari, K.J., Scelfo, A., Jammula, S.G., Cuomo, A., Barozzi, I., Stützer, A., Fischle, W., Bonaldi, T., Pasini, D., 2014. Polycomb-Dependent H3K27me1 and H3K27me2 Regulate Active Transcription and Enhancer Fidelity. Mol. Cell 53, 49-62. https://doi.org/10.1016/j.molcel.2013.10.030

Fischer, A.P., Miles, S.L., 2017. Silencing HIF-1 $\alpha$ induces TET2 expression and augments ascorbic acid induced 5-hydroxymethylation of DNA in human metastatic melanoma cells. Biochem. Biophys. Res. Commun. 490, 176-181. https://doi.org/10.1016/j.bbrc.2017.06.017

Fraser, K.P.P., Houlihan, D.F., Lutz, P.L., Leone-Kabler, S., Manuel, L., Brechin, J.G., 2001. Complete suppression of protein synthesis during anoxia with no post-anoxia protein synthesis debt in the red-eared slider turtle Trachemys scripta elegans. J. Exp. Biol. 204, 4353-4360. https://doi.org/10.1242/jeb.204.24.4353

Frerichs, K.U., Smith, C.B., Brenner, M., Degracia, D.J., Krause, G.S., Marrone, L., Dever, T.E., Hallenbeck, J.M., 1998. Suppression of protein synthesis in brain during hibernation involves inhibition of protein initiation and elongation. Proc. Natl. Acad. Sci. U. S. A. 95, 14511-14516. https://doi.org/10.1073/pnas.95.24.14511

Fu, X., Jin, L., Wang, X., Luo, A., Hu, J., Zheng, X., Tsark, W.M., Riggs, A.D., Ku, H.T., Huang, W., 2013. MicroRNA-26a targets ten eleven translocation enzymes and is regulated during pancreatic cell differentiation. Proc. Natl. Acad. Sci. U. S. A. 110, 17892-17897. https://doi.org/10.1073/pnas.1317397110

Fuks, F., Hurd, P.J., Deplus, R., Kouzarides, T., 2003. The DNA methyltransferases associate with HP1 and the SUV39H1 histone methyltransferase. Nucleic Acids Res. 31, 2305-2312. https://doi.org/10.1093/nar/gkg332

Gerber, V.E.M., Wijenayake, S., Storey, K.B., 2016. Anti-apoptotic response during anoxia and recovery in a freeze-tolerant wood frog (Rana sylvatica). PeerJ 2016, e1834. https://doi.org/10.7717/peerj.1834

Gopalakrishnan, S., Sullivan, B.A., Trazzi, S., Della Valle, G., Robertson, K.D., 2009. DNMT3B interacts with constitutive centromere protein CENP-C to modulate DNA methylation and the histone code at centromeric regions. Hum. Mol. Genet. 18, 3178-3193. https://doi.org/10.1093/hmg/ddp256

Green, S.R., Storey, K.B., 2017. Regulation of glutamate dehydrogenase (GDH) in response to whole body freezing in wood frog liver linked to differential acetylation and ADPribosylation. Arch. Biochem. Biophys. 636, 90-99. https://doi.org/10.1016/j.abb.2017.10.010

Gupta, A., Brooks, C., Storey, K.B., 2020. Regulation of NF- $\kappa$ B, FHC and SOD2 in response to oxidative stress in the freeze tolerant wood frog, Rana sylvatica. Cryobiology 97, 28-36. 
https://doi.org/10.1016/j.cryobiol.2020.10.012

Hadj-Moussa, H., Storey, K.B., 2018. Micromanaging freeze tolerance: the biogenesis and regulation of neuroprotective microRNAs in frozen brains. Cell. Mol. Life Sci. 75, 36353647. https://doi.org/10.1007/s00018-018-2821-0

Hafner, A., Bulyk, M.L., Jambhekar, A., Lahav, G., 2019. The multiple mechanisms that regulate p53 activity and cell fate. Nat. Rev. Mol. Cell Biol. https://doi.org/10.1038/s41580019-0110-x

Hawkins, L.J., Storey, K.B., 2020. Advances and applications of environmental stress adaptation research. Comp. Biochem. Physiol. -Part A Mol. Integr. Physiol. 240, 110623. https://doi.org/10.1016/j.cbpa.2019.110623

Hawkins, L.J., Storey, K.B., 2018. Histone methylation in the freeze-tolerant wood frog (Rana sylvatica). J. Comp. Physiol. B Biochem. Syst. Environ. Physiol. 188, 113-125. https://doi.org/10.1007/s00360-017-1112-7

Heldmaier, G., Ortmann, S., Elvert, R., 2004. Natural hypometabolism during hibernation and daily torpor in mammals, in: Respiratory Physiology and Neurobiology. Respir Physiol Neurobiol, pp. 317-329. https://doi.org/10.1016/j.resp.2004.03.014

Hemmings, S.J., Storey, K.B., 1994. Alterations in hepatic adrenergic receptor status in Rana sylvatica in response to freezing and thawing: Implications to the freeze-induced glycemic response. Can. J. Physiol. Pharmacol. 72, 1552-1560. https://doi.org/10.1139/y94-223

Hermann, A., Goyal, R., Jeltsch, A., 2004. The Dnmt1 DNA-(cytosine-C5)-methyltransferase methylates DNA processively with high preference for hemimethylated target sites. J. Biol. Chem. 279, 48350-48359. https://doi.org/10.1074/jbc.M403427200

Hochachka, P.W., Lutz, P.L., 2001. Mechanism, origin, and evolution of anoxia tolerance in animals, in: Comparative Biochemistry and Physiology - B Biochemistry and Molecular Biology. Elsevier Inc., pp. 435-459. https://doi.org/10.1016/S1096-4959(01)00408-0

Holden, C.P., Storey, K.B., 1996. Signal transduction, second messenger, and protein kinase responses during freezing exposures in wood frogs. Am. J. Physiol. - Regul. Integr. Comp. Physiol. 271. https://doi.org/10.1152/ajpregu.1996.271.5.r1205

Hyun, K., Jeon, J., Park, K., Kim, J., 2017. Writing, erasing and reading histone lysine methylations. Exp. Mol. Med. https://doi.org/10.1038/emm.2017.11

Ichimura, T., Watanabe, S., Sakamoto, Y., Aoto, T., Pujita, N., Nakao, M., 2005. Transcriptional repression and heterochromatin formation by MBD1 and MCAF/AM family proteins. J. Biol. Chem. 280, 13928-13935. https://doi.org/10.1074/jbc.M413654200

Ito, S., Shen, L., Dai, Q., Wu, S.C., Collins, L.B., Swenberg, J.A., He, C., Zhang, Y., 2011. Tet proteins can convert 5-methylcytosine to 5-formylcytosine and 5-carboxylcytosine. Science (80-. ). 333, 1300-1303. https://doi.org/10.1126/science.1210597

Jaenisch, R., Bird, A., 2003. Epigenetic regulation of gene expression: How the genome integrates intrinsic and environmental signals. Nat. Genet. https://doi.org/10.1038/ng1089

Jair, K.W., Bachman, K.E., Suzuki, H., Ting, A.H., Rhee, I., Yen, R.W.C., Baylin, S.B., Schuebel, K.E., 2006. De novo CpG island methylation in human cancer cells. Cancer Res. 
66, 682-692. https://doi.org/10.1158/0008-5472.CAN-05-1980

Jeltsch, A., Jurkowska, R.Z., 2014. New concepts in DNA methylation. Trends Biochem. Sci. 39. https://doi.org/10.1016/j.tibs.2014.05.002

Jeziorska, D.M., Murray, R.J.S., De Gobbi, M., Gaentzsch, R., Garrick, D., Ayyub, H., Chen, T., Li, E., Telenius, J., Lynch, M., Graham, B., Smith, A.J.H., Lund, J.N., Hughes, J.R., Higgs, D.R., Tufarelli, C., 2017. DNA methylation of intragenic CpG islands depends on their transcriptional activity during differentiation and disease. Proc. Natl. Acad. Sci. U. S. A. 114, E7526-E7535. https://doi.org/10.1073/pnas.1703087114

Jiang, D., Wei, S., Chen, F., Zhang, Y., Li, J., 2017. TET3-mediated DNA oxidation promotes ATR-dependent DNA damage response. EMBO Rep. 18, 781-796. https://doi.org/10.15252/embr.201643179

Jiang, D., Zhang, Y., Hart, R.P., Chen, J., Herrup, K., Li, J., 2015. Alteration in 5hydroxymethylcytosine-mediated epigenetic regulation leads to Purkinje cell vulnerability in ATM deficiency. Brain 138, 3520-3536. https://doi.org/10.1093/brain/awv284

Joanisse, D.R., Storey, K.B., 1996. Oxidative damage and antioxidants in Rana sylvatica, the freeze-tolerant wood frog. Am. J. Physiol. - Regul. Integr. Comp. Physiol. 271. https://doi.org/10.1152/ajpregu.1996.271.3.r545

Kalakonda, N., Fischle, W., Boccuni, P., Gurvich, N., Hoya-Arias, R., Zhao, X., Miyata, Y., MacGrogan, D., Zhang, J., Sims, J.K., Rice, J.C., Nimer, S.D., 2008. Histone H4 lysine 20 monomethylation promotes transcriptional repression by L3MBTL1. Oncogene 27, 42934304. https://doi.org/10.1038/onc.2008.67

Kapoor, A., Yao, W., Ying, H., Hua, S., Liewen, A., Wang, Q., Zhong, Y., Wu, C.J., Sadanandam, A., Hu, B., Chang, Q., Chu, G.C., Al-Khalil, R., Jiang, S., Xia, H., FletcherSananikone, E., Lim, C., Horwitz, G.I., Viale, A., Pettazzoni, P., Sanchez, N., Wang, H., Protopopov, A., Zhang, J., Heffernan, T., Johnson, R.L., Chin, L., Wang, Y.A., Draetta, G., Depinho, R.A., 2014. Yap1 activation enables bypass of oncogenic KRAS addiction in pancreatic cancer. Cell 158, 185-197. https://doi.org/10.1016/j.cell.2014.06.003

Kim, Y., Nam, H.J., Lee, J., Park, D.Y., Kim, C., Yu, Y.S., Kim, D., Park, S.W., Bhin, J., Hwang, D., Lee, H., Koh, G.Y., Baek, S.H., 2016. Methylation-dependent regulation of HIF-1 $\alpha$ stability restricts retinal and tumour angiogenesis. Nat. Commun. 7. https://doi.org/10.1038/ncomms10347

Kontaki, H., Talianidis, I., 2010. Lysine Methylation Regulates E2F1-Induced Cell Death. Mol. Cell 39, 152-160. https://doi.org/10.1016/j.molcel.2010.06.006

Kudithipudi, S., Schuhmacher, M.K., Kebede, A.F., Jeltsch, A., 2017. The SUV39H1 Protein Lysine Methyltransferase Methylates Chromatin Proteins Involved in Heterochromatin Formation and VDJ Recombination. ACS Chem. Biol. 12, 958-968. https://doi.org/10.1021/acschembio.6b01076

Laget, S., Miotto, B., Chin, H.G., Estève, P.O., Roberts, R.J., Pradhan, S., Defossez, P.A., 2014. MBD4 cooperates with DNMT1 to mediate methyl-DNA repression and protects mammalian cells from oxidative stress. Epigenetics 9, 546-556. https://doi.org/10.4161/epi.27695 
Larson, D.J., Middle, L., Vu, H., Zhang, W., Serianni, A.S., Duman, J., Barnes, B.M., 2014. Wood frog adaptations to overwintering in Alaska: New limits to freezing tolerance. J. Exp. Biol. 217, 2193-2200. https://doi.org/10.1242/jeb.101931

Lavoie, G., Estève, P.O., Laulan, N.B., Pradhan, S., St-Pierre, Y., 2011. PKC isoforms interact with and phosphorylate DNMT1. BMC Biol. 9. https://doi.org/10.1186/1741-7007-9-31

Layne, J.R., Lee, R.E., Heil, T.L., 1989. Freezing-induced changes in the heart rate of wood frogs (Rana sylvatica). Am. J. Physiol. - Regul. Integr. Comp. Physiol. 257. https://doi.org/10.1152/ajpregu.1989.257.5.r1046

Lee, R.E., Costanzo, J.P., 1998. Biological ice nucleation and ice distribution in cold-hardy ectothermic animals. Annu. Rev. Physiol. https://doi.org/10.1146/annurev.physiol.60.1.55

Li, E., 2002. Chromatin modification and epigenetic reprogramming in mammalian development. Nat. Rev. Genet. https://doi.org/10.1038/nrg887

Lister, R., Pelizzola, M., Dowen, R.H., Hawkins, R.D., Hon, G., Tonti-Filippini, J., Nery, J.R., Lee, L., Ye, Z., Ngo, Q.M., Edsall, L., Antosiewicz-Bourget, J., Stewart, R., Ruotti, V., Millar, A.H., Thomson, J.A., Ren, B., Ecker, J.R., 2009. Human DNA methylomes at base resolution show widespread epigenomic differences. Nature 462, 315-322. https://doi.org/10.1038/nature08514

Litchfield, D.W., 2003. Protein kinase CK2: Structure, regulation and role in cellular decisions of life and death. Biochem. J. https://doi.org/10.1042/BJ20021469

Liu, Q., Geng, H., Xue, C., Beer, T.M., Qian, D.Z., 2015. Functional regulation of hypoxia inducible factor- $1 \alpha$ by SET9 lysine methyltransferase. Biochim. Biophys. Acta - Mol. Cell Res. 1853, 881-891. https://doi.org/10.1016/j.bbamcr.2015.01.011

Liu, Q., Liu, L., Zhao, Y., Zhang, J., Wang, D., Chen, J., He, Y., Wu, J., Zhang, Z., Liu, Z., 2011. Hypoxia induces genomic DNA demethylation through the activation of HIF-1 $\alpha$ and transcriptional upregulation of MAT2A in hepatoma cells. Mol. Cancer Ther. 10, 11131123. https://doi.org/10.1158/1535-7163.MCT-10-1010

Lomberk, G., Wallrath, L., Urrutia, R., 2006. The Heterochromatin Protein 1 family. Genome Biol. 7. https://doi.org/10.1186/GB-2006-7-7-228

Lowe, C.H., Lardner, P.J., Halpern, E.A., 1971. Supercooling in reptiles and other vertebrates. Comp. Biochem. Physiol. -- Part A Physiol. 39, 125-135. https://doi.org/10.1016/03009629(71)90352-5

Lundberg, L.E., Stenberg, P., Larsson, J., 2013. HP1a, Su(var)3-9, SETDB1 and POF stimulate or repress gene expression depending on genomic position, gene length and expression pattern in Drosophila melanogaster. Nucleic Acids Res. 41, 4481-4494. https://doi.org/10.1093/nar/gkt158

Lv, X., Jiang, H., Liu, Y., Lei, X., Jiao, J., 2014. Micro RNA -15b promotes neurogenesis and inhibits neural progenitor proliferation by directly repressing TET 3 during early neocortical development . EMBO Rep. 15, 1305-1314. https://doi.org/10.15252/embr.201438923

Lyko, F., 2018. The DNA methyltransferase family: A versatile toolkit for epigenetic regulation. Nat. Rev. Genet. https://doi.org/10.1038/nrg.2017.80 
Maistrovski, Y., Biggar, K.K., Storey, K.B., 2012. HIF-1 $\alpha$ regulation in mammalian hibernators: Role of non-coding RNA in HIF-1 $\alpha$ control during torpor in ground squirrels and bats. $\mathrm{J}$. Comp. Physiol. B Biochem. Syst. Environ. Physiol. 182, 849-859. https://doi.org/10.1007/s00360-012-0662-y

Malik, A.I., Storey, K.B., 2009. Activation of antioxidant defense during dehydration stress in the African clawed frog. Gene 442, 99-107. https://doi.org/10.1016/j.gene.2009.04.007

Martin, C., Zhang, Y., 2005. The diverse functions of histone lysine methylation. Nat. Rev. Mol. Cell Biol. https://doi.org/10.1038/nrm1761

Mazur, P., 1984. Freezing of living cells: mechanisms and implications. Am. J. Physiol. https://doi.org/10.1152/ajpcell.1984.247.3.C125

Mcgarvey, K.M., Greene, E., Fahrner, J.A., Jenuwein, T., Baylin, S.B., 2007. DNA Methylation and Complete Transcriptional Silencing of Cancer Genes Persist after Depletion of EZH2. Cancer Res 67, 5097-102. https://doi.org/10.1158/0008-5472.CAN-06-2029

McGee, S.L., Hargreaves, M., 2019. Epigenetics and Exercise. Trends Endocrinol. Metab. https://doi.org/10.1016/j.tem.2019.06.002

McNally, J.D., Wu, S.B., Sturgeon, C.M., Storey, K.B., 2002. Identification and characterization of a novel freezing inducible gene, li16, in the wood frog Rana sylvatica. FASEB J. 16, 902-904. https://doi.org/10.1096/fj.02-0017fje

Mikkelsen, T.S., Ku, M., Jaffe, D.B., Issac, B., Lieberman, E., Giannoukos, G., Alvarez, P., Brockman, W., Kim, T.K., Koche, R.P., Lee, W., Mendenhall, E., O’Donovan, A., Presser, A., Russ, C., Xie, X., Meissner, A., Wernig, M., Jaenisch, R., Nusbaum, C., Lander, E.S., Bernstein, B.E., 2007. Genome-wide maps of chromatin state in pluripotent and lineagecommitted cells. Nature 448, 553-560. https://doi.org/10.1038/nature06008

Minc, E., Courvalin, J.C., Buendia, B., 2000. HP1 $\gamma$ associates with euchromatin and heterochromatin in mammalian nuclei and chromosomes. Cytogenet. Cell Genet. 90, 279284. https://doi.org/10.1159/000056789

Moore, L.D., Le, T., Fan, G., 2013. DNA methylation and its basic function. Neuropsychopharmacology 38, 23-38. https://doi.org/10.1038/npp.2012.112

Morin, P., Storey, K.B., 2006a. Evidence for a reduced transcriptional state during hibernation in ground squirrels. Cryobiology 53, 310-318. https://doi.org/10.1016/j.cryobiol.2006.08.002

Morin, P., Storey, K.B., 2006b. Evidence for a reduced transcriptional state during hibernation in ground squirrels. Cryobiology 53, 310-318. https://doi.org/10.1016/j.cryobiol.2006.08.002

Morin, P., Storey, K.B., 2005. Cloning and expression of hypoxia-inducible factor $1 \alpha$ from the hibernating ground squirrel, Spermophilus tridecemlineatus. Biochim. Biophys. Acta - Gene Struct. Expr. 1729, 32-40. https://doi.org/10.1016/j.bbaexp.2005.02.009

Morin, P.J., McMullen, D.C., Storey, K.B., 2005. HIF-1 $\alpha$ involvement in low temperature and anoxia survival by a freeze tolerant insect. Mol. Cell. Biochem. 280, 99-106. https://doi.org/10.1007/s11010-005-8236-x

Moritz, C.P., 2017. Tubulin or Not Tubulin: Heading Toward Total Protein Staining as Loading Control in Western Blots. Proteomics. https://doi.org/10.1002/pmic.201600189 
Mu, W., Starmer, J., Yee, D., Magnuson, T., 2018. EZH2 variants differentially regulate polycomb repressive complex 2 in histone methylation and cell differentiation. Epigenetics and Chromatin 11, 1-14. https://doi.org/10.1186/s13072-018-0242-9

Munro, S., Khaire, N., Inche, A., Carr, S., La Thangue, N.B., 2010. Lysine methylation regulates the $\mathrm{pRb}$ tumour suppressor protein. Oncogene 29, 2357-2367. https://doi.org/10.1038/onc.2009.511

Murphy, D.J., 1983. Freezing resistance in intertidal invertebrates. Annu. Rev. Physiol. https://doi.org/10.1146/annurev.ph.45.030183.001445

Nan, X., Ng, H.H., Johnson, C.A., Laherty, C.D., Turner, B.M., Eisenman, R.N., Bird, A., 1998. Transcriptional repression by the methyl-CpG-binding protein MeCP2 involves a histone deacetylase complex. Nature 393, 386-389. https://doi.org/10.1038/30764

Ohtani, K., Degregori, J., Nevins, J.R., 1995. Regulation of the cyclin E gene by transcription factor E2F1. Proc. Natl. Acad. Sci. U. S. A. 92, 12146-12150. https://doi.org/10.1073/pnas.92.26.12146

Oudhoff, M.J., Freeman, S.A., Couzens, A.L., Antignano, F., Kuznetsova, E., Min, P.H., Northrop, J.P., Lehnertz, B., Barsyte-Lovejoy, D., Vedadi, M., Arrowsmith, C.H., Nishina, H., Gold, M.R., Rossi, F.M.V., Gingras, A.C., Zaph, C., 2013. Control of the Hippo Pathway by Set7-Dependent Methylation of Yap. Dev. Cell 26, 188-194. https://doi.org/10.1016/j.devcel.2013.05.025

Packard, M.J., Packard, G.C., 2004. Accumulation of lactate by frozen painted turtles (Chrysemys picta) and its relationship to freeze tolerance. Physiol. Biochem. Zool. 77, 433439. https://doi.org/10.1086/420952

Pan, D., 2010. The hippo signaling pathway in development and cancer. Dev. Cell. https://doi.org/10.1016/j.devcel.2010.09.011

Pan, M.-R., Hsu, M.-C., Chen, L.-T., Hung, W.-C., 2018. Orchestration of H3K27 methylation: mechanisms and therapeutic implication. Cell. Mol. Life Sci. 75, 209. https://doi.org/10.1007/S00018-017-2596-8

Perez-Pinzon, M.A., Rosenthal, M., Sick, T.J., Lutz, P.L., Pablo, J., Mash, D., 1992. Downregulation of sodium channels during anoxia: A putative survival strategy of turtle brain. Am. J. Physiol. - Regul. Integr. Comp. Physiol. 262. https://doi.org/10.1152/ajpregu.1992.262.4.r712

Peters, A.H.F.M., O’Carroll, D., Scherthan, H., Mechtler, K., Sauer, S., Schöfer, C., Weipoltshammer, K., Pagani, M., Lachner, M., Kohlmaier, A., Opravil, S., Doyle, M., Sibilia, M., Jenuwein, T., 2001. Loss of the Suv39h histone methyltransferases impairs mammalian heterochromatin and genome stability. Cell 107, 323-337. https://doi.org/10.1016/S0092-8674(01)00542-6

Rasmussen, K.D., Helin, K., 2016. Role of TET enzymes in DNA methylation, development, and cancer. Genes Dev. https://doi.org/10.1101/gad.276568.115

Rider, M.H., Hussain, N., Horman, S., Dilworth, S.M., Storey, K.B., 2006. Stress-induced activation of the AMP-activated protein kinase in the freeze-tolerant frog Rana sylvatica. Cryobiology 53, 297-309. https://doi.org/10.1016/j.cryobiol.2006.08.001 
Rolfe, D.F.S., Brown, G.C., 1997. Cellular energy utilization and molecular origin of standard metabolic rate in mammals. Physiol. Rev. 77, 731-758.

https://doi.org/10.1152/physrev.1997.77.3.731

Rosenbluh, J., Nijhawan, D., Cox, A.G., Li, X., Neal, J.T., Schafer, E.J., Zack, T.I., Wang, X., Tsherniak, A., Schinzel, A.C., Shao, D.D., Schumacher, S.E., Weir, B.A., Vazquez, F., Cowley, G.S., Root, D.E., Mesirov, J.P., Beroukhim, R., Kuo, C.J., Goessling, W., Hahn, W.C., 2012. $\beta$-Catenin-driven cancers require a YAP1 transcriptional complex for survival and tumorigenesis. Cell 151, 1457-1473. https://doi.org/10.1016/j.cell.2012.11.026

Rosendale, A.J., Philip, B.N., Lee, R.E., Costanzo, J.P., 2014. Cloning, characterization, and expression of glucose transporter 2 in the freeze-tolerant wood frog, Rana sylvatica.

Biochim. Biophys. Acta - Gen. Subj. 1840, 1701-1711.

https://doi.org/10.1016/j.bbagen.2013.12.011

Rouble, A.N., Hawkins, L.J., Storey, K.B., 2018. Roles for lysine acetyltransferases during mammalian hibernation. J. Therm. Biol. 74, 71-76.

https://doi.org/10.1016/j.jtherbio.2018.03.013

Saint-André, V., Batsché, E., Rachez, C., Muchardt, C., 2011. Histone H3 lysine 9 trimethylation and HP1 $\gamma$ favor inclusion of alternative exons. Nat. Struct. Mol. Biol. 18, 337-344. https://doi.org/10.1038/NSMB.1995

Schmid, W.D., 1982. Survival of frogs in low temperature. Science (80-. ). 215, 697-698. https://doi.org/10.1126/science.7058335

Schultz, D.C., Friedman, J.R., Rauscher, F.J., 2001. Targeting histone deacetylase complexes via KRAB-zinc finger proteins: The PHD and bromodomains of KAP-1 form a cooperative unit that recruits a novel isoform of the Mi-2 $\alpha$ subunit of NuRD. Genes Dev. 15, 428-443. https://doi.org/10.1101/gad.869501

Semenza, G.L., 2001. HIF-1 and mechanisms of hypoxia sensing. Curr. Opin. Cell Biol. https://doi.org/10.1016/S0955-0674(00)00194-0

Shen, C., Wang, D., Liu, X., Gu, B., Du, Y., Wei, F.Z., Cao, L.L., Song, B., Lu, X., Yang, Q., Zhu, Q., Hou, T., Li, M., Wang, L., Wang, H., Zhao, Y., Yang, Y., Zhu, W.G., 2015. SET7/9 regulates cancer cell proliferation by influencing $\beta$-catenin stability. FASEB J. 29, 4313-4323. https://doi.org/10.1096/fj.15-273540

Shen, L., Wu, H., Diep, D., Yamaguchi, S., D’Alessio, A.C., Fung, H.L., Zhang, K., Zhang, Y., 2013. Genome-wide analysis reveals TET- and TDG-dependent 5-methylcytosine oxidation dynamics. Cell 153, 692-706. https://doi.org/10.1016/j.cell.2013.04.002

Shen, X., Liu, Y., Hsu, Y.J., Fujiwara, Y., Kim, J., Mao, X., Yuan, G.C., Orkin, S.H., 2008. EZH1 Mediates Methylation on Histone H3 Lysine 27 and Complements EZH2 in Maintaining Stem Cell Identity and Executing Pluripotency. Mol. Cell 32, 491-502. https://doi.org/10.1016/j.molcel.2008.10.016

Shi, X., Kachirskaia, I., Yamaguchi, H., West, L.E., Wen, H., Wang, E.W., Dutta, S., Appella, E., Gozani, O., 2007. Modulation of p53 Function by SET8-Mediated Methylation at Lysine 382. Mol. Cell 27, 636-646. https://doi.org/10.1016/j.molcel.2007.07.012

Smolinski, M.B., Mattice, J.J.L., Storey, K.B., 2017. Regulation of pyruvate kinase in skeletal 
muscle of the freeze tolerant wood frog, Rana sylvatica. Cryobiology 77, 25-33. https://doi.org/10.1016/j.cryobiol.2017.06.002

Song, S.J., Ito, K., Ala, U., Kats, L., Webster, K., Sun, S.M., Jongen-Lavrencic, M., ManovaTodorova, K., Teruya-Feldstein, J., Avigan, D.E., Delwel, R., Pandolfi, P.P., 2013. The oncogenic MicroRNA miR-22 targets the TET2 tumor suppressor to promote hematopoietic stem cell self-renewal and transformation. Cell Stem Cell 13, 87-101. https://doi.org/10.1016/j.stem.2013.06.003

Stankiewicz, A.M., Swiergiel, A.H., Lisowski, P., 2013. Epigenetics of stress adaptations in the brain. Brain Res. Bull. 98, 76-92. https://doi.org/10.1016/J.BRAINRESBULL.2013.07.003

Steponkus, P.L., Lynch, D. V., 1989. Freeze/thaw-induced destabilization of the plasma membrane and the effects of cold acclimation. J. Bioenerg. Biomembr. 21, 21-41. https://doi.org/10.1007/BF00762210

Storey, J.M., Storey, K.B., 2019. In defense of proteins: Chaperones respond to freezing, anoxia, or dehydration stress in tissues of freeze tolerant wood frogs. J. Exp. Zool. Part A Ecol. Integr. Physiol. 331, 392-402. https://doi.org/10.1002/jez.2306

Storey, J.M., Storey, K.B., 1985. Triggering of cryoprotectant synthesis by the initiation of ice nucleation in the freeze tolerant frog, Rana sylvatica. J. Comp. Physiol. B 156, 191-195. https://doi.org/10.1007/BF00695773

Storey, K.B., 1990. Life in a frozen state: Adaptive strategies for natural freeze tolerance in amphibians and reptiles. Am. J. Physiol. - Regul. Integr. Comp. Physiol. https://doi.org/10.1152/ajpregu.1990.258.3.r559

Storey, K.B., Storey, J.M., 2017. Molecular physiology of freeze tolerance in vertebrates. Physiol. Rev. 97, 623-665. https://doi.org/10.1152/physrev.00016.2016

Storey, K.B., Storey, J.M., 2013. Molecular biology of freezing tolerance. Compr. Physiol. 3, 1283-1308. https://doi.org/10.1002/cphy.c130007

Storey, K.B., Storey, J.M., 2004a. Metabolic rate depression in animals: Transcriptional and translational controls. Biol. Rev. Camb. Philos. Soc. https://doi.org/10.1017/S1464793103006195

Storey, K.B., Storey, J.M., 2004b. Physiology, Biochemistry, and Molecular Biology of Vertebrate Freeze Tolerance: The Wood Frog 269-300. https://doi.org/10.1201/9780203647073-17

Storey, K.B., Storey, J.M., 1990. Metabolic rate depression and biochemical adaptation in anaerobiosis, hibernation and estivation. Q. Rev. Biol. 65, 145-174. https://doi.org/10.1086/416717

Storey, K.B., Storey, J.M., 1988. Freeze tolerance in animals. Physiol. Rev. https://doi.org/10.1152/physrev.1988.68.1.27

Storey, K.B., Storey, J.M., 1986. Freeze tolerant frogs: cryoprotectants and tissue metabolism during freeze-thaw cycles. Can. J. Zool. 64, 49-56. https://doi.org/10.1139/z86-008

Suetake, I., Shinozaki, F., Miyagawa, J., Takeshima, H., Tajima, S., 2004. DNMT3L stimulates the DNA methylation activity of Dnmt3a and Dnmt3b through a direct interaction. J. Biol. 
Chem. 279, 27816-27823. https://doi.org/10.1074/jbc.M400181200

Sullivan, K.J., Biggar, K.K., Storey, K.B., 2015. Transcript expression of the freeze responsive gene fr10 in Rana sylvatica during freezing, anoxia, dehydration, and development. Mol. Cell. Biochem. 399, 17-25. https://doi.org/10.1007/s11010-014-2226-9

Sullivan, K.J., Storey, K.B., 2012. Environmental stress responsive expression of the gene li16 in Rana sylvatica, the freeze tolerant wood frog. Cryobiology 64, 192-200. https://doi.org/10.1016/j.cryobiol.2012.01.008

Suzuki, M.M., Bird, A., 2008. DNA methylation landscapes: Provocative insights from epigenomics. Nat. Rev. Genet. https://doi.org/10.1038/nrg2341

Tachibana, M., Sugimoto, K., Fukushima, T., Shinkai, Y., 2001. SET Domain-containing Protein, G9a, is a Novel Lysine-preferring Mammalian Histone Methyltransferase with Hyperactivity and Specific Selectivity to Lysines 9 and 27 of Histone H3. J. Biol. Chem. 276, 25309-25317. https://doi.org/10.1074/jbc.M101914200

Tahiliani, M., Koh, K.P., Shen, Y., Pastor, W.A., Bandukwala, H., Brudno, Y., Agarwal, S., Iyer, L.M., Liu, D.R., Aravind, L., Rao, A., 2009. Conversion of 5-methylcytosine to 5hydroxymethylcytosine in mammalian DNA by MLL partner TET1. Science (80-. ). 324, 930-935. https://doi.org/10.1126/science.1170116

Tang, Y.-A., Tsai, Y.-T., Lin, R.-K., Hsu, H.-S., Chen, C.-Y., Wang, Y.-C., 2014. Deregulation of 553 and RB Transcriptional Control Leads to Overexpression of DNA Methyltransferases in Lung Cancer. J. Cancer Res. Pract. 1, 14-27. https://doi.org/10.1016/s2311-3006(16)30020-9

Tessier, S.N., Luu, B.E., Smith, J.C., Storey, K.B., 2017. The role of global histone posttranslational modifications during mammalian hibernation. Cryobiology 75, 28-36. https://doi.org/10.1016/j.cryobiol.2017.02.008

Tessier, S.N., Storey, K.B., 2010. Expression of myocyte enhancer factor-2 and downstream genes in ground squirrel skeletal muscle during hibernation. Mol. Cell. Biochem. 344, 151162. https://doi.org/10.1007/s11010-010-0538-y

Thienpont, B., Steinbacher, J., Zhao, H., D’Anna, F., Kuchnio, A., Ploumakis, A., Ghesquière, B., Van Dyck, L., Boeckx, B., Schoonjans, L., Hermans, E., Amant, F., Kristensen, V.N., Koh, K.P., Mazzone, M., Coleman, M.L., Carell, T., Carmeliet, P., Lambrechts, Di., 2016. Tumour hypoxia causes DNA hypermethylation by reducing TET activity. Nature 537, $63-$ 68. https://doi.org/10.1038/nature19081

Tiffon, C., 2018. The impact of nutrition and environmental epigenetics on human health and disease. Int. J. Mol. Sci. https://doi.org/10.3390/ijms19113425

Vakoc, C.R., Mandat, S.A., Olenchock, B.A., Blobel, G.A., 2005. Histone H3 lysine 9 methylation and HP1 $\gamma$ are associated with transcription elongation through mammalian chromatin. Mol. Cell 19, 381-391. https://doi.org/10.1016/j.molcel.2005.06.011

Vakoc, C.R., Sachdeva, M.M., Wang, H., Blobel, G.A., 2006. Profile of Histone Lysine Methylation across Transcribed Mammalian Chromatin. Mol. Cell. Biol. 26, 9185-9195. https://doi.org/10.1128/mcb.01529-06

Valenta, T., Hausmann, G., Basler, K., 2012. The many faces and functions of Î 2-catenin. 
EMBO J. https://doi.org/10.1038/emboj.2012.150

Van Breukelen, F., Martin, S.L., 2002. Reversible depression of transcription during hibernation. J. Comp. Physiol. B Biochem. Syst. Environ. Physiol. 172, 355-361. https://doi.org/10.1007/s00360-002-0256-1

Varley, K.E., Gertz, J., Bowling, K.M., Parker, S.L., Reddy, T.E., Pauli-Behn, F., Cross, M.K., Williams, B.A., Stamatoyannopoulos, J.A., Crawford, G.E., Absher, D.M., Wold, B.J., Myers, R.M., 2013. Dynamic DNA methylation across diverse human cell lines and tissues. Genome Res. 23, 555-567. https://doi.org/10.1101/gr.147942.112

Viré, E., Brenner, C., Deplus, R., Blanchon, L., Fraga, M., Didelot, C., Morey, L., Van Eynde, A., Bernard, D., Vanderwinden, J.M., Bollen, M., Esteller, M., Di Croce, L., De Launoit, Y., Fuks, F., 2006. The Polycomb group protein EZH2 directly controls DNA methylation. Nature 439, 871-874. https://doi.org/10.1038/nature04431

Watts, A.J., Storey, K.B., 2019. Hibernation impacts lysine methylation dynamics in the 13-lined ground squirrel, Ictidomys tridecemlineatus. J. Exp. Zool. Part A Ecol. Integr. Physiol. 331, 234-244. https://doi.org/10.1002/jez.2259

Welinder, C., Ekblad, L., 2011. Coomassie staining as loading control in Western blot analysis. J. Proteome Res. 10, 1416-1419. https://doi.org/10.1021/pr1011476

Wijenayake, S., Hawkins, L.J., Storey, K.B., 2018. Dynamic regulation of six histone H3 lysine $(\mathrm{K})$ methyltransferases in response to prolonged anoxia exposure in a freshwater turtle. Gene 649, 50-57. https://doi.org/10.1016/j.gene.2018.01.086

Wijenayake, S., Storey, K.B., 2016. The role of DNA methylation during anoxia tolerance in a freshwater turtle (Trachemys scripta elegans). J. Comp. Physiol. B Biochem. Syst. Environ. Physiol. 186, 333-342. https://doi.org/10.1007/s00360-016-0960-X

Wolfe, J., Bryant, G., 1999. Freezing, drying, and/or vitrification of membrane-solute-water systems. Cryobiology. https://doi.org/10.1006/cryo.1999.2195

Wu, C.W., Storey, K.B., 2012. Pattern of cellular quiescence over the hibernation cycle in liver of thirteen-lined ground squirrels. Cell Cycle 11, 1714-1726. https://doi.org/10.4161/cc.19799

Wu, C.W., Tessier, S.N., Storey, K.B., 2018. Stress-induced antioxidant defense and protein chaperone response in the freeze-tolerant wood frog Rana sylvatica. Cell Stress Chaperones 23, 1205-1217. https://doi.org/10.1007/s12192-018-0926-x

Wu, H., Zhang, Y., 2011. Mechanisms and functions of Tet proteinmediated 5-methylcytosine oxidation. Genes Dev. https://doi.org/10.1101/gad.179184.111

Wu, X., Zhang, Y., 2017. TET-mediated active DNA demethylation: Mechanism, function and beyond. Nat. Rev. Genet. https://doi.org/10.1038/nrg.2017.33

Yehezkel, S., Segev, Y., Viegas-Péquignot, E., Skorecki, K., Selig, S., 2008. Hypomethylation of subtelomeric regions in ICF syndrome is associated with abnormally short telomeres and enhanced transcription from telomeric regions. Hum. Mol. Genet. 17, 2776-2789. https://doi.org/10.1093/hmg/ddn177

Yehuda, R., Lehrner, A., 2018. Intergenerational transmission of trauma effects: putative role of 
epigenetic mechanisms. World Psychiatry 17, 243-257. https://doi.org/10.1002/wps.20568

Zachariassen, K.E., 1985. Physiology of cold tolerance in insects. Physiol. Rev. https://doi.org/10.1152/physrev.1985.65.4.799

Zachariassen, K.E., Kristiansen, E., 2000. Ice nucleation and antinucleation in nature. Cryobiology. https://doi.org/10.1006/cryo.2000.2289

Zhang, J., Hawkins, L.J., Storey, K.B., 2020a. DNA methylation and regulation of DNA methyltransferases in a freeze-tolerant vertebrate. Biochem. Cell Biol. 98, 145-153. https://doi.org/10.1139/bcb-2019-0091

Zhang, J., Hawkins, L.J., Storey, K.B., 2020b. DNA methylation and regulation of DNA methyltransferases in a freeze-tolerant vertebrate. Biochem. Cell Biol. 98, 145-153. https://doi.org/10.1139/bcb-2019-0091

Zhang, J., Storey, K.B., 2012. Cell cycle regulation in the freeze-tolerant wood frog, Rana sylvatica. Cell Cycle 11, 1727-1742. https://doi.org/10.4161/cc.19880

Zhang, Y., Jurkowska, R., Soeroes, S., Rajavelu, A., Dhayalan, A., Bock, I., Rathert, P., Brandt, O., Reinhardt, R., Fischle, W., Jeltsch, A., 2010. Chromatin methylation activity of Dnmt3a and Dnmt3a/3L is guided by interaction of the ADD domain with the histone $\mathrm{H} 3$ tail. Nucleic Acids Res. 38, 4246-4253. https://doi.org/10.1093/nar/gkq147

Zhao, Y., Chen, M., Storey, K.B., Sun, L., Yang, H., 2015. DNA methylation levels analysis in four tissues of sea cucumber Apostichopus japonicus based on fluorescence-labeled methylation-sensitive amplified polymorphism (F-MSAP) during aestivation. Comp. Biochem. Physiol. Part - B Biochem. Mol. Biol. 181, 26-32. https://doi.org/10.1016/j.cbpb.2014.11.001

Zhu, Y., Sun, D., Jakovcevski, M., Jiang, Y., 2020. Epigenetic mechanism of SETDB1 in brain: implications for neuropsychiatric disorders. Transl. Psychiatry. https://doi.org/10.1038/s41398-020-0797-7 
APPENDICES 
Appendix A: Immunoblotting conditions

\begin{tabular}{|c|c|c|c|c|c|c|c|}
\hline Target & $\begin{array}{l}\text { Protein } \\
\text { Amount } \\
(\mu \mathrm{g})\end{array}$ & $\begin{array}{l}\text { Gel } \\
(\%)\end{array}$ & $\begin{array}{l}\text { Run } \\
\text { Conditions }\end{array}$ & $\begin{array}{l}\text { Transfer } \\
\text { Conditions }\end{array}$ & $\begin{array}{l}\text { 30min Milk } \\
\text { Blocking } \\
(\%)\end{array}$ & $\begin{array}{l}\text { 1o } \\
\text { Antibody }\end{array}$ & $\begin{array}{l}20 \\
\text { Antibody }\end{array}$ \\
\hline ASH2L & 15 & 10 & $180 \mathrm{~V}, 90 \mathrm{~min}$ & $160 \mathrm{~mA}, 90 \mathrm{~min}$ & $5 \%$ & $1: 1000$ & $1: 8000$ \\
\hline DNMT1 & 40 & 8 & $180 \mathrm{~V}, 120 \mathrm{~min}$ & $160 \mathrm{~mA}, 110 \mathrm{~min}$ & $2 \%$ & $1: 1000$ & $1: 8000$ \\
\hline DNMT3A & 20 & 10 & $180 \mathrm{~V}, 90 \mathrm{~min}$ & $160 \mathrm{~mA}, 90 \mathrm{~min}$ & $5 \%$ & $1: 1000$ & $1: 8000$ \\
\hline DNMT3B & 15 & 10 & $180 \mathrm{~V}, 90 \mathrm{~min}$ & $160 \mathrm{~mA}, 90 \mathrm{~min}$ & $5 \%$ & $1: 1000$ & $1: 8000$ \\
\hline DNMT3L & 25 & 10 & $180 \mathrm{~V}, 90 \mathrm{~min}$ & $160 \mathrm{~mA}, 90 \mathrm{~min}$ & $5 \%$ & $1: 1000$ & $1: 8000$ \\
\hline ESET & 40 & 8 & $180 \mathrm{~V}, 90 \mathrm{~min}$ & $160 \mathrm{~mA}, 110 \mathrm{~min}$ & $2 \%$ & $1: 1000$ & $1: 8000$ \\
\hline Histone H3 & 15 & 15 & $180 \mathrm{~V}, 50 \mathrm{~min}$ & $160 \mathrm{~mA}, 45 \mathrm{~min}$ & $5 \%$ & $1: 1000$ & $1: 8000$ \\
\hline Histone H4 & 40 & 15 & $180 \mathrm{~V}, 50 \mathrm{~min}$ & $160 \mathrm{~mA}, 45 \mathrm{~min}$ & $2 \%$ & $1: 1000$ & $1: 5000$ \\
\hline $\mathrm{HP} 1 \gamma$ & 25 & 15 & $180 \mathrm{~V}, 50 \mathrm{~min}$ & $160 \mathrm{~mA}, 45 \mathrm{~min}$ & $5 \%$ & $1: 1000$ & $1: 5000$ \\
\hline $\mathrm{H} 3 \mathrm{~K} 4 \mathrm{me} 1$ & 20 & 15 & $180 \mathrm{~V}, 50 \mathrm{~min}$ & $160 \mathrm{~mA}, 45 \mathrm{~min}$ & $5 \%$ & $1: 1000$ & $1: 5000$ \\
\hline H3K9me3 & 20 & 15 & $180 \mathrm{~V}, 50 \mathrm{~min}$ & $160 \mathrm{~mA}, 45 \mathrm{~min}$ & $5 \%$ & $1: 1000$ & $1: 5000$ \\
\hline H3K27me1 & 20 & 15 & $180 \mathrm{~V}, 50 \mathrm{~min}$ & $160 \mathrm{~mA}, 45 \mathrm{~min}$ & $5 \%$ & $1: 1000$ & $1: 5000$ \\
\hline H3K36me2 & 20 & 15 & $180 \mathrm{~V}, 50 \mathrm{~min}$ & $160 \mathrm{~mA}, 45 \mathrm{~min}$ & $5 \%$ & $1: 1000$ & $1: 5000$ \\
\hline H4K20me1 & 40 & 15 & $180 \mathrm{~V}, 50 \mathrm{~min}$ & $160 \mathrm{~mA}, 45 \mathrm{~min}$ & $2 \%$ & $1: 1000$ & $1: 5000$ \\
\hline RBBP5 & 20 & 10 & $180 \mathrm{~V}, 90 \mathrm{~min}$ & $160 \mathrm{~mA}, 90 \mathrm{~min}$ & $5 \%$ & $1: 1000$ & $1: 8000$ \\
\hline SET1A & 40 & 8 & $180 \mathrm{~V}, 150 \mathrm{~min}$ & $160 \mathrm{~mA}, 130 \mathrm{~min}$ & $2 \%$ & $1: 1000$ & $1: 8000$ \\
\hline SETD7 & 30 & 10 & $180 \mathrm{~V}, 90 \mathrm{~min}$ & $160 \mathrm{~mA}, 90 \mathrm{~min}$ & $5 \%$ & $1: 1000$ & $1: 8000$ \\
\hline SETD8 & 40 & 12 & $180 \mathrm{~V}, 90 \mathrm{~min}$ & $160 \mathrm{~mA}, 90 \mathrm{~min}$ & $2 \%$ & $1: 1000$ & $1: 8000$ \\
\hline SMYD2 & 15 & 12 & $180 \mathrm{~V}, 90 \mathrm{~min}$ & $160 \mathrm{~mA}, 90 \mathrm{~min}$ & $5 \%$ & $1: 5000$ & $1: 8000$ \\
\hline SUV39H1 & 40 & 10 & $180 \mathrm{~V}, 90 \mathrm{~min}$ & $160 \mathrm{~mA}, 90 \mathrm{~min}$ & $5 \%$ & $1: 1000$ & $1: 5000$ \\
\hline TET2 & 50 & 6 & $180 \mathrm{~V}, 150 \mathrm{~min}$ & $160 \mathrm{~mA}, 140 \mathrm{~min}$ & $2 \%$ & $1: 1000$ & $1: 8000$ \\
\hline TET3 & 50 & 6 & $180 \mathrm{~V}, 150 \mathrm{~min}$ & $160 \mathrm{~mA}, 140 \mathrm{~min}$ & $2 \%$ & $1: 1000$ & $1: 8000$ \\
\hline TDG & 20 & 10 & $180 \mathrm{~V}, 90 \mathrm{~min}$ & $160 \mathrm{~mA}, 90 \mathrm{~min}$ & $2 \%$ & $1: 1000$ & $1: 8000$ \\
\hline
\end{tabular}


Appendix B: Antibody information

\begin{tabular}{|c|c|c|}
\hline Target & Company & Catalogue \# \\
\hline ASH2L & Cell Signaling & $\# 5019$ \\
\hline DNMT1 & Abclonal & \#A16729 \\
\hline DNMT3A & Genetex & \#GTX128157 \\
\hline DNMT3B & Genetex & \#GTX129127 \\
\hline DNMT3L & Abgent & \#AP1040a \\
\hline ESET & Cell Signaling & \#2196 \\
\hline Histone H3 & Cell Signaling & \#9715 \\
\hline Histone H4 & Cell Signaling & \#2935 \\
\hline $\mathrm{HP} 1 \gamma$ & Cell Signaling & \#2619 \\
\hline $\mathrm{H} 3 \mathrm{~K} 4 \mathrm{me} 1$ & Abcam & \#ab8895 \\
\hline H3K9me3 & Abcam & \#ab8898 \\
\hline H3K27me1 & Active Motif & \#39890 \\
\hline H3K36me2 & Active Motif & \#39256 \\
\hline H4K20me1 & Abclonal & \#A2370 \\
\hline RBBP5 & Cell Signaling & \#13171 \\
\hline SET1A & Abclonal & \#A18231 \\
\hline SETD7 & Cell Signaling & \#2813 \\
\hline SETD8 & Cell Signaling & \#2996 \\
\hline SMYD2 & Cell Signaling & \#9734 \\
\hline SUV39H1 & Cell Signaling & \#8729 \\
\hline TET2 & Abclonal & \#A5682 \\
\hline TET3 & Genetex & \#GTX121453 \\
\hline TDG & Genetex & \#GTX110473 \\
\hline
\end{tabular}




\section{Appendix C: Loading control for immunoblotting}

Standardizing band intensity to total protein has emerged as a prominent method for immunoblot loading control (Collins et al., 2015; Moritz, 2017). Rather than using a single "housekeeping gene", this thesis relies on the previously published method (Welinder and Ekblad, 2011) that uses a group of protein bands on the Coomassie-stained blots that are well-distanced from the band of interest. The summed intensity of identical multiple bands is used as a representative measurement for total protein, which is then used to standardize ECL band intensities. This method effectively controls for sample preparations/variable loading, while circumventing key pitfalls that exist from the classic housekeeping genes that may themselves change in protein levels between control and experimental samples (Dittmer and Dittmer, 2006). Shown are representative Coomassiestained blots (Fig. C1) for (A) RBBP5 and (B) DNMT3L used to standardize protein loading from Chapter 2 - Figure 4.1. 
A

$\mathrm{ECL}$

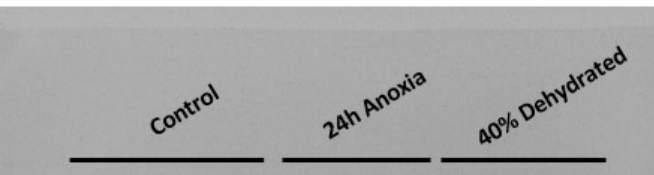

RBBP5 $\sim 70 \mathrm{kDa}$ (two isoforms)

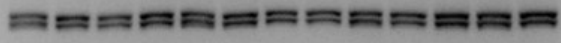

Coomassie

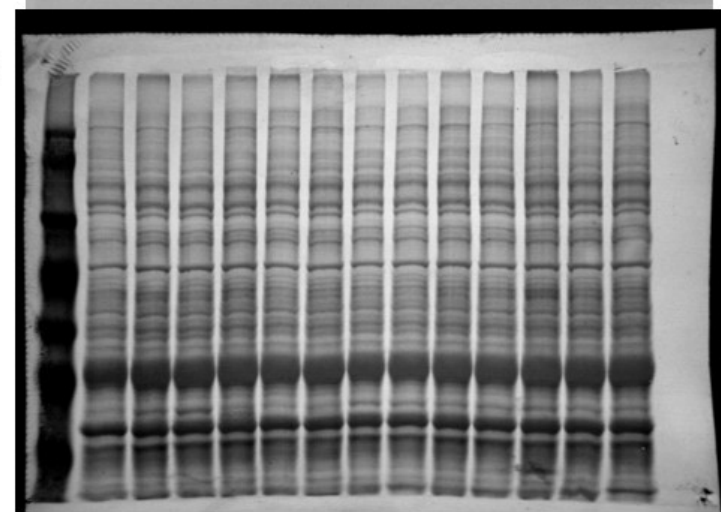

B

$\mathrm{ECL}$

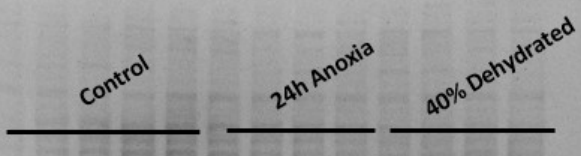

DNMT3L

$\sim 50 \mathrm{kDa}$

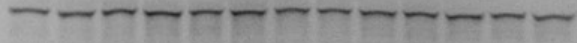

Coomassie

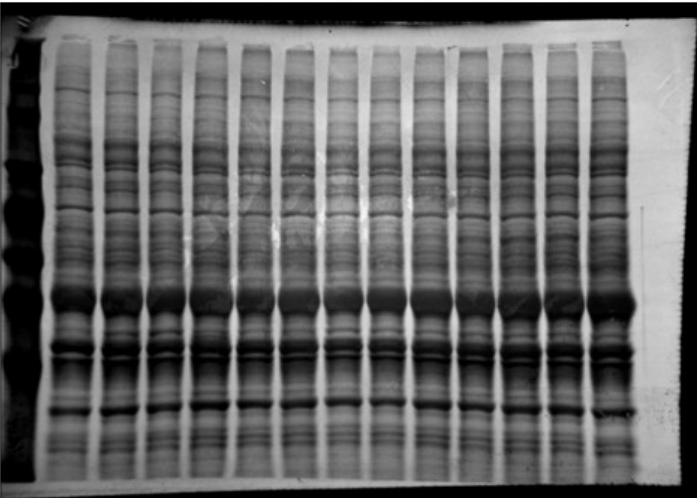

Figure C1: Representative Coomassie-stained immunoblots (lower panel) and corresponding probed ECLs for (A) RBBP5 and (B) DNMT3L. Protein loading was standardized against the summed intensity of multiple Coomassie-stained bands from the same lane. 
Appendix D: Total protein extract validation

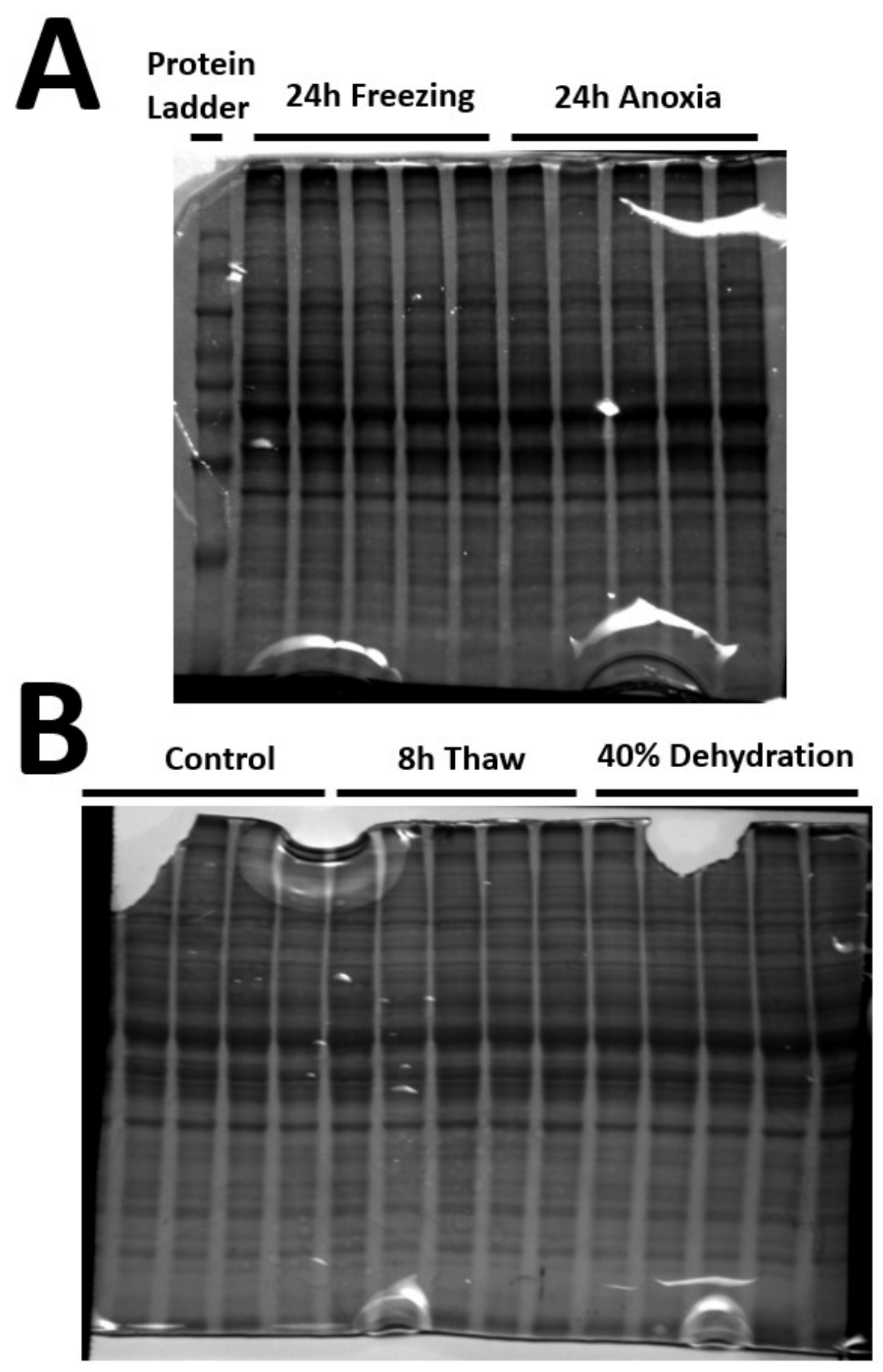

Figure D1. 10\% SDS-PAGE of $15 \mu \mathrm{g}$ aliquots of total soluble protein from $\mathrm{n}=5$ (A) $24 \mathrm{~h}$ frozen, 24h anoxic and (B) control, $8 \mathrm{~h}$ thawed and $40 \%$ dehydrated $R$. sylvatica pooled brain tissue. Protein ladder is included in A. Gels were stained with Coomassie blue and visualized under visible light using a Chemi-Genius Bioimager. Sharp bands indicate high integrity of protein samples. 


\section{Appendix E: Nuclear enrichment validation}

To verify the efficacy of nuclear protein extractions prior to use in ELISA kits, cytoplasmic and nuclear extracts were probed with subcellular markers to check for cytosolic contamination ( $\alpha$-tubulin) and nuclear enrichment (histone H3). Shown below is a representative validation for control samples (Fig. E1). For nuclear samples of all five treatments, nuclear protein was enriched $>10$-fold whereas cytosolic protein was reduced to $<50 \%$, demonstrating the success necessary to proceed to enzymatic assays. 


\section{Cytoplasmic Extracts Nuclear Extracts}

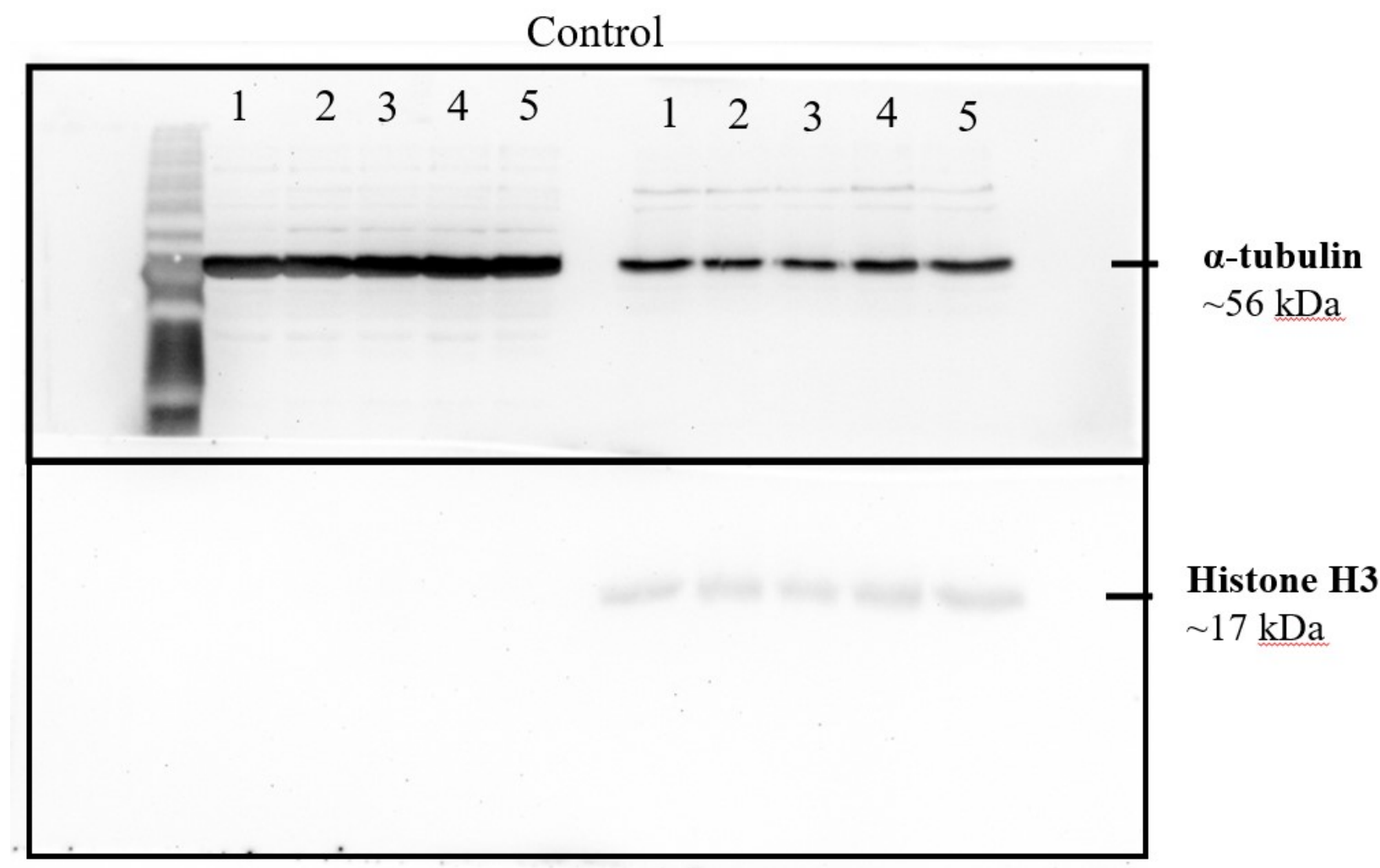

Figure E1: Representative immunoblot of $\alpha$-tubulin (upper panel) and histone H3 (lower panel) comparing expression in cytoplasmic and nuclear extracts from control $R$. sylvatica brain tissue. Membranes were cut, probed separately and overlayed simultaneously for imaging. In nuclear extracts, histone $\mathrm{H} 3$ expression $>10$-fold and $\alpha$ tubulin expression $<50 \%$, relative to cytoplasmic extracts from equivalent samples. 


\section{Appendix F: Genomic DNA validation}

Following extraction, genomic DNA samples were measured using a Take3

Micro-Volume plate (BioTek, Vermont, USA). All samples had a 260/280 ratio > 1.8 and concentrations ranging from $20-70 \mathrm{ng} / \mu \mathrm{L}$. To verify viable gDNA, samples were also run on a $0.5 \%$ agarose gel. Seen below (Fig F1), intact genomic DNA is validated.
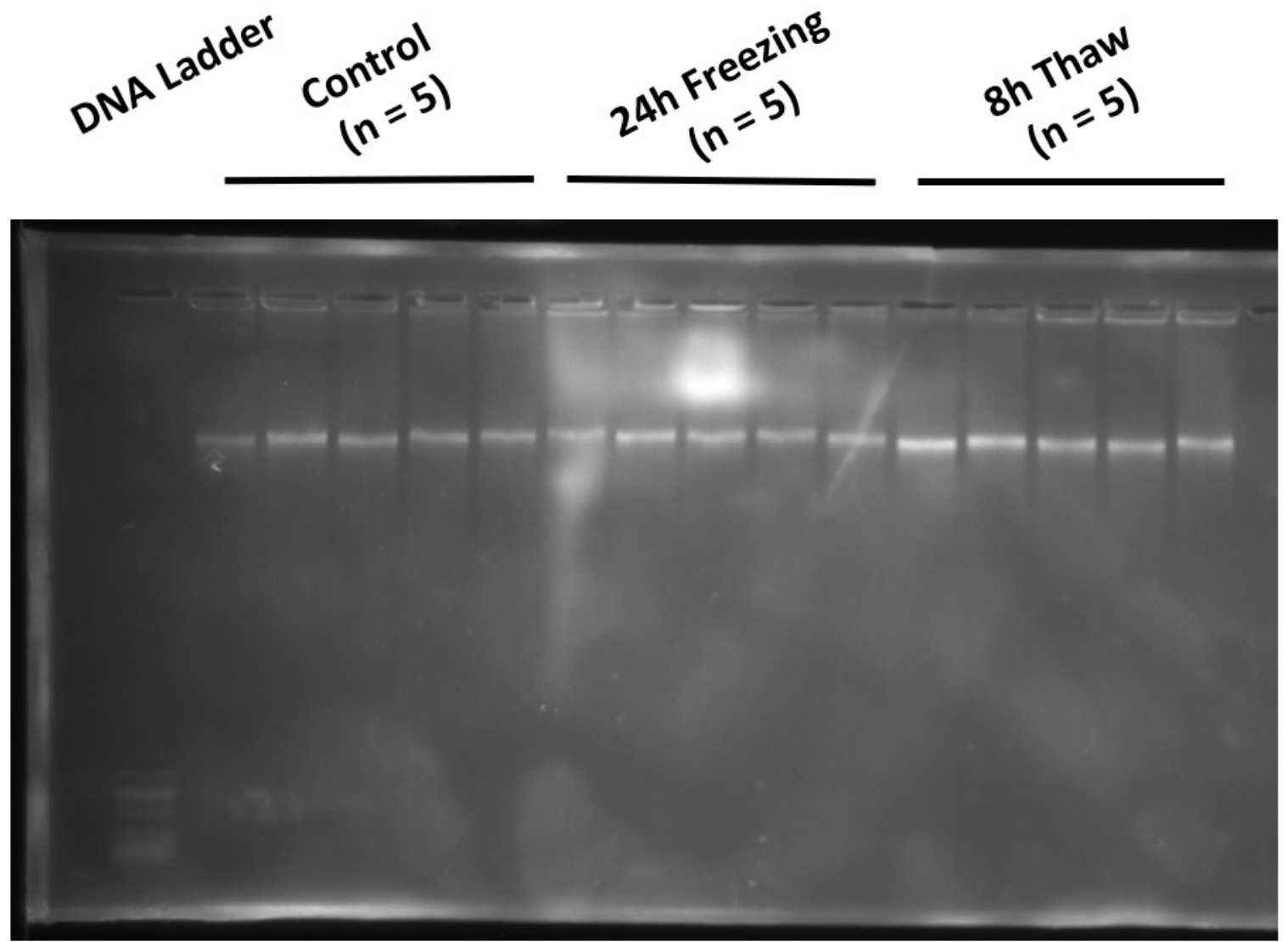

Figure F1: 100 ng of genomic DNA of $n=5$ control, $24 \mathrm{~h}$ frozen and $8 \mathrm{~h}$ thawed $R$. sylvatica brain tissue run on $0.5 \%$ agarose gel. Samples were run with SYBR green dye and visualized under ultraviolet light. 
Appendix G: Anoxia/Dehydrated Immunoblot bands

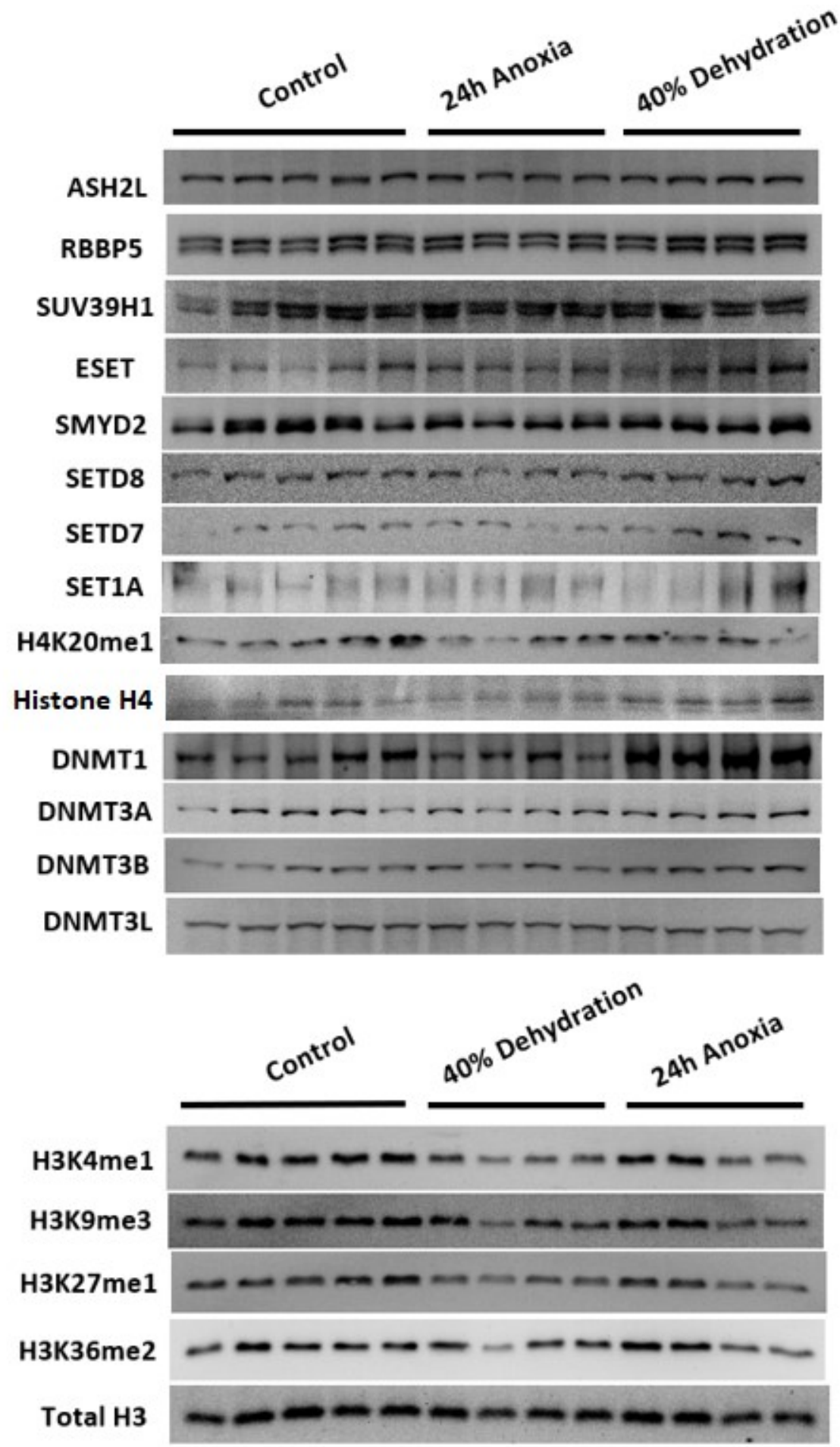

Figure G1: Representative immunoblot bands for targets tested in this thesis, in control, $24 \mathrm{~h}$ anoxic and $40 \%$ dehydrated $R$. sylvatica brain tissue. Equivalent control samples allow comparison of anoxic/dehydrated with freeze/thaw tissue samples. Immunoblot analyses of the above are included in histograms throughout Chapters 3 and 4. 